\title{
ON HAYEKIAN TRIANGLES
}

\author{
WILLIAM BARNETT II* \\ WALTER BLOCK**
}

Resumen: El triángulo es una parte integral de la historia del pensamiento económico. Ha sido utilizado por escritores como Jevons (1871), Taussig (1896), Wicksell $(1934,1969)$ para ilustrar y ayudarnos a comprender la teoría del capital. Desde Hayek (1931) esta figura geométrica se ha utilizado como un instrumento pedagógico básico para explicar la teoría austriaca del ciclo económico. El propósito de este trabajo es sostener que el triángulo es altamente problemático, sino fatalmente defectuoso, por lo que si deseamos que la teoría austriaca del ciclo económico sea comprendida debemos desecharlo completamente, o complementarlo fuertemente con una lista de sus limitaciones. Además, en algunos casos el triángulo ha sido responsable de la relativa falta de desarrollo de la teoría austriaca del ciclo durante un periodo de medio siglo.

Palabras clave: Economía austriaca, teoría del ciclo económico, praxeología, geometría económica, triángulos.

Abstract: The triangle is an integral part of the history of economic thought. It has been used by writers such as Jevons (1871), Taussig (1896), Wicksell (1934, 1969) to illustrate and to help us understand capital theory. Since Hayek (1931) this geometrical figure has been used as a basic pedagogical device to explain the Austrian Business Cycle Theory (ABCT). The purpose of the present paper is to argue that the triangle is highly problematic, if not fatally flawed, and that if $A B C T$ is to be made intelligible this tool of analysis must be either completely jettisoned, or heavily supplemented with a list (see below) of its shortcomings. Moreover in some ways the triangle has been responsible for the relative lack of development of ABCT for over a half century.

Key words: Austrian economics, business cycle theory, praxeology, economic geometry, triangles.

Clasificación JEL: E3, E32.

(*) Bank One Distinguished Professor of International Business and Associate Professor of Economics. Department of Economics. Joseph A. Butt, S.J. College of Business Administration. Loyola University, New Orleans.

(**) Harold E. Wirth Eminent Scholar Endowed Chair and Professor of Economics. Department of Economics. Joseph A. Butt, S.J. College of Business Administration. Loyola University, New Orleans. 


\title{
A triangle ${ }^{1}$ was first employed by Hayek (1931) to illustrate the Austrian Business Cycle Theory (ABCT). ${ }^{2}$ Since then economists have utilized it for this purpose on numerous occasions. ${ }^{3}$ Hayek (1935, 38-40, footnotes added) states:
}

\author{
...I find it convenient to represent successive applications of the \\ original means of production ${ }^{4}$ which are needed to bring forth \\ the output of consumers' goods accruing at any moment of
}

1 Bellante and Garrison (1988, n. 13) state: «Jevons (1970, pp. 229-36) had earlier employed a triangular construction for similar purposes. Attempting to characterize the economy's capital structure in terms of the dimensions of a triangle is what qualifies Prices and Production as an outline. In Hayek's more formal - and more formidable - Pure Theory of Capital (1941), many of the heuristic assumptions of his earlier efforts were relaxed. This volume was to serve as the basis for a more comprehensive treatment of monetary theory (Hayek, 1941, p. v-vi), but no followon volume was ever written.»

Nevertheless, the triangle continues to be used in ABCT; moreover, Hayek's explication in that volume does not deal with most of the issues raised in this paper, and when it does, it leaves much to be desired.

2 There had been prior uses of triangles or triangular type relationships with regard to capital theory. Jevons, 230, 231, 237; Taussig, 1896, 23; Wicksell, 1969, 113; $1934,152,159$ used them for this purpose.

3 This listing is by no means complete, but includes at least the following: Abrams, 1934, 25, 28; Bellante and Garrison, 1988; Block, 1998, 154-157; Cochran and Glahe, 1999, 117; Durbin, 1933, 54; 1935, many pages; Gaitskell, 1933, 285; 292294; Garrison, 1978, 172; 1994, 110, 112; 2001, numerous pages; 2004, 325, 338; 2005, 476, 481, 496, 498, 502, 505, and 511; Hayek, 1931, numerous pages; 1934A, 154; 1934B, 210, 214, 215, 218, 220; 1939, 10, 27; 1941, 105, 110, 117, 131 195, 197, 200, 208, 211, 213, 278, 289, 290, 363; 1948, 23, 25, 29, 31, 33, 35; Horwitz, 2005, 21, 22; Huerta de Soto, 1998, 34, 35; Hughes, 1997, 109; O'Driscoll, 1977, 71; Pamini, 2002, 35, 38, 45, 47, 53; Rothbard, 1962, 282, 286, 314; Salerno, 2001, 55; Skousen, 1990, many pages; 1991, 35, 86, 93, 94, 111; Snowdon, Vane, and Wynarczyk, 1994, 357; Wein-Claudi, 1936, pp. 147, 149; White, 1977. Further, Macfie, 1934, 45-103 and Saulnier, 1938, 213-300, focus on the Hayekian triangle, but do not depict it. In addition, there are several authors who utilize triangle-like, or triangle-ish or quasi triangular diagrams, for purposes only indirectly related to $\mathrm{ABCT}$, or, indeed, capital theory; included under this rubric are Boulding, 1966, 675 and Strigl (1934) [2000], 10. The keen reader will note that the name of one of the authors of this present paper appears on this list. It is reasonable that Menger, Bohm-Bawerk, Weiser not be included; they did not concern themselves with the business cycle. But one Austrian who devoted a lot of his thinking to this topic also cannot be found here - Mises. The authors thank Richard Ebeling for aid with this bibliography.

4 «When I mean land and labor, I shall speak of original means of production (Hayek, 1935, 36, emphasis in original). 
time, by the hypotenuse ${ }^{5}$ of a right-angled triangle, such as the triangle [in figure 1]. ${ }^{6}$ The value of these original means of production is expressed by the vertical projection of the hypotenuse, while the horizontal dimension measured in arbitrary periods from left to right, expresses the progress of time, so that the inclination of the line representing the original means of production used means that these original means of production are expended continuously during the whole production process. The right side of the triangle represents the current output of consumers' goods. The area of the triangle thus shows the totality of the successive stages through which the several units of original means of production pass before they become ripe for consumption. It also shows the total amount of intermediate products which must exist at any moment of time in order to secure a continuous output of consumers' goods. For this reason we may conceive of this diagram not only as representing the successive stages of the production of the output of any given moment of time, but also as representing the processes of production going on simultaneously in a stationary society.

In either way of interpreting it, the pecuniary value ${ }^{7}$ of consumers' goods ${ }^{8}$ at the moment of sale from the producer(s) to the consumer(s), C, is measured along the vertical axis.

5 Throughout, we use the term «hypotenuse» to refer to the side opposite the right-angle in any three-sided figure in a Cartesian plane that has such an angle.

${ }^{6}$ We reproduce Hayek's $(1935,39)$ figure 1 as our figure 1 . The authors thank Gabriella Guevara, a student at Loyola University New Orleans, for the assistance with drawing most of the diagrams in this paper. We have placed all figures in appendix 5 .

7 The output of consumers' goods at a specific point in time must be taken to mean their pecuniary value. (It certainly cannot refer to the physical output, else we encounter inherently unsolvable problems involved in attempting to aggregate heterogeneous goods. And, of course, we cannot use the subjective values of the goods, if for no other reason than that subjective values are necessarily ordinal and therefore impossible of summation.) Yet that requires that for a specific set of consumers' goods produced using the exact same production processes, the structure of production as illustrated by the triangle not be independent of the price level, however measured, or of the structure of relative prices.

8 The triangle is used to illustrate both the production of a particular consumers' good, individually, and also the production of all consumers' goods, collectively. 
Interestingly, in the first interpretation, either time (figure 1) or stages of production (figure 2) may be measured along the horizontal axis, ${ }^{9}$ whereas in the second, only stages of production may be measured along that axis (figure 2). The Hayekian triangle, then, is a right triangle located entirely ${ }^{10}$ in the first quadrant of a 2-dimensional, Cartesian space.

This paper is concerned only with the first interpretation, as the other necessarily involves the use of stages of production, a concept that is fatally flawed, as is explained in section 10, below.

The triangle may then be constructed such that one terminus of the hypotenuse is at the origin and one leg is coincident with the horizontal axis, terminating at a point, $t_{1}$, for the time at which the consumers' goods are sold. Production commences at $t=0$ and the value of the goods in process at any time $t_{1}$, where $t_{1}>0$, is measured by the vertical distance between the $t$-axis and the hypotenuse, thereby illustrating that production is a process that occurs through time, and that the value of the

9 Because it is much more common currently to rotate the frame 90 degrees counterclockwise, as is done herein, from the way Hayek did, the quotation from Hayek immediately following this paragraph appears mutatis mutandis. Standard procedure in mathematics and science is to put the independent and dependent variables on the horizontal and vertical axes, respectively. However, economists have reversed this in the most important diagrams they use, those representing supply and demand. Hayek's placement is in keeping with this oddity of economics. Garrison (1978) was thought by some (the present authors, for example) to be the first to place time on the horizontal axis and value on the vertical in order to bring this bit of Austrian geometry into greater conformity with conventional graphical depictions, although he did have time flow from right to left in this original figure, rather than vice versa, as is standard, and as he did in subsequent work. However, a footnote must be added to this view that originality can be claimed for Garrison in this regard: for Hayek (1934B, 210, figure 1; 1941 [1975], 175, 184, 189,) and Jevons $(1871,231)$ before him, placed time on the horizontal axis. Thus, we can amend this bit of history of economic thought and may say instead that Garrison was the first to consistently use a triangle for ABCT purposes with time on the horizontal axis. If there is any person who has been most closely associated with the Hayekian triangle, it is Roger Garrison. A Google search of the phrase «Hayekian triangle» yields several pages of cites, most to his work.

10 But see text accompanying figure 20 . 
goods in process increases during the production process until it reaches its culmination when the consumers' goods are sold at time $t_{1}$ (figure 1 ). The angle whose vertex is located at the origin reflects the objective rate of discount, itself based upon subjective rate of time preference; i.e., the greater the slope of the hypotenuse the higher the rate of time preference. ${ }^{11}$ Garrison $(2001,46)$ states: «Alternatively stated, the slope of the hypotenuse represents value added (by time and factor input) on a continuous basis. The choice of a linear construction here over an exponential one maintains a simplicity of exposition without significant loss in any other relevant regard.» This assumes that, regardless of the type of triangle used, that the value added «by time and factor input» increases with a regularity that is totally alien in the real world.

\section{INTRODUCTION}

In this paper we maintain that because of 14 fundamental problems considered below, though not necessarily in the order of importance, the «Hayekian triangle» is a faulty analytical tool. First, at the conceptual level regarding all consumers' goods collectively, the aggregative nature of the triangle is

11 It is well understood that the straight line hypotenuse of the form $C=C_{0}(1+$ i) ${ }^{t}$ (figure 1) implies a lack of compounding, and a more correct figure would not be a triangle, but rather a figure in which the hypotenuse was replaced with a concave curve of the form $C=C_{0}((1+i) t-1)$ (figure 3$)$ or $C=C_{0}\left(e^{i t}-1\right)$ (figure 4 ), as the compounding is discrete or continuous, respectively. The slopes are given by $d \mathrm{C} / d \mathrm{t}=\mathrm{C}_{0}(1+\mathrm{i}), d \mathrm{C} / d \mathrm{t}=\mathrm{C}_{0}(\ln (1+\mathrm{i}))(1+\mathrm{i})^{\mathrm{t}}, d \mathrm{C} / d \mathrm{t}=\mathrm{C}_{0} \mathrm{ie}^{\mathrm{it}}$, respectively, and, therefore, in each case, provided $\mathrm{C}_{0}, \mathrm{i}>0$, the slope is either a positive constant, or it increases monotonically in t. Hayek (1934A, 153) himself was well aware of the compounding issue referring to the triangle and in subsequent works used a «curvilinear» triangle: «The curvilinear ${ }^{2}$ triangle $A B C$ represents, in the same way as the triangle I used in Prices and Production, the stock of capital belonging to processes already completed.» [footnote] ${ }^{2}$ : «The reasons which make a curvilinear triangle of the kind shown in the text a more appropriate representation than the simplified form used in Prices and Production are probably obvious.» 
problematical. Second, again re all consumers' goods collectively, as with most other aggregative concepts in economics, there is no coherent way to construct a measure thereof. Third, more «round-aboutness» is confounded with more time consuming; i.e., a structure of production with more stages is confounded with a lengthier period of production. Fourth, the period of production inherent in a more complex structure of production is confounded with the period of production that exists during the transition from a less to a more complex structure of production. Fifth, the concept «stages of production» is incoherent. Sixth, the vertical axis represents the value of consumer goods, not consumption. Therefore, what is needed is not a time-structure of production, which is but one of the two types of actions, but rather a time-structure of action, to include both types of action; to wit: production and consumption. Seventh, the triangle can be used to account either for goods in process (or circulating capital) or, or for fixed capital. It cannot account for both simultaneously, a serious shortcoming as it is intended to be used to explicate the time consuming process of producing consumption goods using heterogeneous fixed capital goods at different points in the process. Eighth, referring to goods in process, the triangle cannot handle post- initiation-of-production infusions of resources. Ninth, when «shifting triangles» are used the time dimension is confused, and this has two baleful consequences. Tenth, the implicit assumption of differentiability regarding the hypotenuse of the triangle is anathema to Austrianism. Eleventh, the triangle model cannot incorporate leisure. Twelfth, the triangle has not been mathematized. As a consequence of these errors, the «triangle» does not demonstrate that which it purports to show. Thirteenth, the triangle is the wrong geometrical figure for these purposes; if one must be used, arguendo, the trapezoid is preferable. Fourteenth, the triangle ignores durable capital goods. This paper consists of 17 sections. Each of the first 14 is used to consider a different 
problem. The fifteenth contains a summary and the sixteenth the conclusions. The seventeenth is given over to three appendices.

1.

THE AGGREGATIVE NATURE OF THE TRIANGLE IS PROBLEMATICAL

Central to Austrian economics is the fact that man acts in the present in an attempt to bring about a more desirable future ${ }^{12}$ than would have obtained had he not acted. Moreover, production is a process in real, historical time through which resources are used to produce consumers' goods. In general, any particular good may be produced in more than one way, and each requires a different period of time from beginning to end. And, during any given time period, a particular good may be produced with a variety of techniques; e.g., a house may be constructed using hammers or nail guns, or both. The exact manner and sequence in which a good is produced may be referred to as its structure of production; ${ }^{13}$ i.e., the structure of production is the configuration of the production process as it occurs through time. It consists in the application of labor, using fixed capital goods, ${ }^{14}$ to natural resources, raw materials, and partially finished goods, in specific sequences, until completion of the last actions in the sequence, at which time the production process is completed as the finished good comes

12 This is true whether the future that is the object of the action is immediate or remote.

13 Rothbard $(1962,7)$ tells a very apropos and charming story of a ham sandwich being produced and consumed at home.

14 One can think of certain production processes that do not directly use fixed capital goods, but they may safely be ignored without doing harm to the analysis. What we have in mind, here, is not a catalyst. Rather, it is a really simple process such as picking a piece of fruit (say, an apple or a banana) and eating it without using any tools. Even though a catalyst remains chemically unchanged after it works its magic, it would still be a fixed capital good. 
into existence. ${ }^{15}$ Consequently, the time periods required for the production of a particular good using different structures of production, much less different goods, will differ. It is possible, then, to have different time periods of production for a given pecuniary value of sales of consumers' goods at a specific point in time. That is, a particular triangle represents but one structure of production among alternatives that could be used to produce the same value of consumers' goods at a given point in time.

In figure $5 \mathrm{~A}, \mathrm{C}_{1}\left(\mathrm{t}_{1}\right)$ and $\mathrm{C}_{2}\left(\mathrm{t}_{2}\right)$ are identical values of consumers' goods produced in ways that have different timestructures of production; to wit: $\mathrm{C}_{1}\left(\mathrm{t}_{1}\right)$ becomes available at $t_{1}$ and $C_{2}\left(t_{2}\right)$ at $t_{2}$. In the former case, we denote the triangle marked 1 (we label the hypotenuses throughout) and in the latter case we refer to the triangle marked 2. Note that the structure of production of 1 is shorter than that of 2 , and the area ${ }^{16}$ under 1 is less than that under 2 , therefore, because the same value of consumers' goods is available in a shorter period of time, it is obviously a superior structure. That is, triangle 1 is superior to triangle 2 since the same level of consumers' goods is available sooner with $1\left[C_{1}\left(t_{1}\right)\right]$ than with $2\left[C_{2}\left(t_{2}\right)\right]$ and the sum of the present value of resources that are being, and will be, at each point in time during the production period used to produce that level of consumers' goods is lower in 1

15 Mises $(1966,479)$ states: «The total expenditure of time required, i.e., working time plus maturing time, may be called the period of production.»

16 The area under the hypotenuse is proportional to the sum (over each subperiod of the total period of production) of the present value of the resources used throughout the production process of the consumers' goods. The smaller is the area, then, the lesser is the commitment of resources, in terms of present value, to the production of consumers' goods. But Hayek (1934A, 153) states «The area of the curvilinear triangles $\mathrm{AB}^{\prime} \mathrm{C}^{\prime}$ (referring to figure 1 on his p. 154) shows the stock of capital.» Note that he does not refer to the value of the stock of capital, nor yet, even more correctly, to the present discounted value of this stock of capital. See Block (1990) for an emphasis on this latter issue. However, Hayek (1934B, 207, emphasis added) refers to «The value of the stock of capital conceived as the discounted value of the expected futures products...» 
than in 2. And, yet, the slope of triangle 1's hypotenuse is necessarily steeper than that of triangle 2 . This indicates a higher objective-doppelganger (the actual discount rate) of the underlying subjective, social rate of time preference for 1 , visà-vis 2 .

Alternatively, figure $5 \mathrm{~B}$ illustrates the same point. The same value of consumers' goods, $C_{1}\left(t_{2}\right)=C_{2}\left(t_{2}\right)$, can be produced using either of two (2) different structures of production - one that commences on triangle 2 at 0 and the other on triangle 1 at $t_{1}$. Again, the shorter structure, triangle 1 commencing at $t_{1}$, is superior. And, the same result holds referring to the discount rate and rate of social time preference. Namely, that the more efficient or productive structure of production, triangle 1 in both cases, is compatible only with a higher rate of interest. This is not only counter intuitive, if flies in the face of standard ABCT. For, it is the lower time preference rate that is supposed to indicate a greater reliance on capital, and, hence, greater overall efficiency or productivity of the economy, particularly labor.

The difficulties with aggregation are well known, at least within Austrian circles. ${ }^{17}$ How does the triangle measure up to the stringent objections leveled by praxeologists at aggregation in other areas? ${ }^{18}$ At first glance, at least compared to the neoclassicals, pretty well. After all, the triangle distinguishes not only between consumption and production, as do all mainstream economists, but also between the different stages

17 Indeed, this has been taken so far as to have created a debate between Kirzner (1976) and Rothbard (1978) over whether or not even homogeneous data, such as money, can properly be aggregated, with the former maintaining it cannot be, and the latter that it can. In our view, the latter was correct. For support of our position, see Salerno, 1994, p. 78, fn. 8.

18 An important element of ABCT is that it rejects, for example, the neoclassicalKeynesian practice of interpreting capital as a homogeneous blob, and labeling it «K», or some such. In sharp contrast, the Austrian theory disaggregates capital into numerous sub categories, according to its place in the structure of production. That is but one reason why $\mathrm{ABCT}$ is superior to macroeconomics based on neoclassical foundations. 
of production, which they most certainly do not. But this really cannot pass muster. For each of the stages contains a plethora of raw materials, capital goods, semi-finished products, etc. Austrian macroeconomics is properly characterized as a microeconomic theory of macroeconomics, but collapsing so many different things into (to be sure) separate levels in the structure of production cannot even begin to approach the usual praxeological emphasis on individual behavior.

2.

THERE IS NO COHERENT WAY TO CONSTRUCT A MEASURE OF THE STRUCTURE OF PRODUCTION ${ }^{19}$

Consider a set of consumers' goods each with its own triangle ( 1 and 2 in figure 6). ${ }^{20}$ In order to arrive at the social structure of production these must be combined in some way. Of the infinite number of possible ways, only two are reasonable prospects: one is to so arrange them that the hypotenuse of each begins at the origin (figure $7 \mathrm{~A}) ;{ }^{21}$ the other is for them to

${ }^{19}$ In our present paper, most of the examples concerning the triangle focus on the difficulties of aggregation, as they do in the present section. If we wanted to virtually double the size of the present paper, we could make every point we do regarding the shortcomings of the triangle with regard, also, to disaggregation. That is, it is no more possible to break down triangle $1+2$ of figure $7 \mathrm{C}$ into its constituent elements found in figure 6 , than it is to build up triangle 1 and triangle 2 of figure 6 into their amalgamations shown in either 7A, 7B or 7C.

20 The slope of the hypotenuse of each triangle would reflect the relevant entrepreneur's discount rate. This raises another problem; to wit: as ordinarily a multiplicity of entrepreneurs will be involved in the production of any particular consumers' good, and each may have a different discount rate, inter alia, because they face different risks, and also evaluate any given risk differently. This is true even absent considerations of compounding, the side of the figure opposite the right angle (the hypotenuse) is most unlikely to be a straight line. That is, ignoring compounding, the hypotenuse of the figure for a single good is likely to be a series of connected (straight-) line segments of different slopes (figures 6, 7A and 7B).

${ }^{21}$ Note that in figure 7A the value of consumers' goods at $t_{1}$ consists of $C_{2}\left(t_{1}\right)$ of goods in process, and $C_{1+2}\left(t_{1}\right)-C_{2}\left(t_{1}\right)=C_{1}\left(t_{1}\right)$ of consumers' goods at the time of sale to consumers. 
be so arranged that the vertices of their right angles all coincide with that of the good whose right angle occurs at the greatest value of $t$ (figure 7B). ${ }^{22}$ Even a cursory examination shows that neither of these methods is capable of providing a combined figure that has a reasonable economic interpretation. ${ }^{23}$ That is, there is no coherent way to combine ${ }^{24}$ the different triangles for each consumers' good into an aggregate triangle for all consumers' goods. ${ }^{25}$

There are other ways triangles could be combined into nontriangles (see, e.g., figures 18 and 19), but we shall ignore them as irrelevant to economics. And, there are any number of ways that multiple triangles could be combined into a single triangle,

22 Note that in figure 7B the value of consumers' goods at $t_{2}$ consists of $C_{1}\left(t_{1}\right)$ $+\mathrm{C}_{2}\left(\mathrm{t}_{2}\right)=\mathrm{C}_{1+2}\left(\mathrm{t}_{2}\right)$.

${ }_{23}$ As will be explained in section 9, infra, in relation to a different issue, had one to choose between these two methods of superimposing triangles in the same figure, the former is the more correct way for purposes of economic analysis.

${ }^{24}$ Even geometrically, what we have done in $7 \mathrm{~A}$ and $7 \mathrm{~B}$ is problematic. It was the best we can do, given geometrical limitations in depicting economic reality. To wit, note that in both $7 \mathrm{~A}$ and $7 \mathrm{~B}$ what is being combined with triangle 2, in order to derive the triangle we are calling $1+2$ is not a right-angled triangle. Rather, the ordinate of 1 at every value of $t$ is added to the ordinate of 2 point at the same value of $\mathrm{t}$, in $7 \mathrm{~A}$, and it is added to every value of 2 , at $t+t_{1}$ in 7B. The result is as if we combined a triangle with a greater than 90 degree (obtuse) angle (at its lower right point, precisely the place where triangle 1 in figure 6 is a right triangle) by making the leg that corresponds to the one that would have been coincident with the $t$ axis now coincident with the hypotenuse of 2 and the obtuse angle tangent to the hypotenuse at $t_{1}$ in 7A and $t_{2}$ in 7B. The only way to avoid this, that is to maintain the right angle of triangle 1 in figure 6 when it is combined with triangle 2 (which appears in 7A and 7B exactly as it was in 6) would be to shift 1 upward vertically until its right angle was just tangent to 1 's hypotenuse (dotted lines and hypotenuse $1^{\prime}$ in figure $7 \mathrm{~A}$ ) or to shift 1 horizontally rightward until its right angle was coincident with that of 2 , at $t_{2}$, and then to shift it vertically upward until its right angle was tangent to the hypotenuse of 2 at $t_{2}$ (dotted lines and hypotenuse $1^{\prime}$ in figure 7B). This, of course, makes no economic sense whatever, as there would then be a vertical gap, in $7 \mathrm{~A}$ or $7 \mathrm{~B}$, between the horizontal leg of $1^{\prime}$ and the hypotenuse of 2 the magnitude of which would have to be subtracted from the sum of the ordinates of the two hypotenuses ( $1^{\prime}$ and 2 ) in order to arrive at the value of $C$ at any point on the t-axis.

25 This is but another example of an insolvable problem arising out of an attempt to aggregate economic data. 
7C. Each such triangle has a length (time period of production), $t_{1}$, along the time axis, a height (value of consumers' goods at the time of sale to consumers'), $\mathrm{C}\left(\mathrm{t}_{1}\right)$ at $\mathrm{t}_{1}$, and an area, ${ }^{26} \mathrm{~A}=$ $t_{1} C\left(t_{1}\right) / 2$. To have any even remotely possible economic meaning, these variables would have to be related to their counterpart(s) in the original triangles. And, yet, there is no consistent way to do this. That is, it would be impossible to combine 1 and 2 in such a way that their combination had a time period equal either to that of 1 , or 2, or their combined lengths, «1 $+2 »$, and a height equal either to that of 1 , or 2 , or their combined heights, «1+2», and an area equal to either that of 1 or 2 , or their combined areas, «1 1 , " and have an economically plausible interpretation (appendix 1 ).

And, it should be noted that there is more than one way to produce a specific set of consumers' goods. (Hayek, 1934A, 157) puts it this way: "... any given demand for consumers' goods can lead to methods of production involving very different demands for producers' goods, and that the particular method of production chosen....»

3.

\section{STAGES OF PRODUCTION V. THE PERIOD OF PRODUCTION}

The direct correlation of the number of stages of production with the duration of the production process is a commonplace in Austrian economics. For example, Garrison (2004, 324), perhaps the best-known and most highly respected Austrian macroeconomist now writing, ${ }^{27}$ clearly equates them: «In its

\footnotetext{
${ }^{26}$ For the economic meaning of the area, see footnote 16.

27 The term «Austrian macroeconomics» herein refers only to the problems considered. It should not be taken to mean that there is an Austrian economics of aggregated variables and/or their averages.
} 
simplest application, the two legs of this right triangle measure consumption [sic] and the corresponding time (reckoned in the number of stages of production) for an economy that has reached intertemporal equilibrium.» See also, Garrison (2001, 47).

As there is no objective way to define a stage of production, unless "stage» is defined as a specific period of time, ${ }^{28}$ there may not be a direct and consistent relationship between the number of stages and the duration of the production process. Indeed, the number of production stages may even be inversely related to production time. ${ }^{29}$ Moreover, different ways to produce a particular good may involve different numbers of stages, one requiring many short stages and another requiring a few long stages. For example, figure 8A illustrates a few long stages, while $8 \mathrm{~B}$ depicts many shorter ones. ${ }^{30}$ Moreover, the same may be said for the relationship between stages and time in comparing the production processes of heterogeneous goods. Therefore, nothing may be said about the relationship between stages and time, a priori.

One bit of strong evidence for the truth of this contention is uncovered when we look clearly at the dimensions (Barnett, 2004) of the triangle, particularly, the horizontal axis. There, we find $\mathrm{T}$, or time. But we also discover stages of production ranged in this direction. That is, a typical triangle will feature four or five production stages, each one of equal width, indicating that they all take up the same amount of time, say, one year, for each of them (figure 9A). However, there is absolutely no reason why each stage should require the same amount of time, regardless of how a stage is defined (figure 9B). Here we can

28 In which case time, not stages, should be used if for no other reason than Occam's razor.

${ }^{29}$ For more on this point see appendix 2.

${ }^{30}$ Note that $\mathrm{t}$ (time), does not appear in our figures 2, 8A, 8B and 9. Here, instead of time, the horizontal axis depicts stages of production. On the importance of dimensions in economics, see Barnett, 2004. 
see that one and the same axis is in effect being «asked» to perform two very different functions. ${ }^{31}$ First, to measure time, and, second, to depict stages of production. But these are very different dimensions. Each one «deserves» a unit of its own. Just as to solve for two unknowns one needs two equations, so is it true that to perform two completely separate jobs there must be two distinguishable axes. There is only one, however, in the triangle. Is there any possible reconciliation? Yes, if and only if time and stages of production are synonyms for each other. Then, our criticism will fall by the boards. But it simply will not do to assume, in effect, as use of the triangle de facto does, that there is no distinction at all to be made between time and stages of production. It cannot be denied that there may, in some cases, be some sort of rough correlation between the two. But to implicitly assert they are the same is incorrect from an economic perspective.

Here is another implication of the triangle as it is commonly used. Consider a given value of consumers' goods at a specific point in time. Compare multiple possible production structures each involving a different period of production: the one that results from the steeper slope (i.e., ceteris paribus, implies a higher social rate of discount) is the more or most desirable. Why? Ceteris paribus, the same amount of consumers' goods will be

31 Skousen, 1991, 93, 94, 111 is perhaps the most blatant about committing this fallacy, going so far as to label one of his axes on each of these pages: «Stages (time).» But all of those who employ the triangle (see fn. 2 supra) are equally guilty of this logical oversight. Yet a third function given to this axis appears in Bellante and Garrison, 1988: «depth of capital structure.» In a system of linear equations if the number of equations is greater or less than the number of unknowns the system is underdetermined or overdetermined, respectively. In the former case there is no solution; in the latter there maybe any number of solutions or no solutions. Only if there are as many equations as there are variables is a unique solution possible. In a geometrical system, each variable is represented along an axis. Therefore, and for similar reasons, one axis cannot represent two (2) different variables - time and stages of production - much less a third, depth of capital structure, unless the three (3) are but one (1) in reality; i.e., or unless the time, stages of production, and depth of capital structure are but synonyms. 
available sooner. However, this, also, is problematical. For example, in figure $5 \mathrm{~B}$, the hypotenuse of triangle 1 has the steeper slope, which according to standard ABCT is less desirable (it is less conducive to economic growth, because of a higher rate of time preference). And yet that triangle, 1, with a period of production, $t_{2}-t_{1}$, has a shorter period of production (by the amount of time $t_{1}-0$ ) than triangle 2, with a period of production of $t_{2}-0$, which implies the very opposite. Obviously, if one can acquire the same value of consumer goods with a shorter period of production, ceteris paribus, that is more desirable.

4.

THE PERIOD OF PRODUCTION INHERENT

IN A MORE COMPLEX STRUCTURE OF PRODUCTION IS CONFOUNDED WITH THE PERIOD OF PRODUCTION THAT EXISTS DURING THE TRANSITION FROM A LESS TO A MORE COMPLEX STRUCTURE OF PRODUCTION

The triangles are used to illustrate, inter alia, a change in the structure of production consequent upon a change in «the» interest rate. We start off with triangle 1, for illustration purposes (figure 10A). A decrease in the interest rate is shown by a new or second triangle (2) that has its vertical height (i.e., value of consumers' goods at the moment of sale to the consumers) superimposed on that of the preexisting triangle. However, 2 is of lesser height. This reflects the reduced value of consumption involved in the increased capital formation caused by the lowered interest rate, which is in turn reflected by a less steep slope of the hypotenuse (the intercept of 2 on the vertical axis, at 0 , is higher than that of 1 , which intersects it at a negative value). In fact, the combination of the lower vertical height and the less steep slope are drawn such that the horizontal length 
is increased; i.e., the hypotenuse of triangle 2 is flattened and the horizontal axis lengthened ${ }^{32}$ compared to triangle 1.

The key to understanding the problem with all this familiar geometry is to realize that the second triangle is but a transitory phenomenon. In fact, changes in time preferences are manifested not in a desire to lengthen the period of production, but rather in a willingness to temporarily forego some consumption «now» in order to be able to increase consumption in the future. The temporary sacrifice is intended to be just that, temporary, and takes the form of producing relatively more capital goods ${ }^{33}$ and relatively fewer consumers' goods, ${ }^{34}$ but only for a period of limited duration. (Were this not so, what would be the point of saving?) During the period of sacrifice the structure of production is lengthened. However, it is quite possible, in fact most likely, that once the necessary sacrifices have been made such that the new capital (goods) structure and concomitant period of production are in place, so that all that is required is maintenance and replacement of depreciated capital goods, the new structure will be shortened relative to the old; i.e., it is likely that the period is lengthened only during the transition from the old to the new, and that thereafter it is, ceteris paribus,

32 It is true that the shorter vertical leg and the shallower slope of 2 do not necessarily (mathematically) result in a longer horizontal leg. However, it is always drawn that way to illustrate the lengthened structure of production that results from the lowered interest rate. This is probably a consequence of the assumption that a reduction in interest rates lengthens the structure of production, instead of the correct understanding, that it alters the structure of production, in ways not necessarily predictable in terms of the length of the structure, which in any case cannot be defined in an economically meaningful and correct way.

33 And durable consumers' goods; see Mises, 1966, 480.

${ }^{34}$ In fact more of both may be produced if idle (in the engineering, not economic, sense) resources, including labor, are brought into production. That is, during this boom which occurs when we move from triangle 1 to 2 , whether this occurs naturally, due only to the lowered time preference rates, or artificially, stemming from, say, governmental expansion of fiat currency, leisure will be reduced and idle plant and equipment brought on-line, allowing for increased production of goods at all stages of the structure of production. 
shortened. That is, there is yet another triangle that replaces the transitory, second one (2). The «final» triangle, the one unseen until now, 3a (we are now on figure 10B), has a greater vertical height and, quite possibly, or perhaps even probably, a shorter horizontal length, $3 \mathrm{~b}$, than the original triangle, although $3 \mathrm{a}$ is the standard way of portraying it. ${ }^{35}$ This illustrates that as a result of the temporary increase in production of capital goods and sacrifice of consumption goods necessary thereto, the future is expected to bring a greater value of consumers' goods, and those produced possibly in a shorter period of time. ${ }^{36}$

In fact, if the two (2) triangles of the standard exposition are superimposed, not with their right angles coincident, but rather so that the hypotenuses intersect the time axis conterminally (figure 11), then it immediately become obvious that triangle 2 must be transitory. Why would 2 be preferable to 1 , when from the time at which the hypotenuses intersect until the production of the consumers' goods is completed and they are sold to consumers, 1 represents a greater value than 2, especially as the important thing is the value at time of sale to consumers? As well, the goods illustrated in 1 are marketed to consumers earlier $\left(t_{1}\right)$ than in $2\left(t_{2}\right)$. There must be a third triangle to represent the post transition, 2 , period.

Several post triangles are conceivable. That raises the issues of what these triangles look like and what, if anything, may be said regarding their ranking in terms of the quantity of goods sold to consumers and their time period of production. One possibility is that the discount rate returns to its original level after the entire transition process is completed. In that case

35 Garrison $(2004,325)$ recognizes that triangle 2 in figure 10B is only transitional, but thinks that the third triangle must depict: «a longer consumption [sic] leg... and a longer production-time leg...» That is, he thinks the third triangle must look like $3 \mathrm{a}$ on figure $10 \mathrm{~B}$, and can not look like $3 \mathrm{~b}$ in that figure. It should be noted that he does not, in that place, or any other that we are aware of, use a figure that includes the third triangle.

${ }^{36}$ For more on this, see appendix 2. 
(figure 12), 3 must overlay 1 throughout the length of the latter, and then extend even further; $; 7$ i.e. it must extend to a point such as $x, y$, or $z$, at which point the abscissa is greater than $t_{1}$, and the ordinate is greater than $C_{1} 1\left(t_{1}\right)$, indicating that the period of production has been lengthened and the value of consumers' goods at the time of sale has been increased. The reason is that it would be absurd to forego consumption during a transition phase in order to arrive at a situation in which consumption were no greater than it was before the sacrifice, $\mathrm{C}_{1}\left(\mathrm{t}_{1}\right)$, and even less if 3 overlays only part of 1 ; i.e., terminates between 0 and $C_{1}\left(t_{1}\right)$, at a point such as $w$.

In other words, if one is at $\mathrm{C}_{1}\left(\mathrm{t}_{1}\right)$ before the transition, it would make no sense to suffer the loss during the transition if one ended up only right back at $C_{1}\left(t_{1}\right)$. Even worse would be to end up at point on the hypotenuse of triangle 1 , such as $\mathrm{w}$, closer to the origin than $\mathrm{C}_{1}\left(\mathrm{t}_{1}\right)$. Now consider points $\mathrm{x}, \mathrm{y}$, and $z$. If any of them was the intended result of the transition, then it is preferable.

37 This raises an interesting issue. Can a specific structure of production be extended, or for that matter, contracted? That is, for a specific triangle can there be similar triangles? Certainly, form a purely mathematical/geometrical viewpoint they can exist. However, from the economic perspective, we understand that although the triangles are similar, in fact, each would represent a different period or structure or process of production. Then the issue is, does an $\mathrm{x} \%$ change in the length of the period of production result in an $\mathrm{x} \%$ change in the value of consumers' goods at the end of the (new) period of production? Note that although, at first blush, this issue may seem to be the same as that of scale economies, specifically, constant returns to scale, it is not. For it is one thing to ask if changing every input by $\mathrm{x} \%$ can, or does, result in an $\mathrm{x} \%$ increase in output. But it is an entirely different matter to ask about the effects of changing the time period of the structure of production, because an alteration in the time period necessarily implies a change in the methods of production. And it is not at all clear that one can change methods, going to a longer or shorter time period, and that output would necessarily change proportionately to the time period change. This is not to say that such a change may be ruled out on praxeological grounds, but only that because different time structures would necessarily involve, at least to some extent, different durable capital goods, it does not seem very likely that such a result would obtain. 
Another possibility is that the discount rate does not rise back to the pretransition level. In that case, there are three (3) possibilities: the interest rate rises above that of the transition level, but not to the pretransition level (3a in figure 13); the rate falls below that of the transition level ( $3 \mathrm{c}$ in figure 13); and, the rate remains the same as that of the transition ( $3 b$ in figure 13), where $3 \mathrm{~b}$ overlays 2 , but extends beyond it). In these cases, also, the period of production would necessarily be increased, ${ }^{38}$ else the value of consumers' goods would be less than before the transition; i.e., less than before the sacrifice. That is, we would have to end up at a point on the hypotenuse such that the ordinate was greater than $\mathrm{C}_{1}\left(\mathrm{t}_{1}\right)$. For example, $\mathrm{x}$ on $3 \mathrm{a}, \mathrm{y}$ on $3 b$, or $z$ on $3 c$, so that the value of consumers' goods is greater than $C_{1}\left(t_{1}\right)$. However, this means that the period of production would have to increase to a length greater than $t_{1}$, as each of these curves, $3 a, 3 b$, and $3 c$, rises above $C_{1}\left(t_{1}\right)$ only at a later time than $t_{1}$. Moreover, the increase in consumers' goods would be less than proportional to the rise in the time period required for production. And, the lower the post-transition discount rate relative to the pre-transition rate, the smaller would be the proportion of the increase in consumers' goods to the increase in the time period of production.

The last possibility is that the discount rate rises above the pretransition level. In that case, there are five (5) possibilities (figure 14): 1) the period of production is shortened and the value of consumers' goods at the end of the period is reduced ( $\mathrm{v}$ on 3 ) relative to that produced at the end of the pretransition

38 In fact, there is a minimum increase in the time period required in order for the value of consumers' goods produced to attain the pre-transition level $\mathrm{C}_{1}\left(\mathrm{t}_{1}\right)$; i.e., the rise would have to be greater than $t_{3}-t_{1}, t 4-t_{1}$, or $t_{5}-t_{1}$ on $3 a, 3 b$, and $3 c$, respectively (figure 13). If there is an upward movement, but this minimum increase is not reached, then although the time period will have lengthened, the value of consumers' goods will be less than pre-transition. And, the lower the post-transition discount rate, the greater the required minimum augmentation in the time period. 
period of production ( $\mathrm{j}$ on 1$) ; 2$ ) the period of production is shortened and the value of consumers' goods at the end of the period is the same as that produced at the end of the pretransition period of production ( $w$ on 3$) ; 3$ ) the period of production is shortened and the value of consumers goods at the end of the period rises relative to that produced at the end of the pretransition period of production ( $x$ on 3$) ; 4$ ) the period of production returns to the same length as that of the pretransition period and the value of consumers' goods at the end of the period is increased relative to that produced at the end of the pretransition period of production (y on 3); and, 5) the period of production is lengthened and the value of consumers goods at the end of the period rises relative to that produced at the end of the pretransition period of production ( $z$ on 3 ). Moreover, the ratio of the pecuniary value of consumers' goods to the length of the period of production is increased. And, the lower the post-transition discount rate relative to the pretransition rate, the greater is the ratio of the pecuniary value of consumers' goods to the length of he period of production, relative to the pretransition ratio.

In this section, then, we do not so far have a criticism of the Austrian triangle per se. Everything we have said we were able to illustrate with this geometrical expression. Our criticism of «mainstream» or «classical» Austrianism has so far consisted, merely, of adding a third triangle, 3 , to the analysis. That is, we would expect, that over time, the vertical height would rise, reflecting an increase in the value of consumers' goods produced, and the hypotenuse would also become steeper, reflecting the economy's ability to produce consumers' goods more quickly, both devoutly to be desired in terms of improving standards of living.

However, ideally, of course, what we really want is a «triangle» with no horizontal distance at all; it would be extended, only, in the vertical direction. That is, a «triangle» that 
would depict a situation in which production occurred instantaneously: one where goods were immediately available, merely upon demanding them, with no structure of production whatsoever needed for attaining these consumer goods. ${ }^{39}$ This new triangle 3 is but a move in that direction.

Such a situation is illustrated not by a three-sided geometrical structure; rather, it is depicted by a vertical line. ${ }^{40}$ Hence, ultimately, this section of the paper not only rejects the usual Austrian triangular analysis by in effect accepting it only subject to yet a third triangle, but discards the geometry in its entirety, at least ultimately.

5.

THE CONCEPT OF «STAGES OF PRODUCTION» IS CONFUSED

Although the concept of «stages of production» is often illustrated by an example; e.g., mining, refining, manufacturing, distributing, and retailing, ${ }^{41}$ this is not analytically satisfactory. These are but arbitrary categories. Any specific production process can be broken down into ever more discrete stages, or combined into fewer of them. The limit to the number of stages is set only by the number of individual human actions involved. ${ }^{42,} 43$ Thus, the number of stages depends upon the

\footnotetext{
${ }^{39}$ One may speculate whether such a situation would constitute a post-scarcity world.

40 The height of the line would depend upon productive capacity; i.e., the quantity of resources, the state of technology, and entrepreneurial talent, after due allowance for the negative impact of governmental intervention.

41 Or, planting wheat, watering it, harvesting it, turning it into flour, baking it into bread, wholesaling and then retailing this foodstuff to consumers.

42 The relevant concept here is methodological singularism (Mises, 1966, 444). See on this Barnett and Block (unpublished B)

43 Should we add at this point: plus the discrete physical/chemical/biological changes that occur, if in fact any do, between the individual human actions? This
} 
judgment of the individual decision maker ${ }^{44}$ analyst. This is not to deny that the concept may be useful in providing the flavor of production through time, but it is not analytically sound in the sense necessary to be measured along the horizontal axis of a triangle that purports to represent the structure of production from an analytical (in this case, geometrical, and, therefore, mathematical) perspective.

Further, these examples are intrinsically confusing. Consider steel in this regard. If anything «deserves» to be located in an early ${ }^{45}$ stage of production, this item certainly does: it is the backbone of so much else, and these other productions cannot take place until the steel comes along on line. However, steel also occurs in very late orders of production. Indeed, steel may be found throughout the structure of production. For example, it is used pretty much at every stage in the production of bread, and its delivery to the final consumer. So, where does steel properly go? At an early stage of production? All though out? Moreover, things that produce steel are in turn produced by steel. For example, the rubber that goes into transportation vehicles is aided by steel, and also dependent upon steel. A similar situation applies with regard to human labor. It, too,

\footnotetext{
is tempting, but, strictly speaking, not logically implied by the triangle. In addition, there are good and sufficient Austrian reasons for not including these considerations: they are not subject to human action. Praxeology is a subjective discipline, and, as these chemical, etc. reactions are objective considerations, they do not fit easily, or, indeed, at all, into that world-view.

44 «It is important to realize that the period of production as well as the duration of serviceableness are categories of human action and not concepts constructed by philosophers, economists, and historians as mental tools for their interpretation of events. They are essential elements present in every act of reasoning that precedes and directs action. It is necessary to stress this point because BohmBawerk, to whom economics owes the discovery of the role played by the period of production, failed to comprehend the difference» Mises $(1966,480)$. In effect, it is our contention that Bohm-Bawerk was not the only Austrian economist to make this error; this would include all of those who utilize the triangle (see fn. 2, supra) without any of the reservations made in the present paper.

${ }^{45}$ Not the earliest. Iron and coal go into its creation, and must come beforehand.
} 
appears at every stage. As well, things that promote the creation of human beings are in turn created by them. ${ }^{46}$

6.

WHAT IS NEEDED IS NOT A TIME-STRUCTURE OF PRODUCTION, WHICH IS BUT ONE OF THE TWO TYPES OF ACTIONS, BUT RATHER A TIME-STRUCTURE OF ACTION, TO INCLUDE BOTH TYPES OF ACTION; TO WIT: PRODUCTION AND CONSUMPTION

Garrison (2001, 47-49) recognizes this and attributes to Jevons ([1871] 1965, 231) the idea of extending the figure with a consumption right triangle that would share the vertical leg of the production triangle but whose time dimension would extend to the right, indicating that consumption of durable consumers' goods would continue, but at a declining rate, into the future; i.e., from left to right along the horizontal axis (figure 15) ${ }^{47}$ Garrison then states: «Durable consumption goods and durable capital goods are obvious and, in some [sic $]^{48}$ applications, important features of the market economy. But to include these features would be to add complexity while clouding the fundamental relationships that are captured by the simpler construction ... Although the allowance for consumption time as well as production time may constitute a move in the direction of realism, there is little to be gained

46 It is no accident that Kirzner's $(1963,19)$ attempt to supplant (see Simpson and Kjar, unpublished) the neoclassical circular flow diagram (Stigler, 6) bears a not inconsiderable resemblance to the structure of production. The point is that if A helps in the creation of $B$, and the reverse is also true, then the triangle can be converted into something along the lines of a circle.

47 These back-to-back triangles might be referred to as a «double triangle.»

48 In our view, «some» vastly understates the case as it relates to the contemporary economy, at least in the US. 
analytically by replacing the multistage Hayekian triangle with the Jevonsian ...figure. ${ }^{49}$ We do not at all agree.

To exclude durable capital goods from consideration because they «would ... add complexity while clouding the fundamental relationships that are captured by the simpler construction» is of course unwise. The whole purpose of the triangle is to serve as a pedagogical means to explain ABCT. And yet, for the sake of simplicity of exposition this geometrical model that ignores an absolutely essential element ${ }^{50}$ of that same theory is employed.

Nor, at least with respect to durable capital goods, would Hayek (1935, 40-41, fn. 2) agree:

But as soon as it is tried to use the diagrammatic representations to show the successive transfers of the intermediate products from stage to stage in exchange for money it becomes evidently impossible to treat durable goods in the same way as goods in process since it is impossible to assume that the individual services embodied in the durable goods will regularly change hands as they approach a stage nearer to the moment when they will actually be consumed. For this reason it has been necessary to abstract from the existence of durable goods so long as the assumption is made that the total stock of intermediate products as it gradually proceeds toward the end of the process of production is exchanged against money at regular intervals.

49 It should be noted that, although Jevons (1965 [1871], 231) draws his double triangle to illustrate the case of «uninvest[ment]» of durable consumers' goods, Hayek (1975 [1941], 136) draws the same figure (rotated about the horizontal axis and then rotated $90^{\circ}$ counterclockwise, although Hayek says it «has here been turned 90 degrees) to illustrate 'disinvestment' of durable goods. As this appears in his Chapter X, The Position of Durable Goods in the Investment Structure, it is clear that Hayek understands this disinvestment to be with respect to durable capital goods as well as durable consumers' goods.

50 Garrison himself subtitled his magnum opus «The Macroeconomics of Capital Structure.» Additionally he has often referred to ABCT as «capital-based macroeconomics.» How can it make sense to exclude durable capital goods from an analysis of the structure of production? 
And (Hayek, 1934B, 208-209)

It is necessary to begin by drawing a clear distinction between the two different ways in which time may be a condition to the production of the ultimate services to the consumer. This distinction between the actual time a process of production lasts and the time through which a product will give its services, to which corresponds the distinction between goods in process and durable goods, is of special importance in this connection... It seems to me, however, that in neither case will one alone of the two concepts provide a sufficient explanation, and that, in particular, the effects of changes in the data can be understood only if the relation between these two concepts is cleared up.

We think it a serious mistake to ignore either durable consumers' goods or durable capital goods for the sake of "simplification», and explicate our analysis and reasons therefore, in Barnett and Block (Unpublished A). ${ }^{51}$ This is not to downplay the role of goods in process. It is only to say that both goods in process and durable capital goods are of the essence of ABCT.

Moreover, Garrison $(2001,48)$ labels his production cum consumption triangle: «The structure of production (continuous input/continuous-output).» There are two problems with this. First, regarding the production-triangle part of the figure, on the preceding page (47), he labels a virtually identical, ${ }^{52}$ "continuous input-point output.» ${ }^{53}$ It seems passing odd that the same figure

51 One might think that for Garrison the Holy Grail is a simple set of diagrams that can be used to explicate Austrian Business Cycle Theory and that he thinks he has found it with those to be found in his book (Garrison, 2001.) However, there is a difference between simple and overly simple. Austrians understand and appreciate the complexity of the real world, especially at the «macro» level.

52 The figures are identical, save that the figure on page 47 refers to stages labeled mining, refining, manufacturing, distributing, and retailing, in addition to early stages and late stages, whereas the figure on page 48 refers only to early and late stages.

53 This is an excellent example of the type of confusion that arises from attempts to use the triangle. 
can be used to illustrate two very different concepts of production. The second problem is that the label for the figure on page 48 that contains, also, the consumption triangle, does not refer to the nature of the consumption depicted. Consistency and clarity warrant that the figure be labeled "continuousinput/continuous (or point)-output/continuous-consumption» and not just «continuous input/continuous-output.»

Garrison $(2001,48)$ also states: «The notion of stages of consumption has much more limited interpretation than the corresponding stages of production. We might think of usedcar lots, second-hand furniture shops, and junk shops as separating the stages.» But the concept of stages of consumption is every bit as inchoate as that of stages of production, discussed supra, in section 5 .

Furthermore, the idea behind the consumption triangle; i.e., that durable consumers' goods both yield their services, and decline in value over time is equally relevant to durable capital goods. This is nothing more than depreciation. And, yet, the ordinate of the hypotenuse of the standard triangle is never decreased to account for this. But this is not surprising, as the triangle is used solely to illustrate the case where the only capital goods are goods in process.

In fact, then, what is required, if triangles are to be used at all, is a Jevonsian style figure (figure 15,) that represents both the time-structure of production, including depreciation of durable capital goods, and the time-structure of consumption, as both structures are affected by changes in interest rates (Barnett and Block, Unpublished A), and thus both should be part and parcel of the ABCT. Of more importance, the triangle can be jettisoned; this would in no way affect $\mathrm{ABCT}$, as the triangle is merely a pedagogical device, and therefore, this would merely affect the way in which ABCT is explicated. Moreover, it is of great importance that the theory itself be extended to incorporate the concept of the 
structure of consumption; i.e., the concept of the structure of consumption must be integrated with the concept of the structure of production into a structure of action that, itself, should be an essential element of ABCT (Barnett and Block, unpublished A).

We are all in favor of Occam's Razor (http://en.wikipedia. org/wiki/Occam's_Razor). But this merely states that of two theories, both of which equally explain a phenomenon, the simpler one is to be preferred. In the present case, it is our contention that the Jevonsian triangle set is much to be preferred to the Hayekian. For one thing, consumption is every bit as influenced by the interest rate as is production, ${ }^{54}$ apart from the fact that most consumption items are of shorter duration than most producers' goods, and thus the effect is greater in the latter than in the former case. However, some consumer durables (houses in particular) remain in service for centuries, and, in the last few decades, have taken up a higher proportion of GDP than in former years, when ABCT was first being introduced. For another, institutional financial alterations over the past few decades have seen this sector of the economy take on a larger role. It is one thing to jettison so important an aspect of the economy as consumption on substantive grounds. To do so on the basis of convenience, or a misreading of Occam's Razor, is entirely another.

54 Consider a factory and a residence that start out at the same value, and last the same 200 hundred years. It is difficult to see why the interest rate would affect them very differently at all. 
7.

\section{THE HAYEKIAN TRIANGLE CAN BE USED TO ACCOUNT EITHER FOR GOODS-IN-PROCESS OR FOR FIXED CAPITAL.} IT CANNOT ACCOUNT FOR BOTH SIMULTANEOUSLY

This is recognized, implicitly, if not explicitly, in the confusion of time and stages ${ }^{55}$ of production (or consumption). ${ }^{56}$ The appropriate dimension of the horizontal axis is time if we are concerned with goods in process, or stages of production if our concern is fixed capital. However, although the slope of the hypotenuse reflects the interest rate in the case of goods-inprocess, there is no such relationship concerning stages of production. In the latter case, it is more appropriate to use a vertical bar chart ${ }^{57}$ than a triangle. Moreover, for purposes of the $A B C T$, stages, qua stages, are irrelevant insofar as interest rates, and changes thereof, are concerned. Rather, it is time that is of the essence where interest rates are concerned.

This is yet another example of «asking» one axis to do the work of representing two very different phenomena. Fixed capital, as its name implies, means preeminently machinery

55 Some might argue that it is not possible to increase investment without increasing the number of stages of production in an economy, but that it is possible to increase investment without increasing the time that elapses from the beginning of production until the consumption stage. But this is erroneous. Investment can be increased without increasing the number of stages - in essence that is the difference between capital widening (same number of «stages», but each stage producing more value than before), and capital deepening (more «stages»). Figure 16A illustrates capital widening, and 16B capital deepening. For the not totally unrelated concept of «depth of capital structure», see Bellante and Garrison, 1988.

56 See section 3, supra.

57 One might be tempted to assert that the triangle is merely a bar chart, with perhaps very thin bars. Strictly speaking, this is incorrect. A careful perusal of Rothbard $(1962,286)$ indicates that a triangle with a straight-line hypotenuse cannot be constructed by connecting the midpoints of the bars depicted therein. From the web (http: / / thesaurus.maths.org/mmkb / entry.html?action=entryById\&id=2287): «A bar chart or bar graph is a way of showing information by the lengths of a set of bars. The bars are drawn horizontally or vertically.» 
that «stays put» in its relevant stage of production. Assuming arguendo that this makes sense in the first place, ${ }^{58}$ what the pro triangle Austrian economist presumably has in mind is, say, a milking machine that remains in whatever stage of production to which this process is (arbitrarily) assigned. In sharp contrast is the milk itself that gets transformed from its raw state to pasteurized to serve as inputs into ice cream, etc. Here, the good in question does not «stay put» but rather emigrates from stage to stage.

A possible objection to our argument is that it does not matter at all for the ABCT whether a given item moves around through the stages or stays in one place until it depreciates out of existence. Even were this true, this is still a flaw in the triangle, as a depiction of economic reality. But, it is not so. The presumption is that goods like milk have many more alternative uses than do milk machines, which are heavily specialized. Thus, in the downturn, the latter will have to be much more radically written down than the former.

8.

IN THE CASE OF GOODS-IN-PROCESS, THE TRIANGLE DOES NOT HANDLE POST-INITIATIONOF-PRODUCTION INFUSIONS OF RESOURCES

That the triangle reflects the interest rate as if there were only simple; i.e., uncompounded interest, is well understood, as is the fact that a more accurate figure would replace the straight line hypotenuse ${ }^{59}$ with a power function (figure 3) to reflect discretely compounded interest or an exponential curve (figure 4) to reflect continuously compounded interest. ${ }^{60}$ However,

\footnotetext{
58 We argue it does not in section 1, supra.

59 Of course, every hypotenuse is a straight line; we use the redundant term for the sake of emphasis.

60 See footnote 11 and accompanying text.
} 
this implies that the value of the goods-in-process increases at a constant rate from the initiation of their production until the fruition of the production process in the form of consumers' goods. Historically, examples given were such as the value of grapes in the field or of uncut trees, or of wine or whiskey in casks, increasing as they matured. These had the advantage of not requiring infusions of other resources ${ }^{61}$ once the production process had commenced, and therefore, it could be assumed that the value grew at a constant rate. ${ }^{62}$ However, in anything but the most simple of processes such as these, post-initiation-ofproduction infusions of resources are the rule, not the exception. In such cases, neither a straight-line hypotenuse nor an exponential curve can accommodate such infusions of value in the form of resources.

In order to capture the effects for the triangle of infusions of resources into the goods in process, the triangle would have to be broken up into segments such that the curve, though continuous would be non-differentiable or non-smooth at the end of each segment. In fact, at each time at which there was an infusion of resources the curve would become vertical. For the length of the vertical segment is equal to the (discounted) value of the resources infused at that point. Then the triangle would look like a step function, with the horizontal parts of the steps sloped upward to the right (figure 17).

61 In making this statement, we, like everyone else, implicitly ignore the continuing contributions of land, protections against criminal incursions through fences, locks, etc., not to mention the resources used after the end of that part of the process in which «nature took its course. That is, the resources necessary to process the grapes into wine and, after another period of increasing value resulting from 'nature's work'», the bottling and marketing of the wine, or after the timber is grown, all the resources necessary to convert timber into lumber and then incorporate, directly or indirectly, the timber into consumers' goods, the resources necessary to bottler and market distilled liquor, etc.

62 Even using such examples of relatively simple production processes, it is not at all clear that the relevant values increase at a constant rate. 
Take an example. Before the reunification of Germany, both East and West Germany, presumably, had their own separate triangles. Now, they merge. How do we illustrate this via the triangle? One way to do so would be to concoct a much larger triangle. There would be no stupendous problem with this course of action on the vertical axis; we posit, arguendo, that the value of consumption of each could be added to the other, and this would eventuate in no more insuperable problems then amalgamating consumption in any other context. However, what of the horizontal axis? Assume for simplicity that both East and West Germany have the same time preference or interest rate, and thus that the angle formed by the hypotenuse and the time axis is the same in each case. Immediately after the political union, but before economic integration occurs and causes any changes in the structure of production in either area, the structure of production of the newly united country may be depicted by simply adding these two triangles together so that the area of the one depicting the amalgamated country is equal in area to the two smaller ones.

Any two right triangles of whatever lengths for the legs and hypotenuse could be added vertically, which would seem to be the only way that makes sense. We can add them in such way that the hypotenuses of both intersect the time axis at the same time, 0 , or so that the right angles are coincident (on the time axis). Of course, if they both have the same time dimension, the two methods yield the same result. In this case the figure is the same as that for the case of capital widening, illustrated, e.g., in figure 16A. If they have different time dimensions, then depending upon the assumptions we make, there are four ways they can be added: 1) with their hypotenuses both intersecting the time axis at time 0 , as illustrated in another context in figures 6 , and $7 \mathrm{~B} ; 2$ ) with their right angles coincident at time $\mathrm{T}$, as illustrated in another context in figures 6 and 7A); 3) with neither the hypotenuses intersecting at the same point 
on the time axis or the right angles coincident, illustrated in figure 18, or 4), with one both begins and ends before the other (see figure 19). In other words, triangle 1 begins at 0 and ends at $t_{1}$; whereas triangle 2 begins at 0 and ends at $t_{2}$. However when we combine them, we do so in a way that 1 is shifted to the right so far that although it begins before 2 ends, it ends after 2 ends. Note that the part of triangle 2 that extends beyond $t_{1}$ has been shifted downward so that it is coincident with the time axis.

All of this just goes to show what nonsense is hidden, or implicit, in the triangles. The foregoing indicates yet another problem with trying to use mathematics when analyzing human action. If both the interest rate and the total (pecuniary) value of consumption; i.e., the combined height of the vertical legs, are to remain unchanged, then we must of necessity extend to the left the horizontal leg of the triangle, e.g., add stages of production before the zero time point (see figure 20). But this plain flat out contradicts our assumption that nothing else, economically, has changed. How can it possibly be that, at time zero, the time of unification, because of the unification, magically, new earlier stages of production somehow arise in the past? Nothing can now be happening in the past, for goodness sakes, even arguendo. Rather, right now, before anything economically has occurred, we must add earlier stages of production, and they must necessarily be in the past. That is, hypotenuse 1 intersects the time axis at 0 , the split second in time immediately before production begins. Therefore, at 0 , right now, we must add the new stages by extending the hypotenuse to the left of 0 ; i.e., into the past (hypotenuse 2). Behold history is mutable; economics is no longer only forward looking; and, costs are not necessarily sunk anymore! Oh wonder of wonders! What hath the triangle wrought? From whence do these earlier stages of production spring? Basic industries, of the sort thought to occupy the leftward tip of the triangle, do not come into being automatically and instantaneously and in the past, and 
yet this is precisely what the triangle model requires in the present case.

9. CONFUSION OF THE TIME DIMENSION

When multiple Hayekian triangles are constructed on the same diagram, invariably the vertical lines representing the value of consumption goods at the moment of sale to the consumer are superimposed upon each other (e.g., figures 5B, 7B, 10A, 10B, $16 \mathrm{~A}, 19,20,21,23,24,26$, and 27$).{ }^{63}$ This results in the vertices formed by the time axis and the different hypotenuses occurring at different points on the time axis. This is a backward point of view, whereas economic analysis is necessarily forward looking. ${ }^{64}$ The points of coincidence should not be the vertical lines representing the value of consumers' goods. Rather, they should be coincident only at the one place that represents the

63 We added the vertical lines of each triangle to the other in the previous example, but this, to the best of our knowledge, has not been done before in the published literature on the subject.

64 Hayek himself apparently was confused on this point. Compare Hayek (1934A, 153, emphasis added):

"The curvilinear ${ }^{2}$ triangle $A B C$ represents, in the same way as the triangle I used in Prices and Production, the stock of capital belonging to processes already completed», with Hayek (1934B, 210, fn 1, emphasis added): «In both cases, however, the periods in question are future periods of time. In the first case the period $\ldots \mathrm{OT}_{1}$ refers to those future moments of time at which the corresponding quantities of 'labour' have to be invested in order to obtain the product at the end of the period, ... while in the second case it refers to the period during which the product of labour invested at its beginning, say the present, will mature.» Now consider Hayek (1934B, 226), «This very widespread impression is due to the fact that the concept of the period of production has generally been interpreted in an historical, backward-looking sense. For this Böhm-Bawerk's manner of exposition is mainly responsible. But, as has been pointed out at the beginning of this article, the essential concept is not the length of the process from which current output results, but the range of periods for which the current supply of factors is being invested», and, Hayek (1934B, 227), «It is for this reason that the backward-looking interpretation of the 'period of production' will always lead to absurd conclusions.» 
point in time when each production process begins; i.e., they should coincide where the hypotenuse of each intersects the time axis: 0 as illustrated in figures $5 \mathrm{~A}, 6,7 \mathrm{~A}, 11,12,13,14$, $16 \mathrm{~B}$, and 21 through 29 . The former approach is to look backward from the time of sale of finished consumers' goods to the consumers to the time structure of production that resulted in the consumers' goods. That is fine for history, but incorrect for theory, which is necessarily forward looking. The latter approach looks forward from the «beginning» of the production processes.

It should now be obvious that the triangle-as-history approach results in a single objective triangle. That is, the specific structure of production that resulted in a particular set of consumers' goods at a certain point in time is a historical reality, regardless of whether any individual is aware of the totality of the facts of that structure. In contradistinction, the triangle-as-future-plan is a subjective triangle. Moreover, it is not one subjective triangle, but a group of subjective triangles, one for each entrepreneur, in the broad Misesian sense of the term. These cannot be aggregated, no way, no how! Therefore, there cannot be a single triangle for the entire economy in any economically meaningful sense. In fact, the very concept of $a$ forward looking triangle implies complete coordination among the plans of entrepreneurs' (in the narrow sense), even if they are not coordinated with consumers' plans.

Moreover, if the former approach is to be analytically correct, no matter at what point in time the vertical lines representing the value of consumer goods' coincide, the hypotenuse must extend indefinitely to intersect the time axis only at a point in the deep recesses of human prehistory. This is so because in looking in retrospect at the process of producing a specific set of consumers' goods, we note that in reality the process began not when direct work first began on those particular goods, but rather it began at some point in 
antiquity. ${ }^{65}$ For example, in retrospect, we see that a car is made with the aid of a particular, previously-produced machine, itself made with the aid of a yet another particular, previouslyproduced machine, etc. However, if we use the latter approach, then the point where the different triangles coincide represents the point in time when production of the set of specific consumers' goods would begin using the different processes, including the relevant, extant, resources. In that case, we see that the forward-looking, structure of production has a finite duration.

10.

\section{THE ASSUMPTION OF DIFFERENTIABILITY REGARDING THE HYPOTENUSE OF THE TRIANGLE IS ANATHEMA TO AUSTRIANISM}

The implicit assumption of differentiability is with respect to the linear function that forms the hypotenuse of the triangle (in the case of simple discounting), or of the exponential function (in the case of continuously compound discounting) or the power function (in the case of discrete compounding) that, respectively, form the analogs of the hypotenuse in a triangular figure. Because these functions are differentiable they are necessarily continuous, ${ }^{66}$ a fact that renders them incompatible

65 This is reminiscent of the Austrian solution to the charge that its theory of money argues in a circle. Today's prices depend upon yesterday's, and so on. According to the money regression theorem, the circle is closed when we arrive, backwards, at the time before money was first used, e.g., to a barter system. For more on this see Mises, 1912, 97-123; Mises, 1998, 408-416, http: / / www.mises.org/ humanaction/chap17sec4.asp. This is an insightful rejoinder to criticism of Austrian monetary theory, but it is insuperable in the present triangle case.

66 Continuity is a necessary, but not sufficient, condition of differentiability. What else is necessary? Why isn't continuity sufficient? The missing condition is that the function must have a derivative at every point. Differentiability implies continuity, but not vice versa. Rothbard's $(1993,638-645) \mathrm{v}$-shaped cost curve is continuous, but not differentiable, because it does not have a derivative at the vertex. 
with praxeology. ${ }^{67}$ Praxeology is the science of human action, and human action is discrete, not infinitesimally divisible. It is not for nothing that Austrians have long inveighed against differentiable curves ${ }^{68}$ in economics - they are incompatible with human action. According to Mises (1996, 12): "Action therefore always involves both taking and renunciation.» $\mathrm{He}$ $(1996,44)$ also states: «No less than from the action of an individual praxeology begins its investigations from the individual action», a principle he refers to as «methodological singularism.» ${ }^{69}$ Action consists, then, in discrete acts of taking and setting aside. Mises (1996, 710 emphasis added) takes note of this problem: «Even if we assume that [a good] is perfectly divisible and take the unit of [it] as infinitesimal...» The fact that the relevant curves of the triangle are continuous therefore is highly problematical. Utilizing them, then, is an exercise in enabling the dog of economics to become a tail, and what should be the tail of mathematics (in economics) to become the dog.

67 Rothbard (1993, 638-645) made this point very forcefully and dramatically with regard to orthodox U-shaped average cost curves. Given a downward sloping demand curve, tangency is achieved only to the left of the most efficient bottom point of average costs, seemingly implying market inefficiency. He showed that such a conclusion intimately depended upon the assumption of differentiability, which is incompatible with human action. (He did so by using a V-shaped cost curve; i.e., a curve that was continuous, but not differentiable.) However, if differentiable curves (see fn. 65, supra) are anathema in the arena of cost curves, as they are everywhere else in economics, due to their incompatibility with human action, then the same must hold true for the case of the structure of production triangle. It, too, is a smooth curved affair, and must be rejected on that ground alone. See on this, also, Barnett and Block, forthcoming.

68 Of course, curves themselves are not differentiable, but the functions that the curves depict are, provided they are continuous over, and have a derivative at every point in, the domain.

69 Because the dictionary (OED, 1989) definition of «singularism» is: «A philosophy which explains the phenomena of the universe from a single principle», we think this word choice infelicitous. 
11.

THE TRIANGLE MODEL CANNOT INCORPORATE LEISURE

The height of the triangle at its maximum represents the pecuniary value of consumers' goods at the moment of sale from the producer(s) to the consumer(s). However, as it only includes the value of consumers' goods that have, in some sense, been produced, it does not include the value of leisure, the consumers' good par excellence. The structure of production is independent of leisure. This can hardly be correct. Can the production structure of different economies be identical if, with the same time-profile of production, each yields the same set of consumers' goods, but yet they enjoy differing amounts of leisure? As leisure is a (consumers') good, the value of leisure produced ${ }^{70}$ should be, but is not, included in the structure of production.

Is this too great an expectation to place on the triangle? It would appear not, since even so elementary a notion in economics as supply and demand is more than adequate to include leisure into the analysis. For example, the backward bending supply curve of labor (for the individual) is a case in point. ${ }^{71}$ In such a figure leisure is the horizontal distance between the 24-hour per day vertical line and the labor supply curve at any real wage.

It should be noted that it is possible that there are multiple structures of production that have the same period of production and the same value of consumers' goods at the end of the production process (figure 21). In that, case the hypotenuses would be different. That raises the issue of which, if any, is

${ }^{70}$ Leisure is «produced» by not using an actor's time in the production of other goods. As with any economic good, it is the object of action, and has a cost associated with it.

71 For more on this see Block and Barnett, unpublished. 
superior. Because the magnitude of the ordinate at any point in time (the abscissa) represents the discounted value of the expected consumers' goods at the end of the period of production, this is measured as the area under the curve. Therefore, the curve under which the area is smallest ( 2 in figure 21) represents the one with the least value of resources ${ }^{72}$ tied up over the period of production, and, consequently it is superior.

As between any two curves whose periods of production differ, but have the same value of consumers' goods at the end of the day, and which have the same areas underneath (figure $22)$, the one with the shorter time period (1 in figure 22) is superior, because the goods become available sooner. And, as between any two curves that have the same period of production and the same areas underneath them (figure 23), the one with the highest value of consumers' goods at the end of the period of production ( 2 in figure 23 ) is superior.

There are three other cases to be considered:

72 Although it is not apodictically the case, in reality such a situation would, in all probability indicate that the curve with the smaller area underneath represents a structure of production with less labor and more leisure. However, the omission of leisure, an absolutely essential type of consumers' good, from the economic analysis based on the triangle, makes it impossible to determine whether any particular triangle is superior to any other. In our analysis we implicitly, and now explicitly, make the admittedly heroic assumption that the value of labor is proportional to the value of all other resources at every point in time during the production process. Therefore, the value of leisure is greater the smaller is the area under the triangle, and vice versa. Because the curves do not take into account leisure, we really cannot say anything about the value or opportunity costs of any of them. A curve might have a shorter period of production with higher a higher value of consumers' goods and a smaller area under it, and yet because leisure is a consumers' good that is absent in the analysis, we cannot draw any conclusions. That is, in the supposedly inferior curve with the higher value of resources tiedup because of a larger area under it, the resources tied-up might be almost totally non-human, so that the missing leisure is very large. Whereas, for the curve with the smaller area under it, almost all the resources might be labor, so that there is almost no leisure. Then the former, apparently less desirable curve might in fact be more desirable. That is, the failure to account for leisure makes it impossible to say anything about the superiority of one curve vis-à-vis another. 
1) The value of consumers' goods at the end of the production process is the same, and either: a) the curve with shorter time period of production also has the smaller area underneath (1 in figure 24$)$, in which case it is superior to the other; or b) the curve with the shorter period of production has a larger area underneath (1 in figure 25), in which case it is not clear, at least to the present authors, which is superior.

2) The time period of production is the same, and either: a) the curve with the higher value of consumers' goods at the end of the production process also has the smaller area underneath (2 in figure 26), in which case it is superior to the other; or b) the curve with the higher value of consumers' goods at the end of the production process has the larger area underneath (1 in figure 27), in which case it is not clear, at least to us, which is superior.

3) The area underneath the curves is the same, and either: a) the one with the higher value of consumers' goods at the end of the production process also has the shorter time period of production (2 in figure 28), in which case it is superior to the other; or b) the one with the higher value of consumers' at the end of the production process has the longer period of production (2 in figure 29), in which case it is again not clear which is superior.

It cannot be overly stressed that all this indeterminacy shows the triangle in yet again another problematic light. One would have thought that the way to answer these unanswerable questions is to resort to some sort of utilization of the concept of present discounted value. After all, the question of which is worth more, something smaller available sooner, or something greater, but only available later, is not a question totally unknown in the dismal science. That such a question cannot be answered in general by resorting to the triangle points up 
another weakness of this geometrical expression, for economic analysis.

12.

\section{THE TRIANGLE HAS NOT BEEN MATHEMATIZED}

It is more than passing strange that, if the structure of production can be illustrated by a triangle, it has not been mathematized. Certainly, it is not the triangle per se that is explanatory of the structure of production. In terms of the standard use of this geometrical figure, what is important is the hypotenuse, and only the hypotenuse. ${ }^{73}$ That is, what is important is the location of each point on the hypotenuse; i.e., the coordinates of each point. Situate a Hayekian triangle (figure 1) such that the hypotenuse intersects the time axis at the origin. Then the vertical leg is unnecessary. The abscissa and ordinate represent, respectively, the elapsed time from the commencement of the production process and the (expected) value of consumers' goods at that point in time. If we assume compound discounting at a rate $r$, then at any time, $\mathrm{t}, 0 \leq \mathrm{t} \leq \mathrm{T}$ (where $\mathrm{T}$ is the time when the consumers' goods are sold) the value of consumers' goods, $C$, is given by: or $\mathrm{C}_{\mathrm{t}}$ $=\mathrm{C}_{0}\left((1+\mathrm{r})^{\mathrm{t}}-1\right)$ or $\mathrm{C}=\mathrm{C}_{0}\left(\mathrm{e}^{\mathrm{rt}}-1\right),{ }^{74}$ as the compounding is

73 Hayek, himself $(1935,41-42$, fn. 1) stated: «It is convenient to treat the quantity of intermediate products at any point of this stream as a function of time $f(t) \ldots$ In the diagrams used in the text the function $f(t)$ is represented by the hypotenuse, its concrete value $f(\mathrm{x}+\mathrm{r})$ by the horizontal side and the integral by the area of the triangle.»

74 Note the sterility and deterministic nature of the model: the value of consumption at any point in time, $t$, depends only upon its value at some initial period, 0 , and the rate of capitalization, $i$. That is, given the value of the goods in process at some initial time, the value grows at a constant rate until it «matures» at some later point in time when the consumers' goods are sold to consumers. This is all too suggestive of neoclassical growth models. 
discrete or continuous, respectively. Certainly, one could place such an equation in a mainstream mathematical model. ${ }^{75}$ But Austrian economists find such models sterile, as well they should. And, for the same reason, they should reject the triangle as sterile. ${ }^{76}$

This is not so much a criticism of the triangle per se as it is an attempt to undermine it at least in Austrian eyes, by linking it to a phenomenon they could be expected to reject out of hand: mathematical model building. Our contention is that had Hayek (1931) not couched ABCT in terms of the triangle, but, instead, analyzed it on the basis of the equivalent mathematical equations, while he might have made even greater inroads into mainstream economics, he would have had less effect on how Austrians deal with such issues.

13.

THE TRIANGLE

IS THE WRONG GEOMETRICAL FIGURE

The Hayekian triangle is an "optimal» one in the same sense that the traditional «cost» curves ${ }^{77}$ of microeconomics are optimal. Those curves represent for any level of output of the relevant $\operatorname{good}(\mathrm{s})$ the minimum expense of production. In precisely the same manner so do Austrian triangles represent the maximum value of consumers' goods in the production process, whether at the moment of sale or in process, at any point in time. And, just as there are other, unshown, cost curves that

75 The only adjustment necessary if the triangle intersects the time axis at a point $\left(t_{1}\right)$ other than the origin, is to modify the function to shift the abscissa accordingly; i.e., $C=C_{0}\left((1+r)^{t-1}-1\right)$ or $C=C_{0}\left(e^{r(t-1)}-1\right)$, as the compounding is discrete or continuous, respectively.

76 For more on this, see appendix 3.

77 Because costs are subjective, the term «cost» curves is a misnomer and, as a means of pedagogy, the source of much miseducation. More correct is the term «expense» curves. For more on this see: Barnett and Saliba (n.d.). 
represent less efficient; i.e., higher cost, ways of producing the same quantities of a good(s), so too are there unshown triangles that represent a smaller value of consumers' goods that could have been produced at any point in time.

A necessary implication of this is that there is an opportunity cost of the value of consumers' goods at any point in time, including 0 . As an opportunity cost represents a positive value, the value of consumers' goods as represented by the height of the triangle must be positive. An alternative way to understand this point is that at 0 , i.e., right now, there are extant land and labor that have positive value, if for no other reason than that they have alternative uses. A necessary consequence of either approach is that, if a two-dimensional figure is to be used to represent the complexity of the structure of production of an economy, the proper figure is an irregular trapezoid having the shape of a rectangle or square and a right triangle so constructed that one leg of the triangle is coincident with one leg side of the quadrilateral, and the right angle is to the right of the figure (figure 30).

Hayek (1934B, 213-214, see his figure 2 and accompanying text) created a three-dimensional figure that exhibited a trapezoid of the type we described above in our figure 30 :

All these apparently rather complicated relationships can be represented in a fairly simple way if we add to the former diagram, which showed only physical quantities, a third dimension, representing the relative value of these quantities. For this purpose we place the figure so far discussed, in the horizontal plane of a three-dimensional system of coordinates and measure the values attached to these quantities along the third (perpendicular) V-axis.

Hayek assumed a linear hypotenuse for the triangle in the horizontal plane; i.e., a triangle in which quantities are measured along one axis and time along the other. And then (1934B, 213): 
The value of the total quantity of 'labour'78 [footnote added by present authors] invested during the course of the process would be shown by a rectangle with the [length of the hypotenuse in the horizontal (quantity-time plane] representing the number of units of 'labour,' as a base, and ...the value of a unit of 'labour,' as its height.

Because he assumed that the labor is not invested all at once, but continuously throughout the period of production, the rectangle is projected onto the time-value plane. Hayek (1934B, 214) then states:

The value of any unit of 'labour' will have to grow, while it remains invested, at the same compound rate of interest. This rate is shown by the curve $\mathrm{T}_{0} \mathrm{~T}_{1}$, and the family of identical curves beginning along $\mathrm{T}_{0} \mathrm{~L}_{1}$ ' forming together the interest surface $\mathrm{T}_{0} \mathrm{~T}_{1}{ }^{\prime} \mathrm{L}_{1}{ }^{\prime}$.

But the curve $\mathrm{T}_{0} \mathrm{~T}_{1}$ in Hayek's figure 2 is but one side of a quadrilateral, $0 \mathrm{~T}_{0} \mathrm{~T}_{1}{ }^{\prime} \mathrm{T}_{1}$, in the time-value plane that has the shape of an irregular trapezoid formed by a rectangle as base and on top of it the leg of a curvilinear, right triangle that is parallel to the time axis coincident with the leg of the rectangle that is parallel to, but situated above, the time axis. We repeat this figure of Hayek's as our figure $\mathrm{H} 2$.

Thus even on its own grounds, the triangle is highly problematical. The point we are making here is not that the trapezoid is safeguarded from the criticisms we have above launched at the triangle itself. Rather, it is that even if, arguendo,

78 «'Labour' stands here and throughout this article for an assumed uniform original factor of production. Intermediate and final products are represented in such units as are the production of a unit of such 'labour,' so that each ordinate of the curve $0 \mathrm{~L}_{1}{ }^{\prime}$ measures the quantity of intermediate product at the respective stage of production, while the final output, obtained at the end of the period $0 \mathrm{~T}_{1}$ is equal to $\mathrm{T}_{1} \mathrm{~L}_{1}{ }^{\prime}$, or the total quantity of labour applied in the course of the process» (Hayek, 1934b, 209-210). 
none of these above mentioned criticisms were valid, still, the triangle would not be the appropriate geometrical figure with which $\mathrm{ABCT}$ can best be illustrated. Instead, it would be the trapezoid. The only circumstance under which the triangle itself, not the trapezoid, would suffice would be if we were to go back to the very beginning of mankind, when we had literally nothing in the way of tools, semi finished products. If evolution is correct, even this is impossible, since there were ape-men like creatures before our direct ancestors came upon the scene, and they could not have survived with a zero amount of capital, etc., as is depicted at the point where the hypotenuse hits the origin. Even if evolution is incorrect, and the bible story is true wherein Adam and Eve were abruptly cast out of the Garden of Eden, it cannot be the case that these two started out with absolutely nothing. They had, after all, some modicum of human capital, skills, etc. After all, they did eat from the Tree of Knowledge, so they had some knowledge as to how the world works. That is, from an Austrian point of view, there were always the original factors of production, labor and land, plus durable capital goods and semi finished consumers' goods. ${ }^{79}$

79 A possible objection to our thesis that the trapezoid, not the triangle, is more compatible with $\mathrm{ABCT}$ goes as follows: «We do not need the trapezoid, the triangle will do just fine, because the latter already takes into account the phenomenon that the square part of the trapezoid is supposed to incorporate. For example, in figure $\mathrm{H} 1$ the original means of production are continually being added to the intermediate products. True, the intermediate products start off at zero at the top of the triangle, but this does not at all apply to the original means of production.» This objection misses our point. In our view, the difficulty does not concern the original means of production. Rather, it involves intermediate products and durable capital goods that can never be literally zero, as depicted on the triangle. Even apes use sticks to get honey; even birds use twigs to build nests. 
14.

\section{IGNORES DURABLE CAPITAL GOODS}

Another fundamental problem with the triangle is that, because it ignores durable capital goods, it confounds an increase in capital and capital goods with a lengthening of the capital structure. If the only capital goods one has are goods in process and the only output of final (as distinguished from finished) goods is consumers' goods, then the only way to depict an increase in capital goods during the transition phase using the triangle is to lengthen the time dimension. This is because during the transition, capital is formed by shifting resources from action in the later part of the period of production to action in the earlier part. As this occurs, fewer consumers' goods (by value) are completed and more are started, in processes of longer duration. That is, the situation changes from triangle 1 to 2, with 2 having a lower height at the point of sale to consumers (figure $31 \mathrm{~A}$ or $31 \mathrm{~B}$ ). Now, unless the triangle is lengthened, and that by an amount large enough to more than counter the decrease in consumers' goods at the point of sale to consumers, the resultant triangle would depict fewer capital goods during the transition then before. What is never discussed when one focuses on these triangles is the fact that an increased period of production requires a new structure of production. Because we have no durable capital goods, but only consumers' goods in process, that means the only resources are the original factors of production, land and labor; thus, there must be alternative ways to produce consumers' goods using only these resources.

The inadequacy of this approach may be illustrated by introducing two new geometric figures: an irregular trapezoid (figure 32A), and another triangle (figure 32B). The trapezoid represents durable capital goods in the same way that the triangle represents goods-in-process. The ordinate of the 
trapezoid represents the value of the stock of capital goods at any point of time during the period of production. That it is less at $t_{1}$ than at 0 indicates that some of the capital stock depreciated during the production period. The additional triangle represents the production of new durable capital goods; i.e., investment. So as the ordinates of each of the triangles in figures $31 \mathrm{~A}$ and 31B represent, at any time, the value of consumers' goods in process up to and including the point of sale to consumers, the ordinate of the triangle in figure 32B represents at any time, the value of capital goods in process up to and including the point of sale to businesses.

We are now in a position to see why Hayek's $(1934$ B, 231) statement: «That anything which will tend to lengthen this investment structure of current labour will lead to increases of the quantity of capital and anything which tends to shorten it will lead to a reduction of capital, remains a point of fundamental importance» is incorrect. A reduction in the production of consumers' goods in order to form capital can now be depicted by a consumers' goods triangle (2 in figure 33A that is the same length, representing the same time period, and structure of production, but that has a smaller height than the original consumers' goods triangle (1 in figure 33A). This indicates that the same production processes are being used to produce the same set of consumers' goods only in lesser amounts, because resources have been shifted from the production of consumers' goods to production of durable capital goods. ${ }^{80}$ At the same time the increase in the production of durable capital goods can now be depicted by a capital goods triangle ( 2 in figure 33B) that is the same length, representing the same period, and structure of production, but that has a greater height than the original capital goods triangle (1 in figure $33 \mathrm{~B})$. This indicates that the same production processes

${ }^{80}$ For an explication of this point see appendix 4 
are being used to produce the same set of durable capital goods only in greater amounts, because resources have been shifted to the production of durable capital goods from production of consumers' goods.

In this section we use four figures, one each for consumers' goods in process, including initial stocks thereof (34A), the stock of consumers' durable goods (34B), the stock of durable capital goods (34C), and capital goods in process, including initial stocks thereof (34D), in a consideration of some further implications for illustration of capital theory by means of 2dimensional plane geometry. ${ }^{81}$ If we analyze them jointly we see that at the beginning of the period of production, there are extant stocks of: 1) durable consumers' goods, $\mathrm{CD}(0)$ in figure $34 \mathrm{~B}$; 2 ) durable capital goods, $\mathrm{K}(0)$ in figure $34 \mathrm{C}$; 3 ) consumers' goods in process, $\mathrm{C}(0)$ in figure $34 \mathrm{~A} ;{ }^{82}$ and, 4$)$ capital goods in process, $\mathrm{I}(0)$ in figure $34 \mathrm{D} .{ }^{83}$ At the end of the period of production of consumers' goods there is a stock of consumers' goods at the point of sale to consumers, $\mathrm{C}\left(\mathrm{t}_{1}\right)$ in figure $34 \mathrm{~A}$. Also, there is a stock of new capital goods at the point of sale to businesses, ${ }^{84} \mathrm{I}\left(\mathrm{t}_{1}\right)$ in figure $34 \mathrm{D}$. Moreover, during the period of production, 0 to $t_{1}$, because of consumption, the initial stock of durable consumers' goods has decreased from $\mathrm{CD}(0)$ to $\mathrm{CD}\left(\mathrm{t}_{1}\right)$ in figure $34 \mathrm{~B},{ }^{85}$ and, because of depreciation, the initial

81 It is important, nay, critical, to remember that the values of any variables, including the times at which the pecuniary values of goods are evaluated, are, at any and all periods or points in time post 0 , expected values.

82 An absence of an initial stock of consumers' goods in process could be depicted by changing the quadrilateral in figure $34 \mathrm{~A}$ to a triangle by shifting $\mathrm{C}(0)$ to the origin.

83 An absence of an initial stock of capital goods in process could be depicted by changing the quadrilateral in figure $34 \mathrm{D}$ to a triangle by shifting $\mathrm{I}(0)$ to the origin.

84 This includes the case where some business(es) that produce capital goods «sell to themselves;» i.e. retain for their own use, some of the newly produced capital goods.

${ }^{85}$ Consumption $(\mathrm{CN})$ during the period from 0 to $\mathrm{t}_{1}$ is given by $\mathrm{CN}\left(\mathrm{t}_{1}-0\right)=\mathrm{CD}(0)$ $-\mathrm{CD}\left(\mathrm{t}_{1}\right)$. 
stock of durable capital goods has decreased from $\mathrm{K}(0)$ to $\mathrm{K}\left(\mathrm{t}_{1}\right)$ in figure $34 C .86$

Furthermore, the stock of consumers' durable goods extant at 0 will be consumed over the period 0 to $t_{3}$ and the consumption goods in process at 0 will be completed and sold to consumers at $t_{1}$ and consumed over the period from $t_{1}$ to $t_{2}$. The stock of capital goods extant at 0 will be depreciated over the period 0 to $t_{4}$ and the capital goods in process at 0 will completed and sold to businesses at $t_{5}$ and depreciated over the period from $t_{5}$ to $t_{6}$. A little reflection on the relationships among $t_{1}-t_{6}$ should convince us that the triangle cannot be used to depict anything remotely relevant to a real-world, capital-using economy, especially if that world includes not only durable capital goods, but durable consumers' as well, and, a fortiori if it is supposed to illustrate an equilibrium state of some sort; e.g., an evenly rotating economy.

That is, if nothing else, for the triangle is to accommodate durable consumers' goods it is necessary that their economic lives would have to be exactly equal to the period of production of consumers' goods in order that the newly produced consumers' durables replace exactly those consumed during the period of production. ${ }^{87}$ Did they not, the sum of the remaining units of the initial stock of durable goods plus the new production would, at $t_{1}$, either be greater than or less than the initial stock at 0 . But if a single triangle cannot depict an equilibrium situation, how much less can it depict a realworld situation in a continuous state of adjustment in disequilibrium?

\footnotetext{
${ }^{86}$ Depreciation (D) during the period 0 to $t_{1}$ is given by $D\left(t_{1}-0\right)=K(0)-K\left(t_{1}\right)$.

87 The only alternative would be if the durable consumers' goods were of the nature of a homogeneous or fungible stock such that depreciation would be in terms of quantity only, and not in terms of quality, in which case the economic life of the stock would have to be some exact multiple of the period of production of consumers' goods.
} 
Moreover, the same relationship would have to exist, mutatis mutandis, between the depreciation of extant stock of durable capital goods at 0 , and the production of new durable capital goods.

Finally, not only would the period of production of new consumers' goods and the period of consumption have to be identical, say $t_{1}$, and the period of production of new capital goods and the period of depreciation to be identical, say $t_{2}$, but they would have to be equal to each other. A miracle to behold! Will wonders never cease?

This section so far might be misread to indicate not that geometrical representations of ABCT are highly problematic, but that, instead, they can be saved with the judicious use of the trapezoid. Nothing could be further from the truth. The other 13 objections to this method are still in force. The burden of the present section is a more modest one: to show yet another flaw in the utilization of geometry to shed light on $\mathrm{ABCT}$, not to try to salvage the triangle.

15.

SUMMARY

Hayek pioneered the use of the triangle to explain the ABCT. Subsequently, it has been widely adopted by other Austrian economists as a pedagogical device. The triangle is an aggregative concept. Because of their correct focus on the actions of individuals, Austrians are constantly on the alert for the instances of the misuse or abuse of aggregation in economic analysis. ${ }^{88}$ The triangle, however, is one such case where they

${ }^{88}$ It is not, however, as if Austrians reject the use of any and all aggregative concepts. Rather, in those instances where they do use them, it is because, after due consideration, they have been found to advance economic analysis and understanding. For example, they do, of course, make use of such concepts as the market demand for, and supply of, a particular (homogeneous) good, themselves aggregative concepts. See fn. 17 supra, for further discussion of this issue. 
have failed either to realize that it is an aggregative concept or, in the alternative, to realize that the number and nature of the flaws render the concept highly problematic, even to the point of being detrimental.

Each individual consumers' good has, at a minimum, one structure of production, understood as the exact manner and time pattern in which any specific good is produced. ${ }^{89}$ Associated with each such structure is a specific time sequence in which the value of specific resources enters into the production process..$^{90}$ Even if we assume that the appropriate discount rate for each process, and, therefore, each time sequence of production for the same good is identical, their time profiles can, and almost certainly do, differ; i.e., one process for producing $X$ starting at a particular point in time in a specific economic environment will necessarily involve some differences in the nature, type, sequencing and timing of resources than that for another. Therefore, the production triangle for every production process for good $\mathrm{X}$ will be different from that of every other such process. Moreover, even if, per impossible, each began at the same time, $t=0$, there is no reason to think that the duration of each process would necessarily be identical.

89 The structure of production is the configuration of the production process as it occurs through time. It consists in the application of labor, using fixed capital goods, to natural resources, raw materials, and partially finished goods, in specific sequences, until completion of the last actions in the series, at which time the production process is completed as the finished good comes into existence and is placed into the hands of the consumer. For an eloquent explanation of this latter claim, see Kirzner (1973).

${ }^{90}$ In addition, the precise method will, except in most unusual cases that may be ignored as irrelevant, involve a set of more or less durable capital goods. Because the significant aspect of production insofar as interest rates and changes thereof are concerned is the time element, two factors are of decisive importance: the length of time during which the value of a specific resource is expected to be tiedup in the production process before it is realized through sale of the consumers' good, and the number of units of the consumers' good the resource is expected to contribute to the production of, over the expected economic life of the resource. For more on this point, see Barnett and Wood (2002, 29-30, n.12). 
The production of two different bicycles might start out concurrently; there is no guarantee they will be finished simultaneously. One might languish at the retailer long after the other is purchased. Consequently, even if each triangle were to start from the same point on the time axis, each could well end at a different point on that axis. If, then, we were to add these triangles in the value dimension at any given point we would be adding values of finished consumers' goods to the value of partially completed consumers' goods; i.e., resources, with results that are confused, to say the least. And, the problem is only magnified when we aggregate to the economy-wide level by adding not only the different production triangles for the same consumers' good, but production triangles for all other consumers' goods as well. Moreover, this problem is exacerbated because production of different goods of course commences at different times.

Further, because of the ubiquity of durable consumers goods, an analogous concept, the structure of consumption, and its attendant time sequence, is also necessary for each individual consumers' good if we are to understand the functioning of a modern economy. Again, each individual consumers' good has, at a minimum, one structure of consumption, understood as the exact manner and sequence in which any specific good is consumed. ${ }^{91}$ Associated with each such structure is a specific time sequence during which the value of the specific consumers' good is realized. ${ }^{92}$ Even if we assume that the appropriate

91 The structure of consumption is the configuration of the consumption process as it occurs through time. It consists in the use of leisure, using durable and nondurable consumers' goods, in specific sequences, including periods in which the consumers' good is «idle;» i.e., not being consumed, until the economic life of the relevant consumers' good comes to an end, at which time the consumption process is completed.

92 In addition, the precise method will, except in most unusual cases that may be ignored as irrelevant, involve a set of more or less durable consumers' goods. Because a significant aspect of consumption insofar as interest rates and changes thereof are concerned is the time element, two factors are of decisive importance: the length of time during which the value of a specific consumers' good is expected 
discount rate for each consumers' good, and, therefore, each time sequence of consumption for the same good is identical, their time profiles can, and almost certainly do, differ; i.e., one process for consuming $X$ starting at a particular point in time in a specific economic environment will necessarily involve some differences in the nature, type, sequencing and timing of complementary consumers' goods. Therefore, the consumption triangle for every consumption process for good $X$ will be different from that of every other such process. Moreover, although each might begin at time $t=0$, there is no reason to think that the duration of each process would necessarily be the same. Consequently, if each triangle were to start from the same point on the time axis, each could well end at a different point on that axis. The problem is only magnified when we aggregate to the economy-wide level by adding not only the different triangles for the same consumers' good, but consumption triangles for all other consumers' goods.

Finally, imagine the «triangle» that results from adding huge number of different production cum consumption triangles in an economy. The resultant figure, of indeterminate shape, is impossible to interpret and absolutely incomprehensible. ${ }^{93}$

16.

\section{CONCLUSIONS}

Although the two authors agree, fully, with the critique of the triangle in ABCT offered above, they sharply differ as to their assessment of its overall value and usefulness for pedagogy. They also diverge in terms of nostalgia for the triangle, on the basis of which both were first introduced to ABCT.

to be tied-up in the consumption process before it is entirely realized at the expiration of its economic life, and the number of times it will be utilized over its expected economic life.

93 For more on this see appendix 3. 
Here is a statement on this matter from the second listed coauthor:

In the early days (Hayek, 1931, 1939, 1941, 1948; Rothbard, 1962), this geometrical figure was utilized with time on the vertical axis, and dollars on the horizontal. Starting with Garrison (2001), this practice has been reversed. But, no matter how it has been drawn, it cannot be denied that the triangle has played a pivotal role in ABCT. And not only for illustration, heuristic or even teaching purposes. The structure of production triangle has also enabled generations of Austrians to think more clearly about macroeconomic issues.

One clear advantage of the structure of production triangle is that it tends to make ABCT more accessible to mainstream macroeconomists. ${ }^{94}$ In fact, it is no exaggeration to say that without paraphernalia of this sort, neoclassical economists, for whom geometry and mathematical expressions are veritable mother's milk, would tune out virtually completely. No one would argue that ABCT has taken the profession by storm. However, it is my claim that without putting this perspective into language most economists respect, and thus can be enticed to read, praxeology has made inroads which would otherwise have been denied to it.

A bit of evidence in support of this contention is the success of Garrison (2000), both the person and that particular book, in explicating ABCT. Another is the fact that Hayek won the Nobel Prize (in 1974), and did heavily utilize this technique $(1931,1939,1941,1948)$, while there were others, ${ }^{95}$ who at least

94 The socialist Abrams $(1934,25)$ stated: «This and the similar diagram that follows are taken from Prof. Hayek's 'Prices and Production.' Indeed, this whole general analysis is based upon his work. It is almost unnecessary at this date to add that no discussion of money, no matter how humble or ambitious its scope, can hope to achieve any worthwhile results unless it uses the machinery that Prof. Hayek has so brilliantly put at the disposal of English-speaking students in the last few years.» Richard Ebeling supplied this quote, for which we thank him.

95 Mises (1912) comes to mind. 
some would say contributed even more to ABCT than him, who did not. I am of course not going out on a limb, very far out on one, and claiming that Hayek won this prize because of his diagrams, and that Mises failed to do so for lack of them; this is not at all my view. However, in attempting to make the positive case for the triangle in ABCT, I would be remiss did I not even mention this fact.

Another point on the credit side of the ledger for the triangle is that $\mathrm{ABCT}$ is rather complex. Not for praxeologists the simplicity of the Keynesian cross diagram. Sometimes, and this includes the best of us, we zig when we should zag in our explication of ABCT. The triangle is a very valuable heuristic device even for those of us who have been weaned on this theory many years ago. Even though the present paper discusses numerous difficulties with this device, and serious ones at that, I do not recommend a complete jettisoning of the triangle. When used with full knowledge of its drawbacks, it can still have some, albeit, limited, advantages.

Here is a statement on this matter from the first listed coauthor:

In sum, the Hayekian triangle is not so much simple as it is simplistic, which should not come as a surprise as it is an attempt to illustrate the immeasurable complexity of a real world economy with a simple aggregative structure such as the triangle, or, in slightly more advanced mathematical terms, with a single 2-variable function. Regrettably, the Hayekian triangle is fatally flawed, and is of no use whatsoever. It should be jettisoned on the part of all serious researchers. It should be of interest only to antiquarians.

Moreover, it is fatally flawed not only regarding research, but also as a pedagogical device. I say this because, though it may assist some in understanding $\mathrm{ABCT}$, bad habits are hard to break, and if future professional Austrian economists, especially those who go on to study for the Ph.D. first learn 
ABCT by means of the triangle, it will be that much harder for them to develop a correct and complete understanding of the structures of production and consumption. This will hinder them as scholars and lead to a lessened interest in ABCT, resulting in a continuation of what I think has been a neglect of the theory in terms of development thereof. Furthermore, it alienates mainstream economists who, supposedly are good mathematicians, ${ }^{96}$ and rightfully can make no sense of it. If the purpose is to attract the mainstream then the «Hayekian triangle» should be abandoned in favor what might be called the «Hayekian function.» At least then they could make enough simplistic assumptions to make the function differentiable, so that they could use their favorite analytical tool - calculus - to assist them in understanding ABCT.

Thus we see that the "triangle» leaves no room for entrepreneurs, uncertainty, and the heterogeneity of the real world. But these are essential elements of Austrian economics and any theory of the business cycle that claims to be Austrian must include them; e.g., clusters of entrepreneurial mistakes. The triangle then, being an attempt to capture, mathematically, the highly complex and dynamic realm of the incalculable number of real world interactions of vast numbers of individual human beings, is absolutely incompatible with Austrian economics; it was a mistake from the beginning, and should be an abandoned.

96 But appearances can be deceiving. For an argument that mathematical sophistication is wanting on the part of many mainstream economists, see Barnett (2003 and 2004). 


\section{APPENDIX 1}

Consider two right-triangles (in the first quadrant of a Cartesian plane) 1, with legs a and b, and 2, with legs c and d, (figure 35), that are to be combined into a third, 3 . Let them both have one leg (a for 1, and c for 2) along the $\mathrm{x}$-axis and the other leg be parallel to the y-axis, with the hypotenuse of each having one terminus at the origin.

Then the area of 1 (A1) is ab/2 and the area of 2 (A2) is cd/2, and the combined area is $(a b+c d) / 2$. The abscissa of 3 must be either $a, c$, or $a+c$, and the ordinate either $b, d$, or $b+d$. Thus there are nine possible areas for 3 (A3):

\begin{tabular}{|c|c|c|c|}
\hline & $B$ & $d$ & $b+d$ \\
\hline a & $\mathrm{A} 3=\mathrm{ab} / 2$ & $\mathrm{~A} 3=\mathrm{ad} / 2$ & $\mathrm{~A} 3=(\mathrm{ab}+\mathrm{ad}) / 2$ OK only if $\mathrm{a}=\mathrm{c}$ \\
\hline c & $\mathrm{A} 3=\mathrm{bc} / 2$ & $\mathrm{~A} 3=\mathrm{cd} / 2$ & $\mathrm{~A} 3=(\mathrm{bc}+\mathrm{cd}) / 2$ OK only if $\mathrm{a}=\mathrm{c}$ \\
\hline$a+c$ & $\begin{array}{l}\mathrm{A} 3=(\mathrm{ab}+\mathrm{bc}) / 2 \\
\mathrm{OK} \text { only if } \mathrm{b}=\mathrm{d}\end{array}$ & $\begin{array}{l}\mathrm{A} 3=(\mathrm{ad}+\mathrm{cd}) / 2 \\
\text { OK only if } \mathrm{b}=\mathrm{d}\end{array}$ & $\begin{aligned} \mathrm{A} 3= & (\mathrm{ab}+\mathrm{ad}+\mathrm{bc}+\mathrm{cd}) / 2= \\
& \mathrm{A} 1+\mathrm{A} 2+(\mathrm{ad}+\mathrm{bc}) / 2 \\
\mathrm{~A} 3= & \mathrm{A} 1+\mathrm{A} 2+(\mathrm{ad}+\mathrm{bc}) / 2\end{aligned}$ \\
\hline
\end{tabular}

Consider these cases numbered from left to right, then top to bottom:

1) $3=a b / 2$; but $a b / 2=A 1$; therefore unless $A 2=0$; i.e., unless triangle 2 is non-existent, $\mathrm{A} 3<\mathrm{A} 1+\mathrm{A} 2$;

5) $\mathrm{A} 3=\mathrm{cd} / 2$; but $\mathrm{cd} / 2=\mathrm{A} 2$; therefore unless $\mathrm{A} 1=0$; i.e. unless triangle 1 is non-existent; $\mathrm{A} 3<\mathrm{A} 1+\mathrm{A} 2$;

3) and 6) $\mathrm{A} 3=(\mathrm{ab}+\mathrm{ad}) / 2$ or $\mathrm{A} 3=(\mathrm{ab}+\mathrm{ad}) / 2$; in either of these cases $\mathrm{A} 3=\mathrm{A} 1+\mathrm{A} 2$ only if $\mathrm{a}=\mathrm{c}$. That is, the period of production for triangles 1 and 2 would have to be the same; 
7) and 8) $\mathrm{A} 3=(\mathrm{ab}+\mathrm{bc}) / 2$ or $\mathrm{A} 3=(\mathrm{ad}+\mathrm{cd}) / 2$; in either of these cases $\mathrm{A} 3=\mathrm{A} 1+\mathrm{A} 2$ only if $\mathrm{c}=\mathrm{d}$. That is, the value of consumers' goods at the point of sale the consumers would have to be the same;

9) $\mathrm{A} 3=(\mathrm{ab}+\mathrm{ad}+\mathrm{bc}+\mathrm{cd}) / 2$; but $(\mathrm{ab}+\mathrm{ad}+\mathrm{bc}+\mathrm{cd}) / 2=\mathrm{A} 1+$ $\mathrm{A} 2+(\mathrm{ad}+\mathrm{bc}) / 2$; therefore unless at least one (1) of $\mathrm{a}$, or $\mathrm{b}$, or $\mathrm{c}$, or $\mathrm{d}=0, \mathrm{~A} 3>\mathrm{A} 1+\mathrm{A} 2$. At best that would mean either triangle 1 or triangle 2 was non-existent; at worst, both;

2) or 4) $\mathrm{A} 3=\mathrm{ad} / 2$ or $\mathrm{A} 3=\mathrm{bc} / 2$; these are essentially the same in that $\mathrm{A} 3+\mathrm{A} 1+\mathrm{A} 2$ requires that the ratio of the period of production of the first triangle to that of the second plus the ratio of the value of consumers' goods at the time of sale to the consumers of the second triangle to that of the first must total to one (1), regardless of whether 1 or 2 is taken to be the first triangle, and the other, the second.

Thus, although mathematically possible, it is economically implausible, to say the least, that two or more triangles can be combined.

\section{APPENDIX 2}

Perhaps the confusion concerning the relationship between stages of production and the temporal length of the production process is a consequence of the following statements by BohmBawerk. Mises, Hayek, Rothbard, and Garrison.

First, Bohm-Bawerk:

The lesson to be learned from all of these examples is quite clear. It is to the effect that roundabout methods are more fruitful than direct methods in the production of consumers' goods. And as a matter of fact, this greater fruitfulness manifests itself in two ways. Whenever a consumers' good can be produced either by direct or by indirect methods, superiority of the latter 
is demonstrated by the fact that the indirect method either turns out a greater quantity of product with the same quantity of labor or the same quantity of product with a smaller quantity of labor (Bohm-Bawerk, 1959, 12).

The disadvantage which attends the capitalist method of production consists in a sacrifice of time. Capitalist roundaboutness is productive but time consuming. It yields more or better consumption goods, but not until a later time (BohmBawerk, 1959, 82).

It is true that Bohm-Bawerk notes that:

Exceptional cases may occur in which a roundabout method is not only better but also quicker... But that is not the rule. In an overwhelming majority of cases, the adoption of circuitous methods imposes conditions that require us to wait for a time and sometimes for a very long time indeed, before we obtain possession of the product in consumable form (Bohm-Bawerk, 1959, 82).

But that is mere speculation, unsupported by analysis or data. There is no reason or a priori basis for this conjecture. Innovations often speed up the production process and even reduce the stages of production. Examples of the former are modern computers and communications technologies, and of the latter, Wal-Mart and JIT manufacturing.

And:

It goes without saying that it is no refutation of our proposition to contend that, with the help of previously finished capital objects, a given product can be produced more quickly than by the direct »capitalless» method. This sort of refutation might be exemplified by the argument that a tailor needs only one day to turn out a coat with the help of a sewing machine, whereas it might require three days without that capital object. But it is obvious that the sewing by machine is only a portion - and 
indeed the smallest portion - of the circuitous capitalist path. The principal length of that path is covered by the making of the sewing machine. And it is equally apparent that the traversing of the entire length of the path requires a great deal more than three days (Bohm-Bawerk, 1959, 82).

However, although it may be correct during the transition phase in which Bohm-Bawerk's "previously finished capital objects» are first produced that the period of production is lengthened, this in no way establishes that the period of production is lengthened during the post-transition period. Let us use his example of the production of coats. Assume it takes 100 days to produce a sewing machine. Consider three periods: pre transition, transition, and post transition. In any pre transition period of 300 days, 100 coats can be produced. During the transition of 100 days, the sewing machine is produced, but no coats are produced. In any post transition period of 200 days, 100 days can be used to produce 100 coats and the other 100 days used to produce another sewing machine. Therefore, provided a sewing machine can be used to produce at least 100 coats before it wears out, the period of production, post transition has been shortened. That is, we can produce 100 coats every 200 days for an indefinitely long (because the 200 day period allows 100 days for the production of a replacement machine, as well as the 100 days required to produce 100 coats) compared to the post transition situation in which it 100 coats required 300 days to produce. ${ }^{97}$

Next, Mises:

97 More generally, if $\mathrm{D}_{0}$ and $\mathrm{D}_{1}$ are the numbers of days it takes to produce a coat pre and post transition, respectively, and $\mathrm{M}$ is the number of days it takes to produce the sewing machine, then the period of production will be shortened post transition provided $C>M /\left(D_{0}-D_{1}\right)$, where $C$ is the number of coats that can be produced during the working life of the machine. 
...As acting man prefers those processes which, other things being equal, produce the products in the shortest time, only such processes are left for further action which consume more time. ...Bohm-Bawerk speaks of the higher productivity of roundabout ways of production requiring more time. It is more appropriate to speak of the higher physical productivity of production processes requiring more time.

The higher productivity of these processes does not always consist in the fact that they produce-with the same quantity of factors of production expended - a greater quantity of products. More often it consists in the fact that they produce products which could not be produced at all in shorter periods of production. These processes are not roundabout processes. They are the shortest and quickest way to the goal chosen. If one wants to catch more fish, there is no other method available than the substitution of fishing with the aid of nets and canoes for fishing without the aid of this equipment. There is no better, shorter, and cheaper method for the production of aspirin known than that adopted by the chemical plants. If one disregards error and ignorance, there cannot be any doubt about the highest productivity and expediency of the processes chosen. If people had not considered them the most direct processes, viz., those leading by the shortest way to the end sought, they would not have adopted them (Mises 1996 [1949], 481-482, footnote omitted).

...It is more appropriate to speak of the higher physical productivity of processes requiring more time. The higher productivity of these processes does not always consist in the fact that they produce - with the same quantity of factors of production expended - a greater quantity of products.... If one wants to catch more fish, there is no other method available than the substitution of fishing with the aid of nets and canoes for fishing without the aid of this equipment....

...But if temporally remoter goals are aimed at, lengthening of the period of production is a necessary corollary of the venture (Mises, 1996 [1949], 481-482). 


\section{Then Hayek:}

That anything which will tend to lengthen this investment structure of current labour will lead to increases of the quantity of capital and anything which tends to shorten it will lead to a reduction of capital, remains a point of fundamental importance (Hayek, 1934B, 231).

And:

I have already pointed out that it is an essential feature of our modern, 'capitalistic,' system of production that at any moment a far larger proportion of the available original means of production is employed to provide consumers' goods for some more or less distant future than is used for the satisfaction of immediate needs. The raison d'être of this way of organizing production is, of course, that by lengthening the production process we are able to obtain a greater quantity of consumers' goods out of a given quantity of original means of production (Hayek, 1935, p. 37-38).

And:

The thing which is of main interest for us is that any such change from a method of any given duration to a method which takes more or less time implies quite definite changes in the organization of production, or, as I shall call this particular aspect, to distinguish it from other more familiar aspects, changes in the structure of production (Hayek, 1935, p. 37-38).

And:

On the simplifying assumption that the total length of the of the marginal processes that are made possible by an increase in the supply of investible funds, is always greater than the total length of any process already used, this situation can be represented by the following diagram. [Present authors: This 
is Hayek's $(1935,138)$ figure 8 , which we repeat as our H3] The curvilinear1 triangle $A B C$ represents, in the same way as the triangle I have used in the preceding lectures, the stock of capital belonging to the processes already completed. (The area of the curvilinear triangle $A B^{\prime} C^{\prime}$ shows the stock of capital before the additions were begun). [footnote] 1 . The reasons which make a curvilinear triangle of the kind shown in the text a more appropriate representation than the simplified form used in Lecture II are probably obvious. See p. 39 (Hayek, 1935, 137).

Now, Rothbard:

It is obvious that the production process takes time, and the more complex the production process the more time must be taken (Rothbard, 1993 [1962], 288).

\section{Last, Garrison:}

In its simplest application, the two legs of [Hayek's] right triangle measure consumption [sic] and the corresponding production time (reckoned in the number of stages of production) for an economy that has achieved an intertemporal equilibrium. A primitive instance of this intertemporal equilibrium and of potential changes in it can be illustrated by Robinson Crusoe who for some time was content to sustain himself by catching fish with the aid of little or no fishing equipment. A greater output of fish is possible but only if Crusoe is willing to take time away from fishing in order to fashion a net and possibly a boat. Consumable output would have to fall while the production process is being enhanced. Once the new, more capital-intensive (and more time-consuming) process is completed, however, the level of output would rise above its initial level. The new intertemporal equilibrium can be depicted by a Hayekian triangle with a longer consumption [sic] leg, representing more fish, and a longer production-time leg, representing the increase in time spent maintaining the new production process (Garrison, 2004, 324-325). 
The foregoing is problematical. First, there is no mention of the meaning of the height of the triangle save that of the right leg, and that is misstated as "consumption» rather than as the pecuniary value of consumption, or, better yet, the pecuniary value of the consumption goods at the moment of sale to the consumers.

Second, in a world of heterogeneous capital goods, not to mention heterogeneous labor and natural resources, the concept of capital intensity is incoherent. Which, for example, is a more capital intensive process: a man fishing using a boat and a rod and reel or the same man fishing with a net from the shore? Or a man hunting a deer with, on the one hand, a rifle and, on the other, a shotgun. Capital intensity cannot be measured using pecuniary value, else the capital intensity can change with no change in the physical reality; nor, for the same reason, can it be measured in terms of the quantity of output. Neither can it be measured by, to coin a term, the «socially necessary» labor required to produce it.

Third, the placement of the phrase «and more timeconsuming» in conjunction with its inclusion within parentheses, implies that the "new, more capital intensive» process is necessarily also "more time consuming.» This is reinforced by reference to "a longer production-time leg» of the Hayekian triangle. We offer a counter-factual example; references are to table 1.

Crusoe works eight (8) hours a day to catch one fish by hand. The other 16 hours constitute leisure. (See day 1.) This an ERE or steady state equilibrium. ${ }^{98}$ It takes him eight (8) hours of fishing by hand to catch one fish, a total of eight (8) hours of work of any and all kinds to catch one fish, and thus 128 calendar days to catch 16 fish.

98 It is a basic tenet of Austrian economics that no such state of affairs can characterize economic reality. 
It takes eight hours to make a net without any tools. Although a net becomes weaker and weaker with every hour of use, it will still hold fish, until after 64 hours of use it breaks completely apart and becomes useless.

One day, Crusoe spends eight hours during which he weaves a net from scratch to completion, but makes no change in his leisure. ${ }^{99}$ Of course, he goes hungry that day. (See day 2A.) Alternatively, he spends eight hours making a net from scratch to completion, fishes by hand for eight hours, and reduces his leisure by eight hours. In this case, he catches a fish and does not go hungry. (See day 2B.) Either of these is a transition day, after which he faces a new set of alternatives, and no longer concerns us.

Now what happens? Consider three such alternatives, each of which is an ERE or steady state equilibrium and which we compare with the initial such condition. In the first, day $3 \mathrm{~A}$, he maintains his original level of leisure, 16 hours per day, spends ${ }^{100} 7.11^{+}$hours per day fishing with the net, and $0.88^{+}$ hours per day making a replacement net. Therefore, his total hours of work also remain the same, though the nature of the work differs in part. In this situation, he is able to continuously replace his net as it wears out, and catch $1.77777^{+}$fish per day. Therefore, it takes him four of fishing with a net to catch one fish, a total of four and one-half hours hours of work of any and all kinds to catch one fish, and 9 calendar days to catch 16 fish.

In the second scenario, day 3B, he spends four hours per day fishing with the net in order to maintain his original quantity (1) of fish caught per day and 0.5 hours per day making a replacement net; his leisure increases to 19.5 hours per day. Therefore, his total hours of work decrease to four and one-half

\footnotetext{
99 The eight (8) hours is, of course, socially-necessary-labor time.

100 The superscript + sign indicates a repeated decimal.
} 
per day, though the nature of the work differs in part. In this situation, also, he is able to continuously replace his net as it wears out. Therefore, it takes him four hours of fishing with a net to catch one fish, a total of four and one-half hours hours of work of any and all kinds to catch one fish, and 16 calendar days to catch 16 fish.

In the last situation, day $3 \mathrm{C}$, he wishes to enjoy the benefits of his improved productivity partly in the form of increased fish and partly in the form of increased leisure. He chooses to spend 6 hours a day fishing with a net and catching 1.5 fish and threequarters of an hour making a replacement net; and, he enjoys $17^{1} / 4$ hours of leisure. Therefore, it takes him four of fishing with a net to catch one fish, a total of four and one-half hours (4.5) hours of work of any and all kinds to catch one fish, and $10^{2} /{ }_{3}$ calendar days to catch 16 fish.

It is obvious that, however we look at it, the structure of production on day three has been shortened relative to that on day one. That is, though the structure of production was lengthened during the transition period [day two] from day one to day three, even to the point of being «infinitely», or better yet, undefinably long in the case of day 2, thereafter it has been "permanently» shortened. However, on day three there are two stages of production; to wit: working on a replacement net and fishing with the extant net; whereas, on day one there is only one stage of production - fishing by hand. Therefore, not only is there no necessary direct relationship between the number of stages of production and the time structure of production, but they may even be inversely related. Q.E.D. 


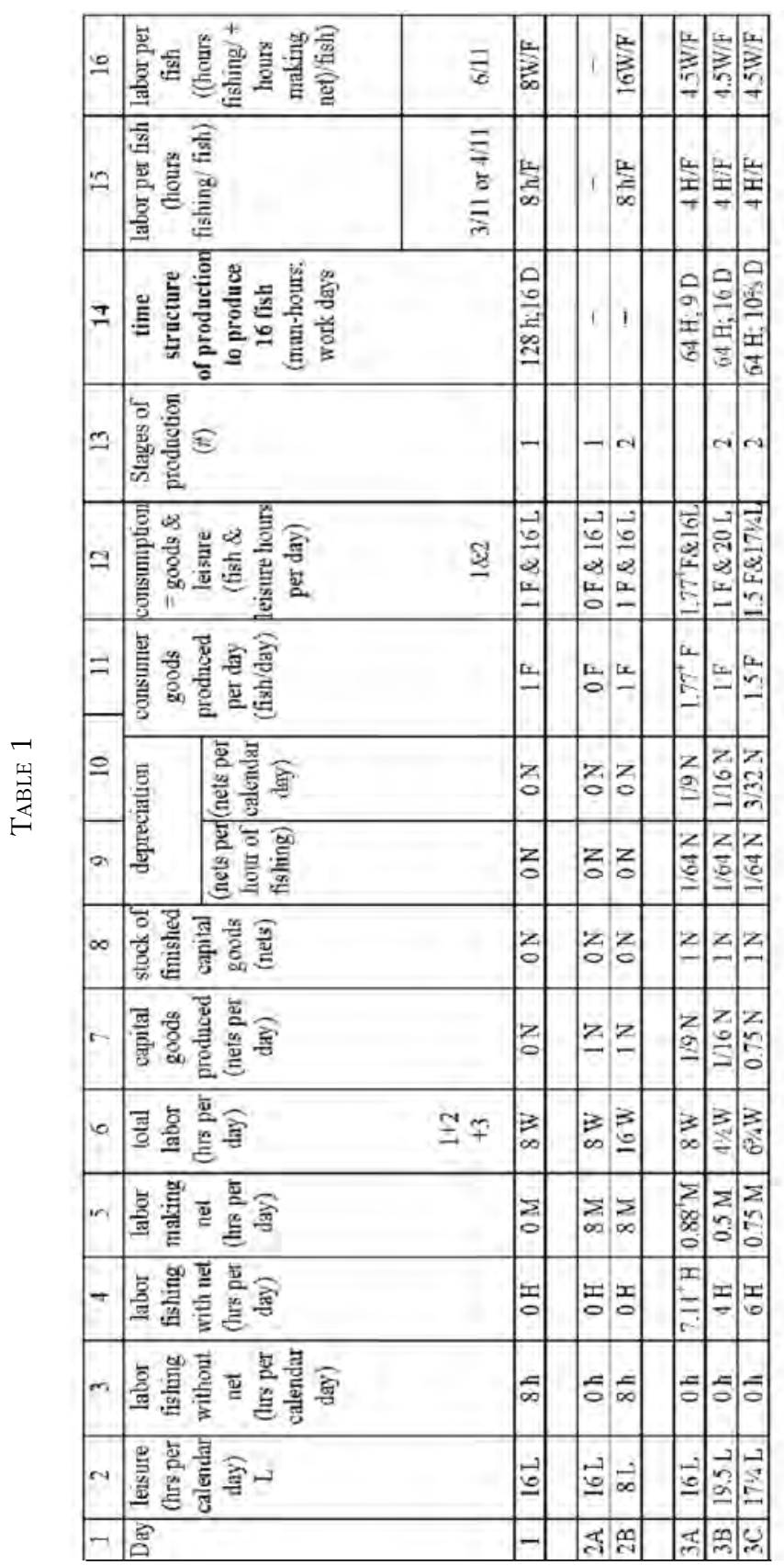




\section{APPENDIX 3}

In this appendix we eschew «plain old» plane geometry for analytical geometry. We also ignore the incompatibility of differentiable functions with praxeology. We assume that the discount rate, $r$, is the same for all goods and that there is no compounding.

Let:

$\mathrm{C}_{\mathrm{i}}=$ the ith consumers' good;

$\mathrm{C}_{\mathrm{it}}=$ the expected (at time $\mathrm{t}=0$ ) pecuniary value of a quantity of consumers' good $i$ at time $t$, to include the expected value of the partially completed units of that consumers' good at time $t$;

$\mathrm{C}_{\mathrm{i} 0}=\mathrm{P}_{\mathrm{i}} \mathrm{Q}_{\mathrm{i} 0} \forall \mathrm{i}$;

$\mathrm{P}_{\mathrm{i}}=$ the expected price of unit of $\mathrm{C}_{\mathrm{i}}$ at time of sale;

$\mathrm{Q}_{\mathrm{i} 0}=$ the quantity of the $\mathrm{i}^{\text {th }}$ consumers' good at time production of that particular good commences, to include the expected value of the partially completed units at the moment;

$\mathrm{Q}_{\mathrm{i} 0}=\mathrm{Q}_{0} \forall \mathrm{i}$; and,

$\mathrm{r}=$ the relevant rate of discount for $\mathrm{C}$.

Based on the standard Hayekian triangle, consider the production structure of an economy producing four (4) consumers' goods, $\mathrm{C}_{1}, \ldots \mathrm{C}_{4}$, assuming production commences at time $\mathrm{t}=0$; and,

\section{Let:}

$0<\tau_{\mathrm{i}}<\mathrm{T} ; \forall \mathrm{i}$;

$\mathrm{C}_{1 \mathrm{t}}=\mathrm{C}_{10}(1+\mathrm{r}) \mathrm{t} ; 0 \leq \mathrm{t} \leq \mathrm{T}$, where 0 and $\mathrm{T}$ are times at which production of $C_{1}$ commences and $C_{1}$ is sold, respectively; $\mathrm{C}_{2 \mathrm{t}}=\mathrm{C}_{20}(1+\mathrm{r}) \mathrm{t} ; 0 \leq \mathrm{t} \leq \tau_{\mathrm{h}}$, where 0 and $\tau_{\mathrm{h}}$ are times at which production of $\mathrm{C}_{2}$ commences and $\mathrm{C}_{2}$ is sold, respectively; 
$\mathrm{C}_{3 \mathrm{t}}=\mathrm{C}_{30}(1+\mathrm{r})\left(\mathrm{t}-\tau_{\mathrm{i}}\right) ; \tau_{\mathrm{i}} \leq \mathrm{t} \leq \mathrm{T}$, where $\tau_{\mathrm{i}}$ and $\mathrm{T}$ are times at which production of $C_{3}$ commences and $C_{3}$ is sold, respectively; and,

$\mathrm{C}_{4 \mathrm{t}}=\mathrm{C}_{40}(1+\mathrm{r})\left(\mathrm{t}-\tau_{\mathrm{j}}\right) ; \tau_{\mathrm{j}} \leq \mathrm{t} \leq \tau_{\mathrm{k}}$, where $\tau_{\mathrm{j}}$ and $\tau_{\mathrm{k}}$ are times at which production of $\mathrm{C}_{4}$ commences and $\mathrm{C}_{4}$ is sold, respectively.

There are 24 possible temporal orders of $\tau_{\mathrm{j}^{\prime}} \tau_{\mathrm{i}}, \tau_{\mathrm{h}^{\prime}}$ and $\tau_{\mathrm{k}^{\prime}}$ and thus 24 possible figures of the function $C_{t}=\Sigma C_{i t}, 1=1, \ldots$, 4. For illustrative purposes, we choose but one (1): $\tau_{j}<\tau_{i}<\tau_{h}$ $<\tau_{\mathrm{k}}$. Then:

$$
\begin{array}{rlrl}
C_{t}=\left(P_{1}+P_{2}\right) Q_{0}(1+r) t & \text { if } 0 \leq t \leq \tau_{j} \\
C_{t}=\left(P_{1}+P_{2}\right) Q_{0}(1+r) t+P_{4} Q_{0}(1+i)\left(t-\tau_{j}\right) & \text { if } \tau_{j} \leq t \leq \tau_{i} \\
\Sigma C_{i t^{\prime}} 1, . ., 4,= & C_{t}=\left(P_{1}+P_{2}\right) Q_{0}(1+r) t+P_{4} Q_{0}(1+i)\left(t-\tau_{j}\right)+P_{3} Q_{0}(1+i)\left(t-\tau_{j}\right) & \text { if } \tau_{i} \leq t \leq \tau_{h} \\
C_{t}=P_{1} Q_{0}(1+r) t+P_{4} Q_{0}(1+r)\left(t-\tau_{j}\right)+P_{3} Q_{0}(1+r)\left(t-\tau_{i}\right) & \text { if } \tau_{h} \leq t \leq \tau_{k} \\
\left.C_{t}=P_{1} Q_{0}(1+r) t+P_{3}\right) Q_{0}(1+r)\left(t-\tau_{j}\right) & \text { if } \tau_{k} \leq t \leq T
\end{array}
$$

That is the function for the "hypotenuse» of a somewhat more realistic «triangle», and that is depicted in figure 31.

Consider, now, the implications of this model. The value of consumers' goods depends only on: 1) the quantity thereof at the time production of each such good commences $Q_{0} ; 2$ ) the price each such good is expected (at time $=0$ ) to command at the moment of sale to the consumers, $\mathrm{P}_{\mathrm{i}} ; 3$ ) the rate of interest, $r$; and 4) the time elapsed between the initiation of production of each good and its sale to consumers, or if it has not yet been completed and sold, the time of interest; i.e., $t$, $T$ and the various $\tau \mathrm{s}$. This is very mechanistic, reminiscent of mainstream growth models. ${ }^{101}$

101 On this see virtually any model in Barrow and Sala-i-Martin (1998). 


\section{APPENDIX 4}

The equation of the hypotenuse of the triangle 1 (in figure 33A) is given by: $C_{1}\left(t_{1}\right)=V_{1}(0)\left(i+i_{1}\right) t 1$, [or, if one wants compound interest, either $C_{1}\left(t_{1}\right)=V_{1}(0)\left((1+i)^{t 1}-1\right)$ or $C_{1}\left(t_{1}\right)$ $=\mathrm{V}_{1}(0)\left(\mathrm{e}^{\mathrm{it} 1}-1\right)$, as the interest is compounded discretely or continuously], where $C_{1}\left(t_{1}\right)$ is the value of consumers' goods at the time of sale to consumers, $t_{1}, V_{1}(0)$ is the initial value of resources used in the production process represented by triangle 1 , and $\mathrm{i} 1$ is the discount rate relevant to triangle 1 . The same notation is used, mutatis mutandis, for triangle 2 . As $\mathrm{V}_{1}(0)$ is denominated in value terms, we may write $\mathrm{V}_{1}(0)=\mathrm{R}_{1}(0) \mathrm{X}_{1}(0)$, where $R_{1}(0)$ and $X_{1}(0)$, represent, for triangle 1 , the price per unit of resources and the initial quantity of resources at time 0 , respectively. Similarly for triangle 2 , we may write $\mathrm{V}_{2}(0)$ $=\mathrm{R}_{2}(0) \mathrm{X}_{2}(0)$, with analogous meaning. Then, $\mathrm{C}_{1}\left(\mathrm{t}_{1}\right)=\mathrm{R}_{1}(0) \mathrm{X}_{1}(0)$ $\left(i+i_{1}\right) t_{1}$ and $C_{2}\left(t_{1}\right)=R_{2}(0) X_{2}(0)\left(i+i_{2}\right) t_{1}$. Moreover, as $C_{1}\left(t_{1}\right)$ is also denominated in value terms we may write $C_{1}\left(t_{1}\right)=$ $P_{1}\left(t_{1}\right) Q_{1}\left(t_{1}\right)$, where $P_{1}\left(t_{1}\right)$ is the price of consumers' goods at the time of sale to consumers' and $Q_{1}\left(t_{1}\right)$ is the quantity of consumers' goods sold at that time. Similarly, for triangle 2, $\mathrm{C}_{2}\left(\mathrm{t}_{1}\right)$ $=\mathrm{P}_{2}\left(\mathrm{t}_{1}\right) \mathrm{Q}_{2}\left(\mathrm{t}_{1}\right)$.

Compare these two (2) triangles 1 and 2; the hypotenuse of each originates at time 0 , when the abscissa is 0 , just as production commences, and terminates at the time, $t_{1}$, when the consumers' goods are sold to consumers; i.e., when the abscissa is $t_{1}$. Thus both have the same period of production. However, let the value of consumers' goods at the time of sale to the consumers, $C_{1}\left(t_{1}\right)$ and $C_{2}\left(t_{1}\right)$, for 1 and 2, respectively, differ. Regardless of which functional form we use, one (1) of the triangles will lie above the other throughout their range. Let 1 be that triangle; i.e., $C_{1}\left(t_{1}\right)>C_{2}\left(t_{1}\right)$. The only possible causes for this difference are either $R_{1}(0) \neq R_{2}(0)$ or $X_{1}(0) \neq X_{2}(0)$ or $i_{1} \neq i_{2}$, or some combination thereof. 
The essence of ABCT is an unsustainable distortion of the structure of production; i.e., an unsustainable misallocation of resources, brought about by a governmental-policy-induced lending of money into existence and attendant reduction, ceteris paribus, in interest rates. Therefore, because the triangle is used to explain ABCT, we take the cause of the morphing of triangle 1 into 2 to be a decrease in the discount rate; i.e., $\mathrm{i}_{1}>$ $\mathrm{i}_{2}$. However, that can not be the sole cause, for it means that the quantities of resources at 0 is the same for both triangles; i.e., $X_{1}(0)=X_{2}(0)$. But as the period of production and thus the structure of production are also the same, the quantity of consumers' goods must also be the same; that is $=Q_{1}\left(t_{1}\right)=$ $\mathrm{Q}_{2}\left(\mathrm{t}_{2}\right)$. But this is incompatible with ABCT as there is no shift in resource use from consumers' to capital goods, nor is there a decrease in the quantity of consumers' goods produced.

Therefore, something else besides the discount rate must have changed if the story illustrated by the triangles in figure $33 \mathrm{~A}$ is to be compatible with ABCT. And, it must be the quantity of resources used and the output of consumers' goods, both of which must have decreased; i.e., $X_{1}(0)>X_{2}(0)$ and $Q_{1}\left(t_{1}\right)>$ $\mathrm{Q}_{2}\left(\mathrm{t}_{1}\right)$. The reduced discount rate signals a decrease in time preferences manifested as a fall in demand for consumers' goods and an increase in demand for producers' goods. In order for production to shift in accord therewith, the demand for resources on the part of the capital goods industries must increase and that stemming from the consumers' goods industries must fall. However, It is quite probable that the former will occur before the latter, and as a consequence, prices of resources will rise; i.e., $\mathrm{R}_{1}(0)<\mathrm{R}_{2}(0)$. Nevertheless, the combined effects must be such that any increase in prices is more than offset by fall in interest rates and the decrease in the use of resources for the production of consumers' goods. This is depicted in figure $33 \mathrm{~A}$ by the morphing of triangle 1 into 2 . 


\section{APPENDIX 5}

Figure 1
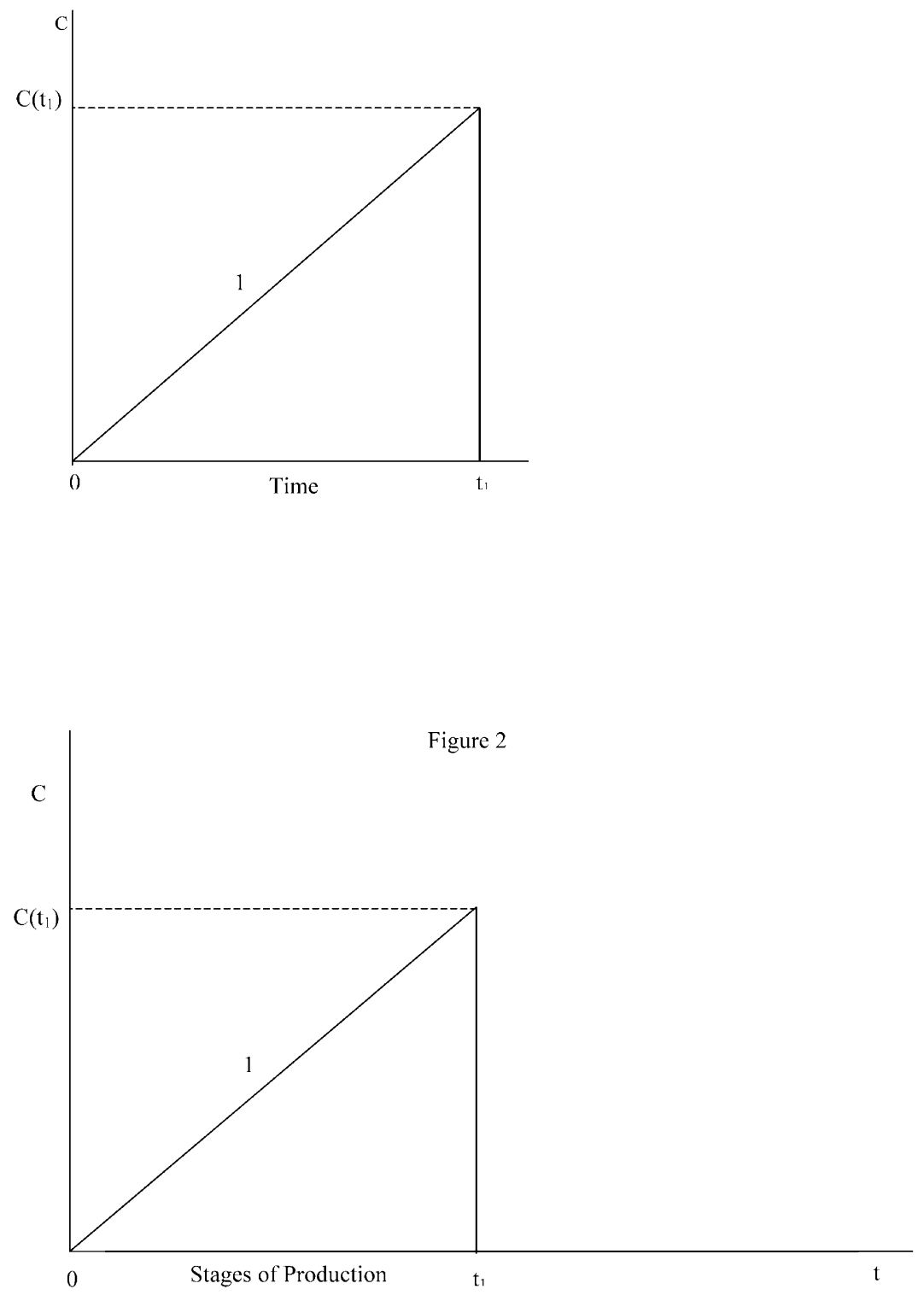

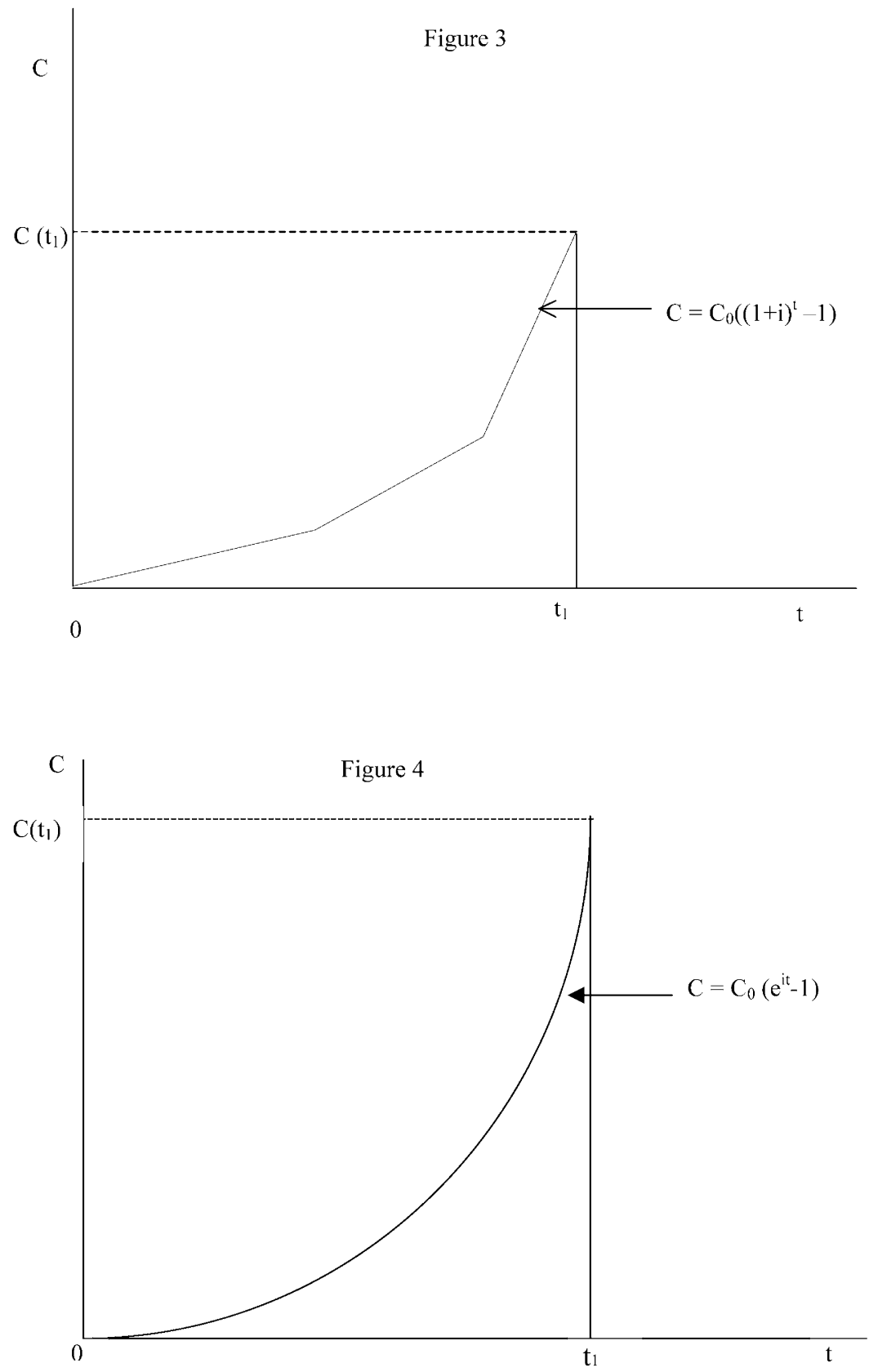

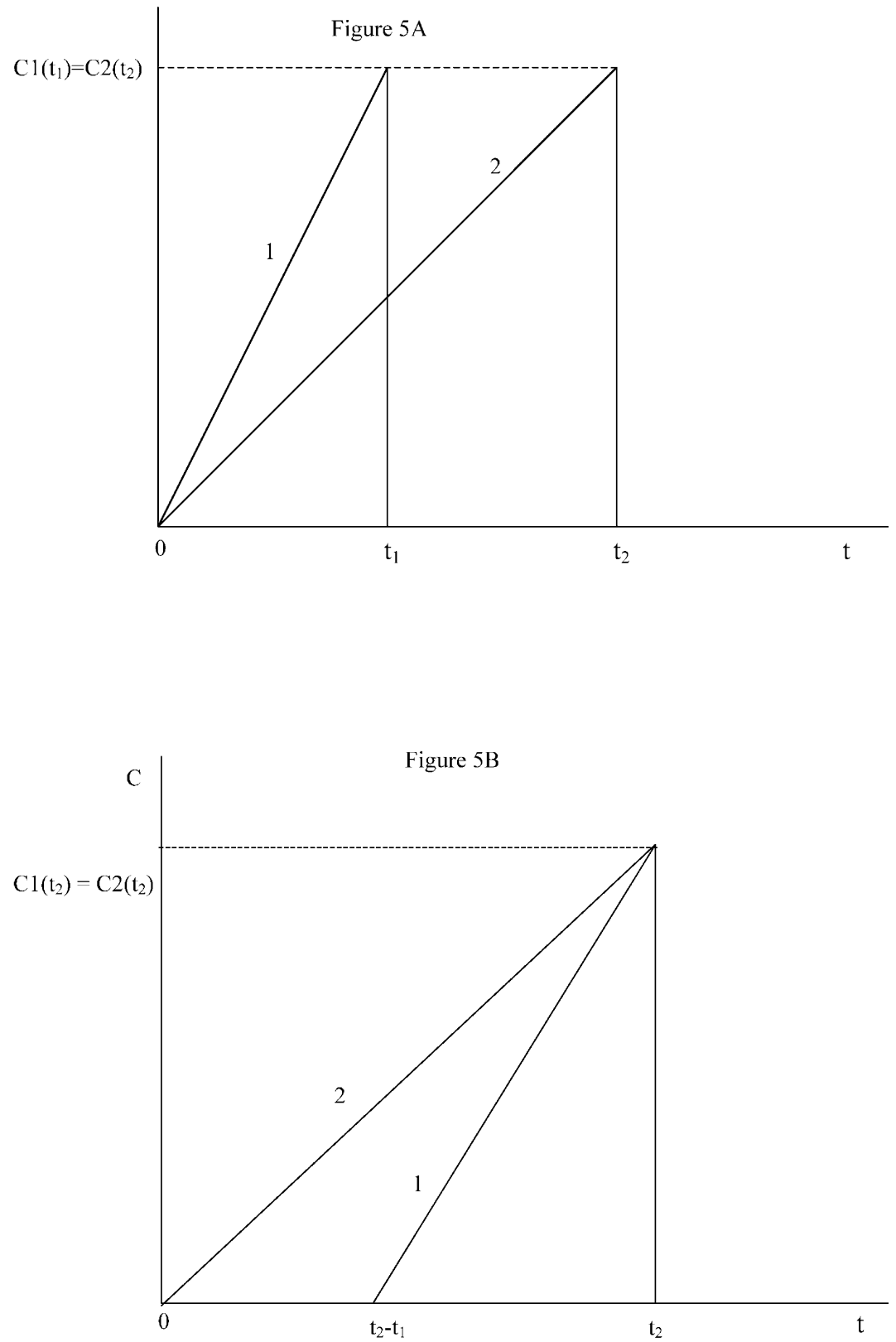

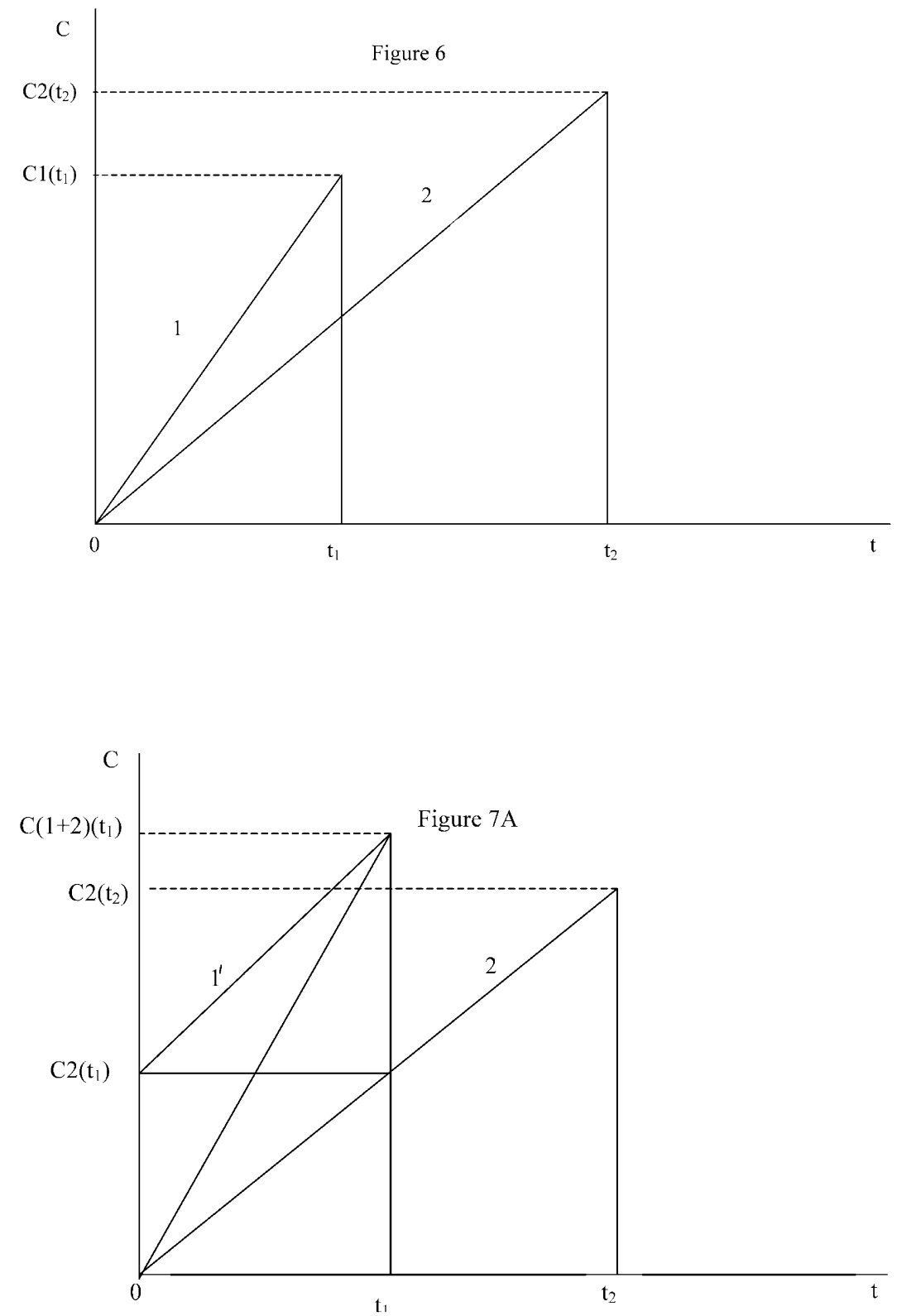

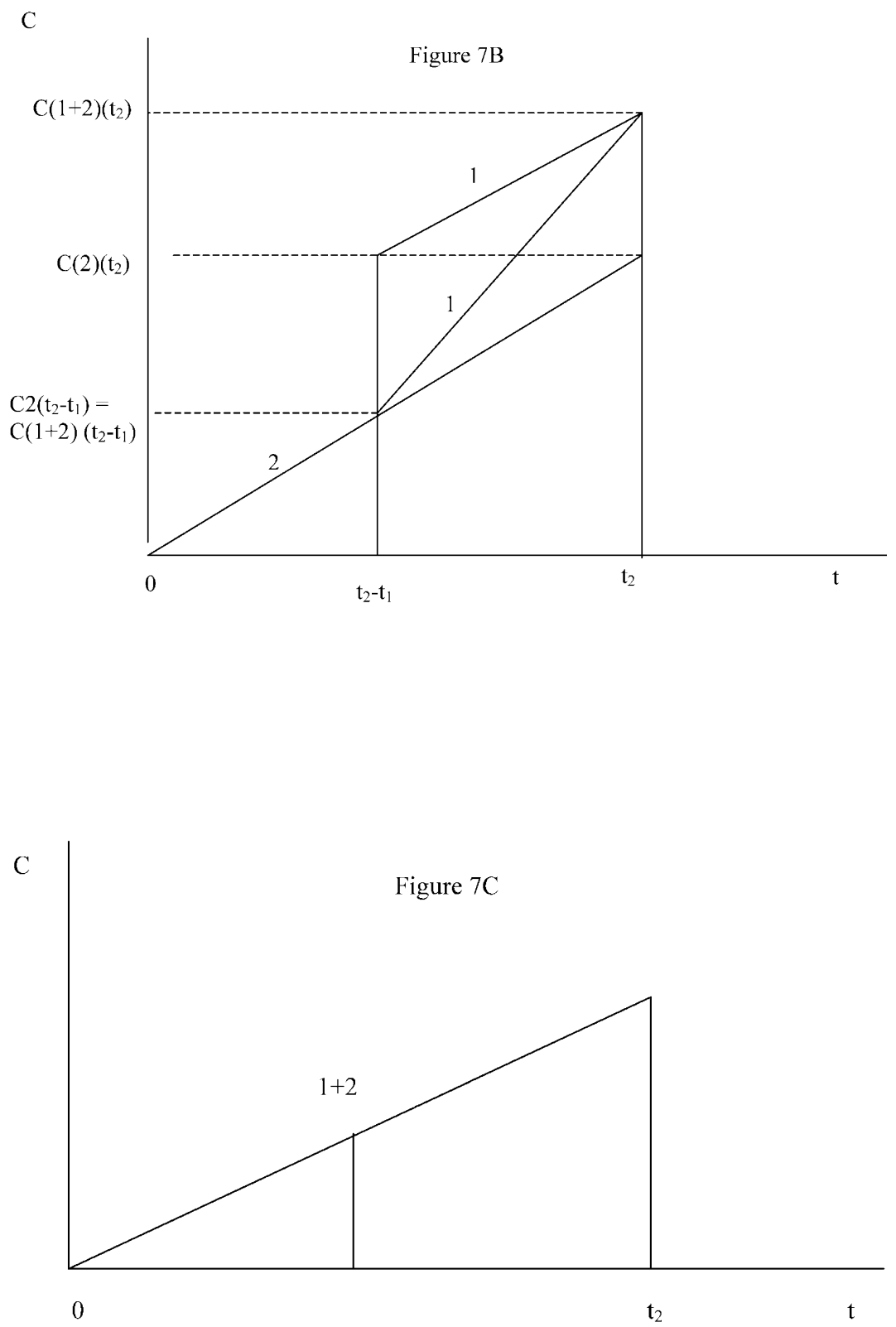


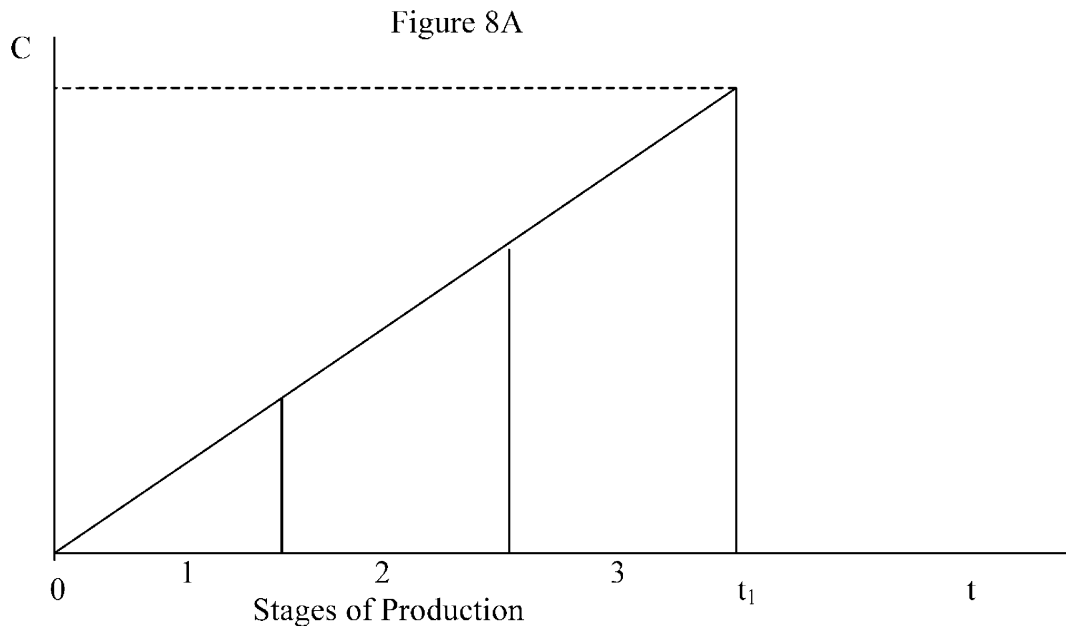

Figure 8B

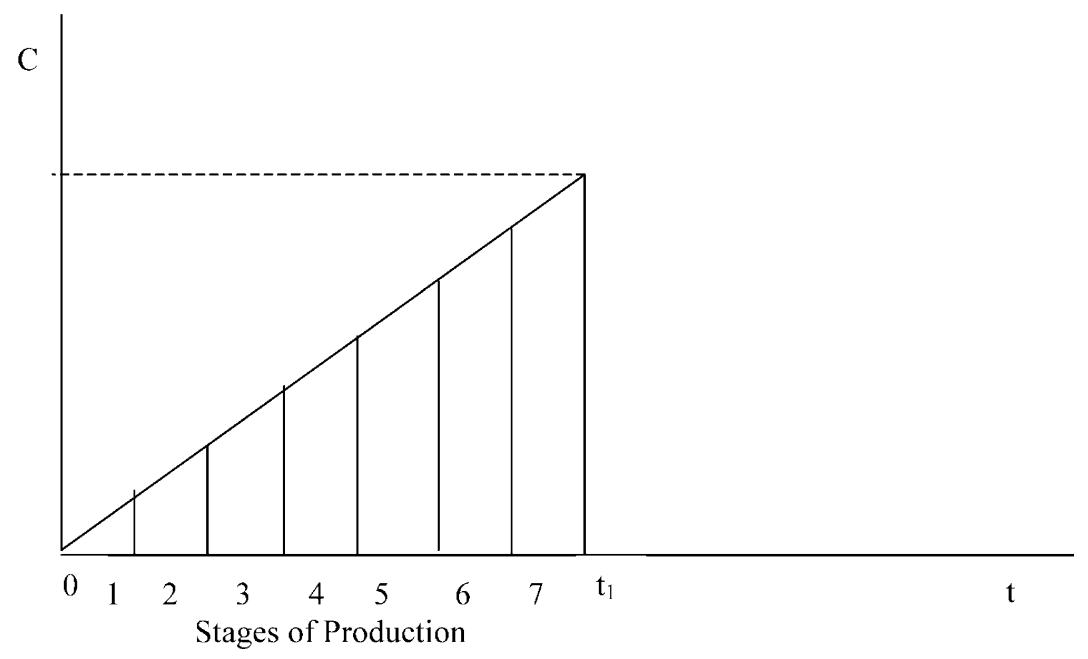


Figure 9A

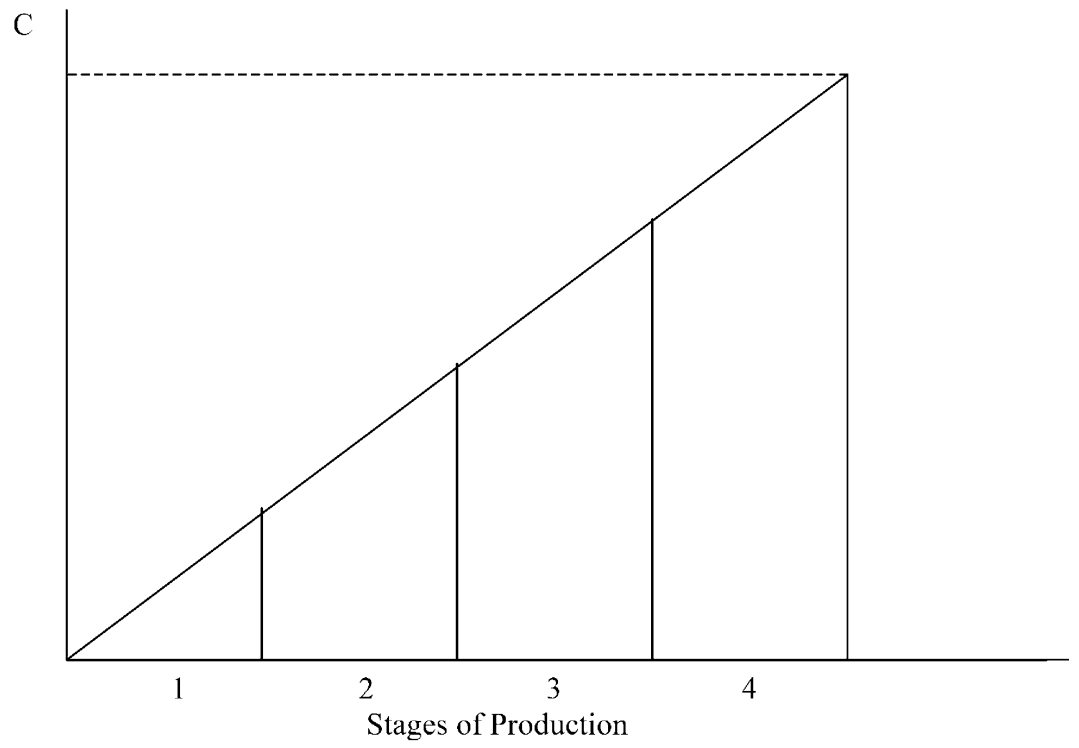

Figure 9B

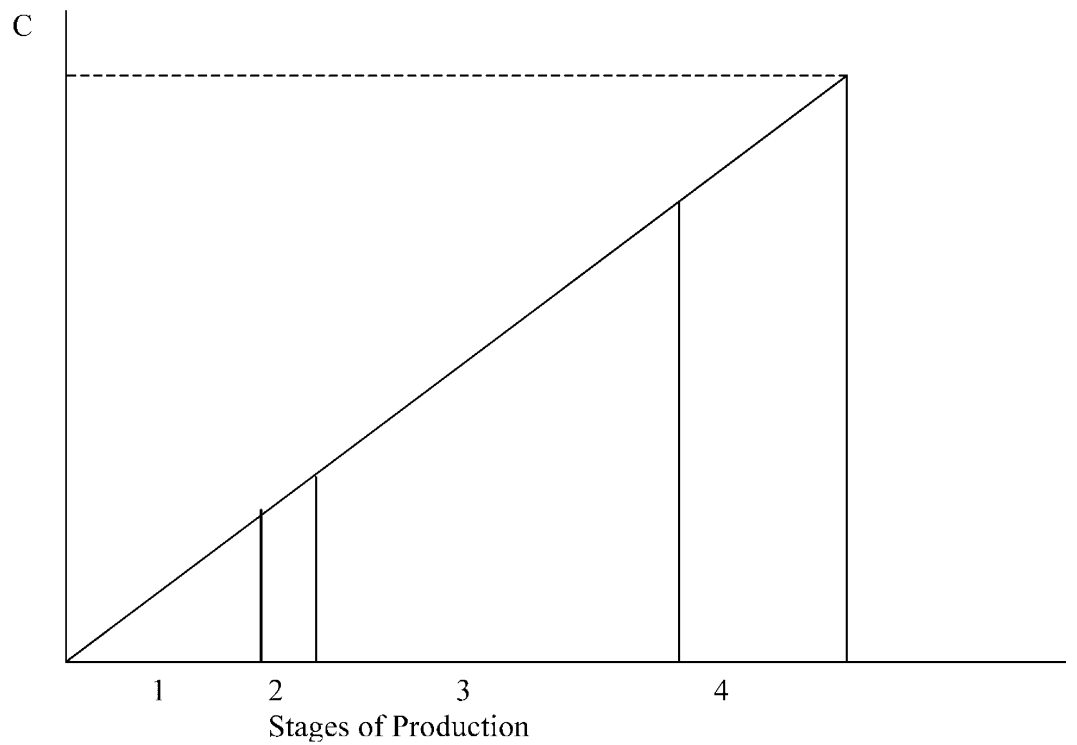



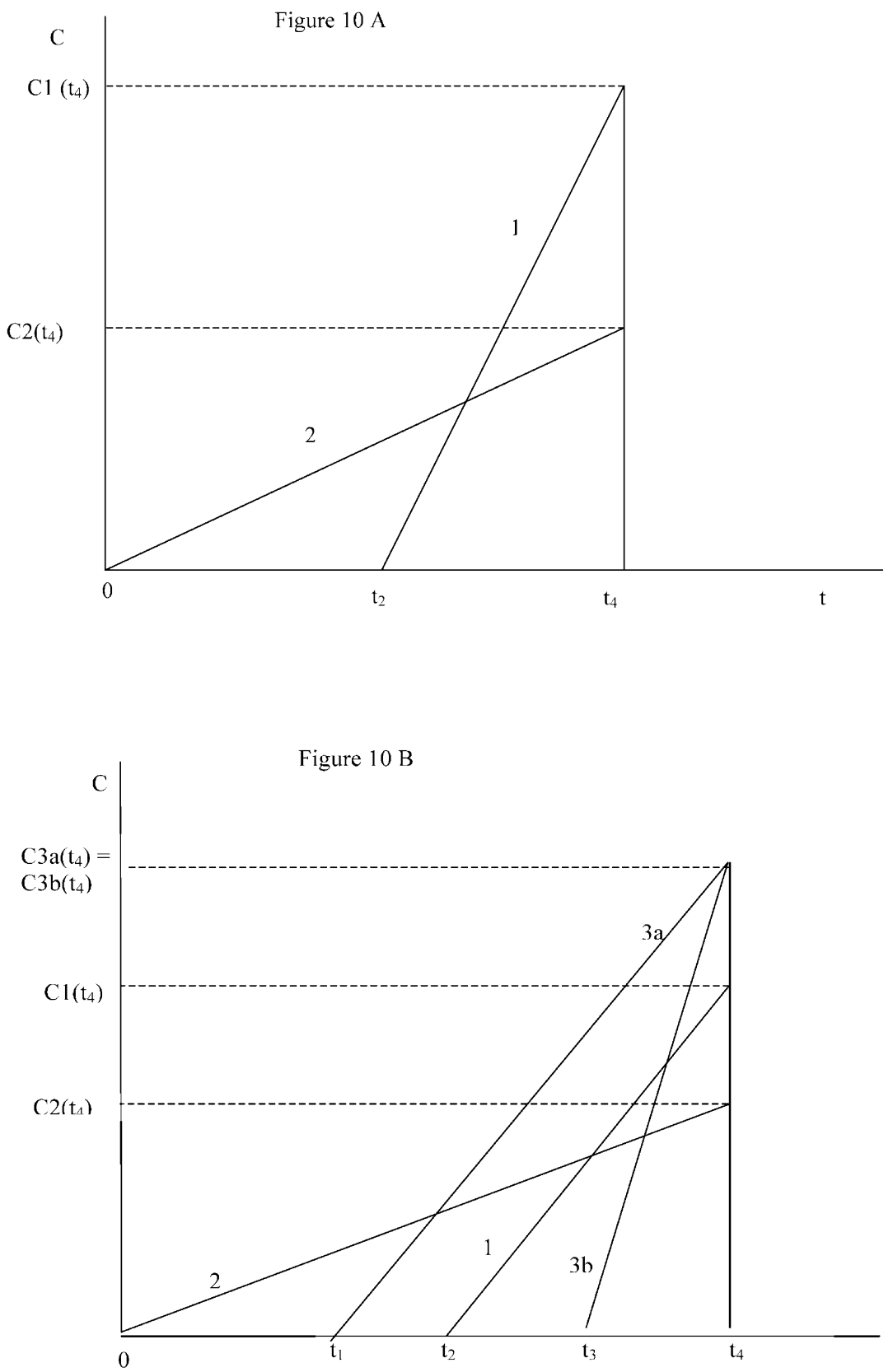

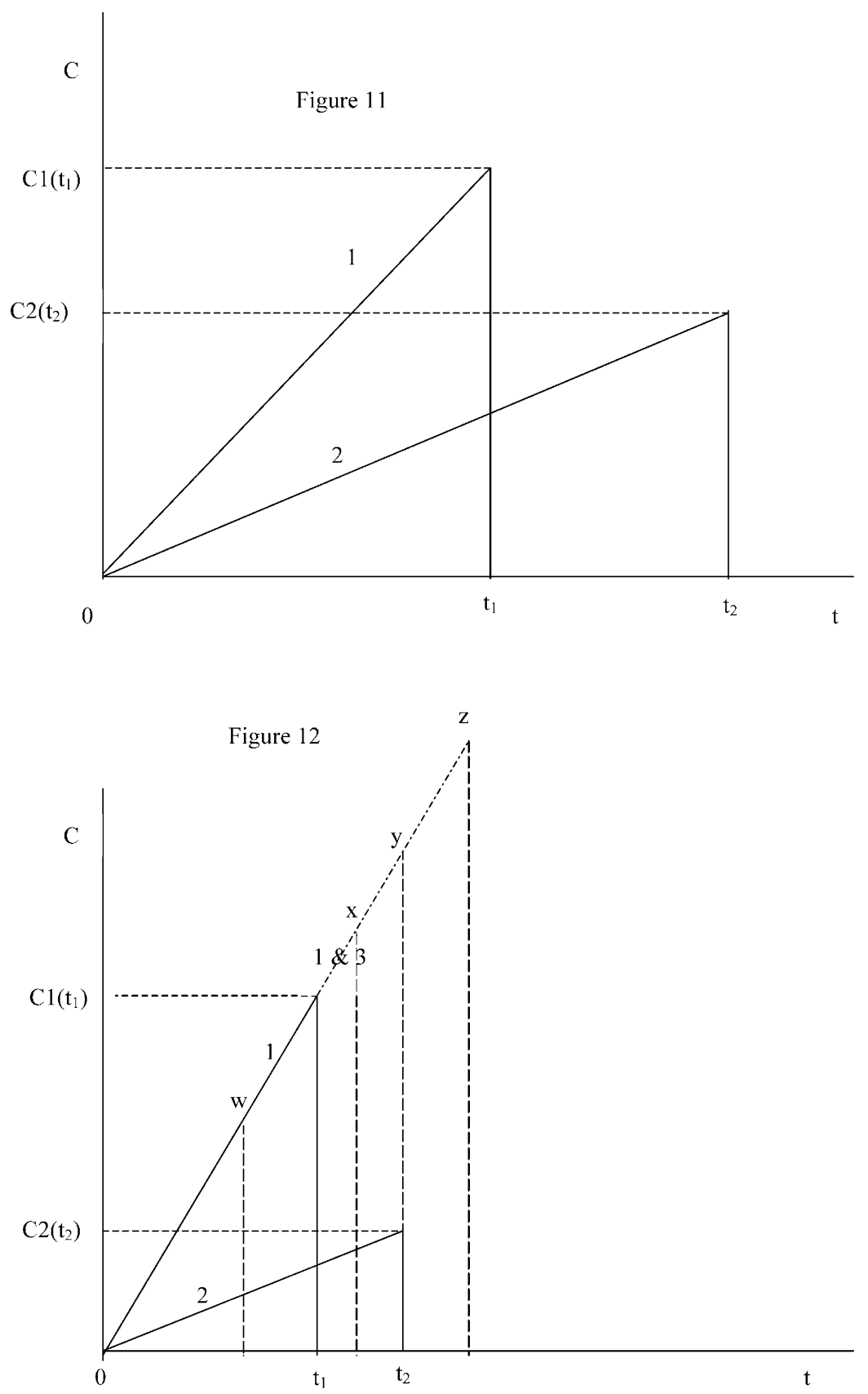

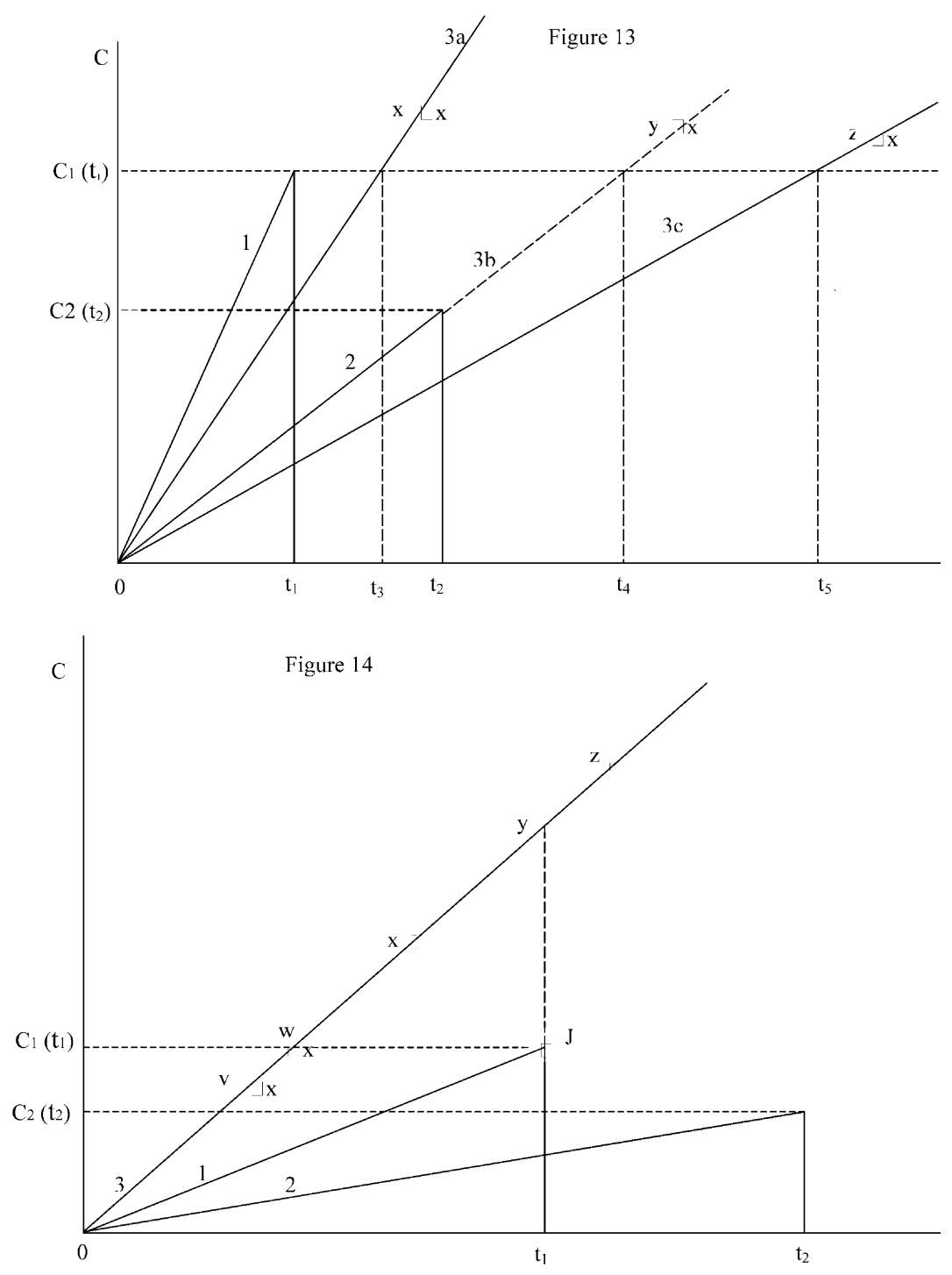


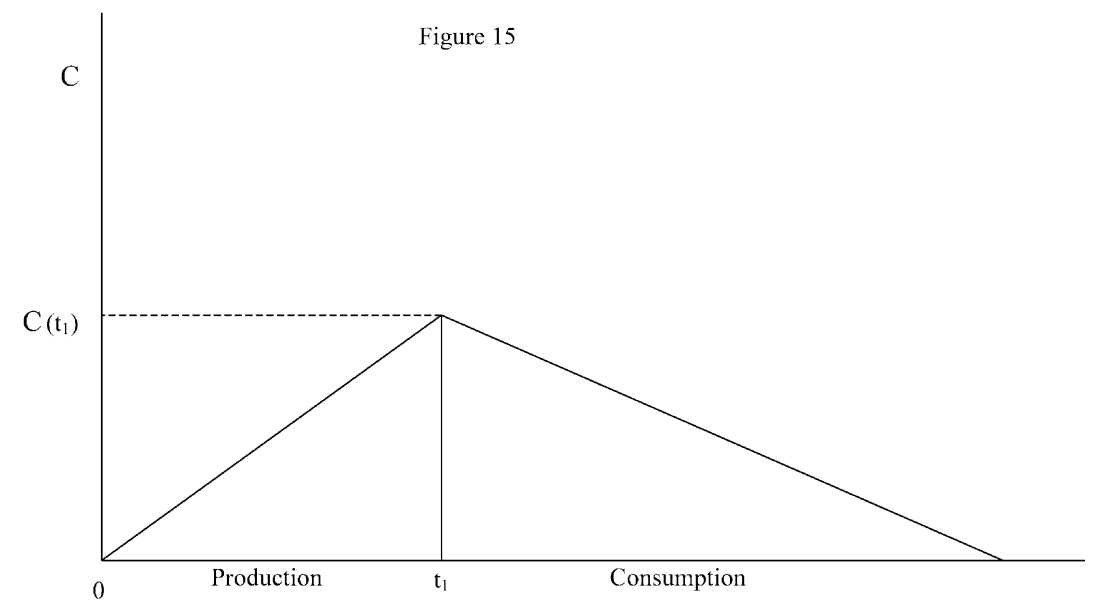



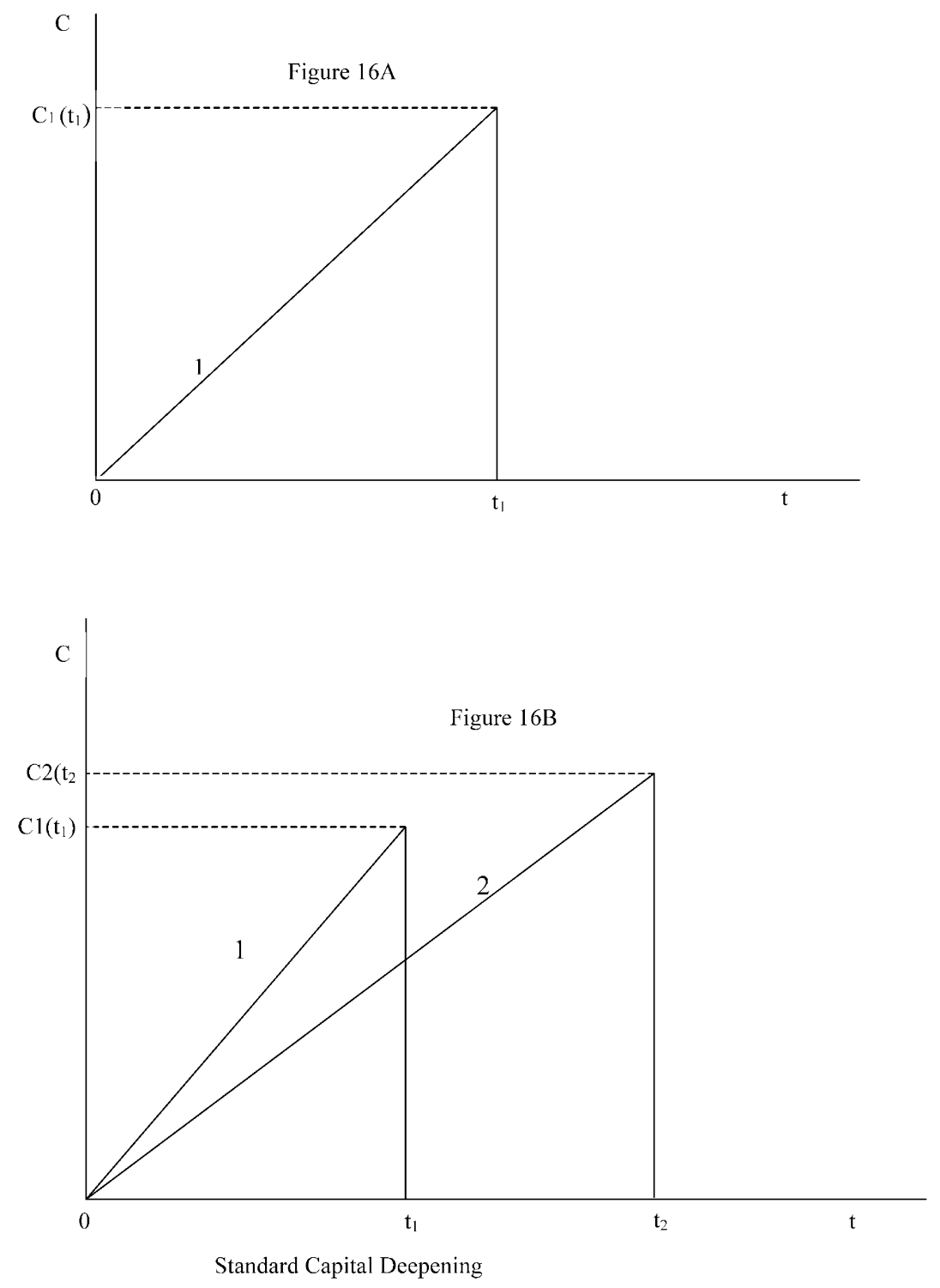


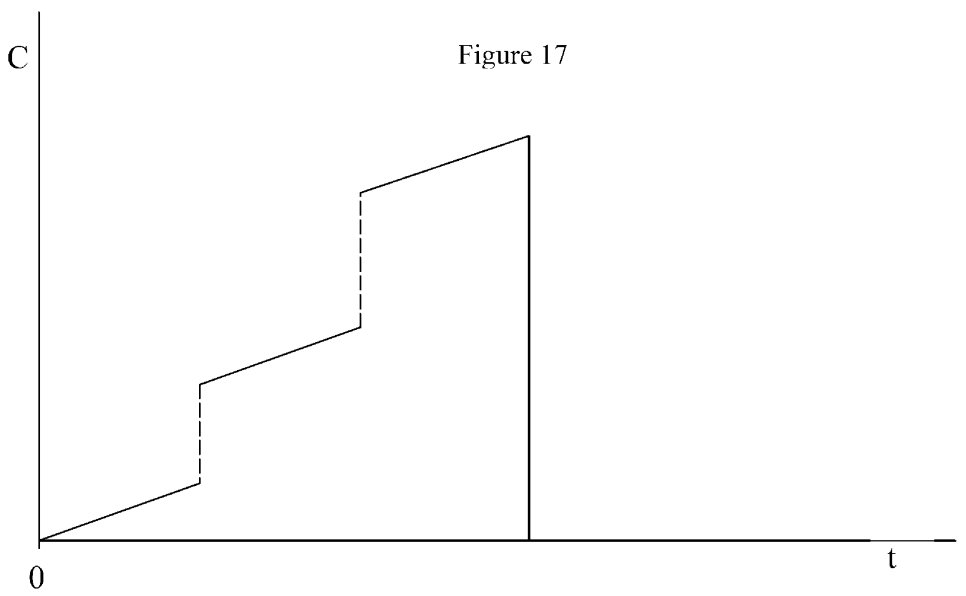


Figure 18
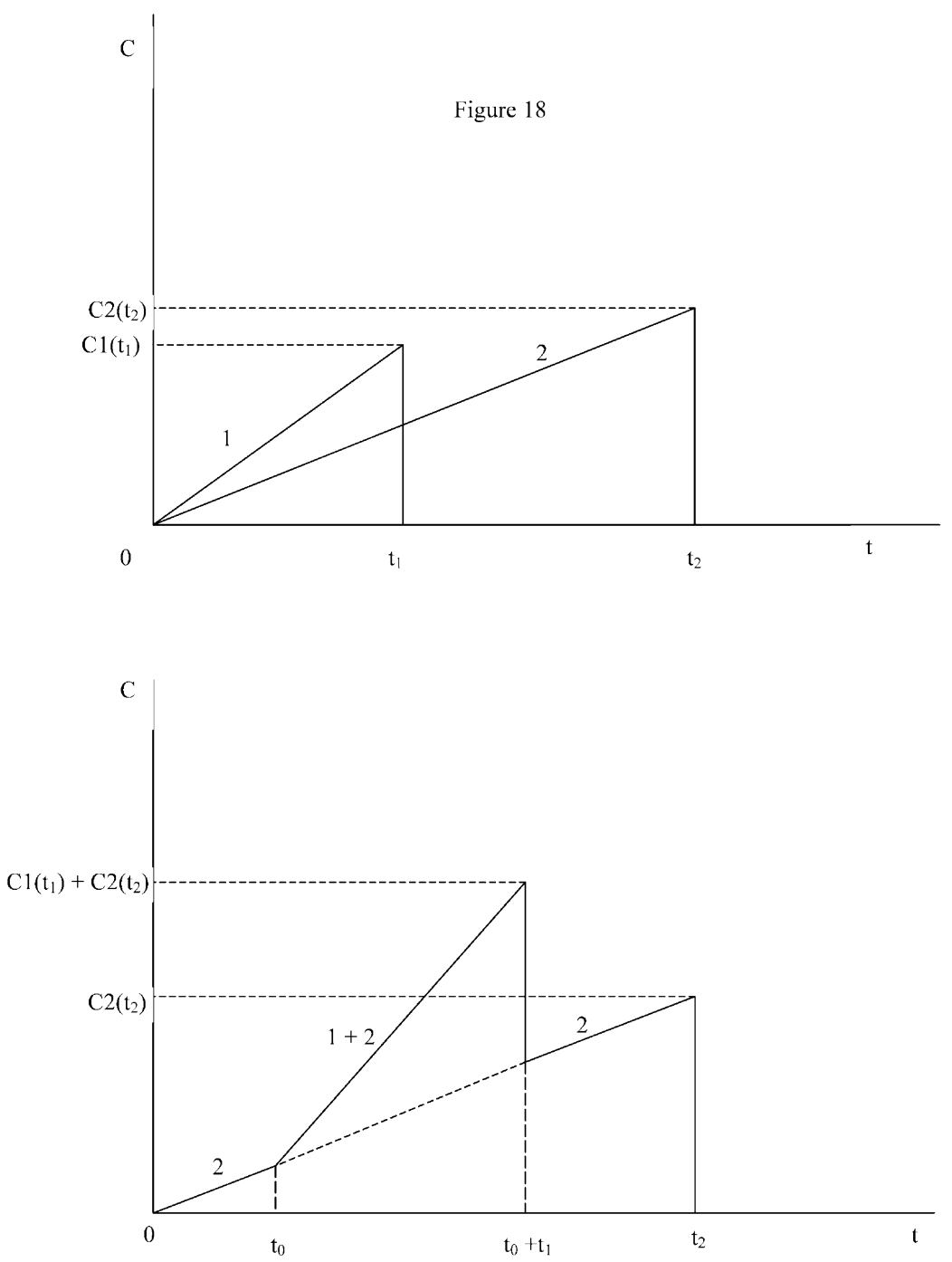

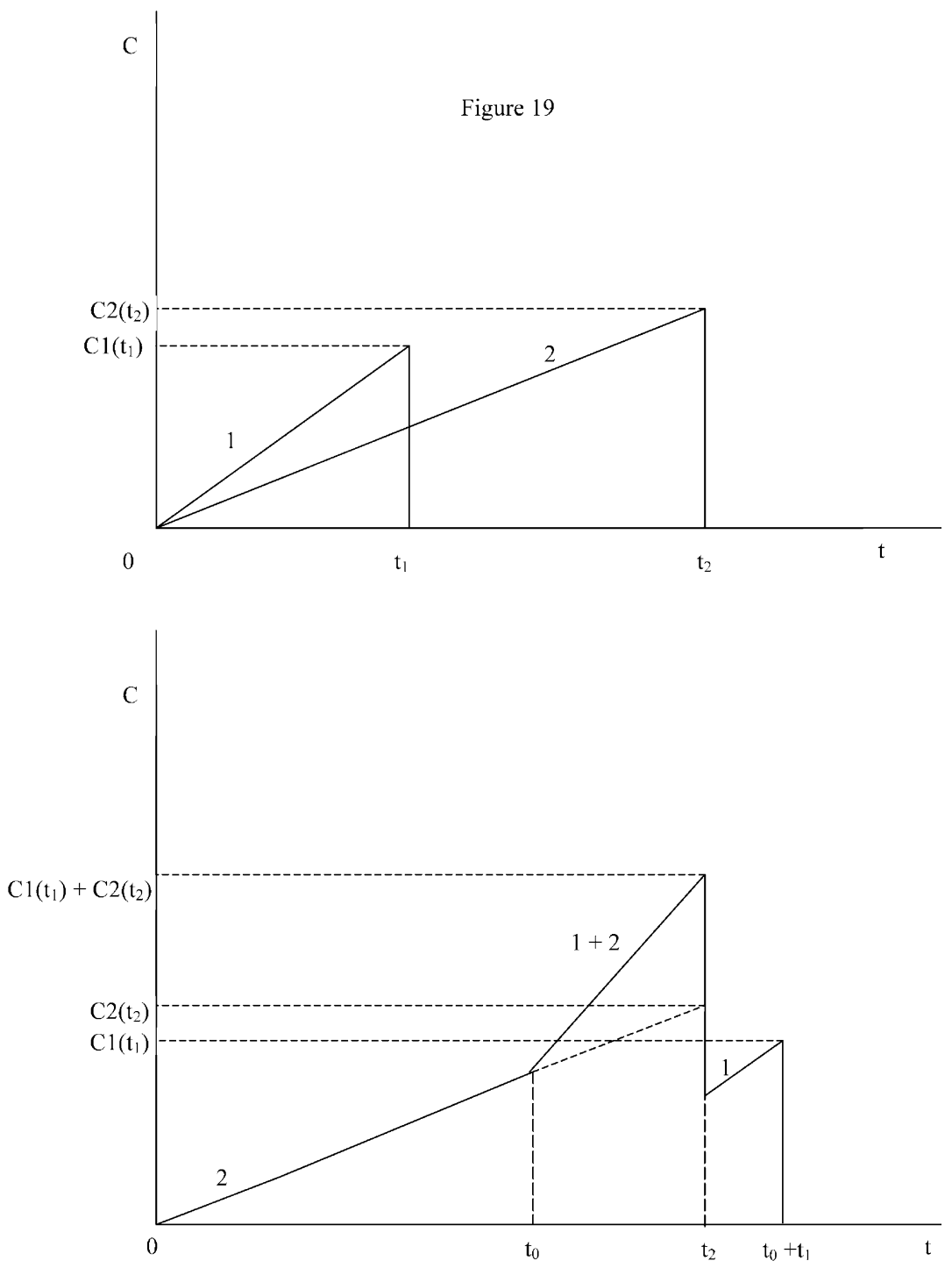

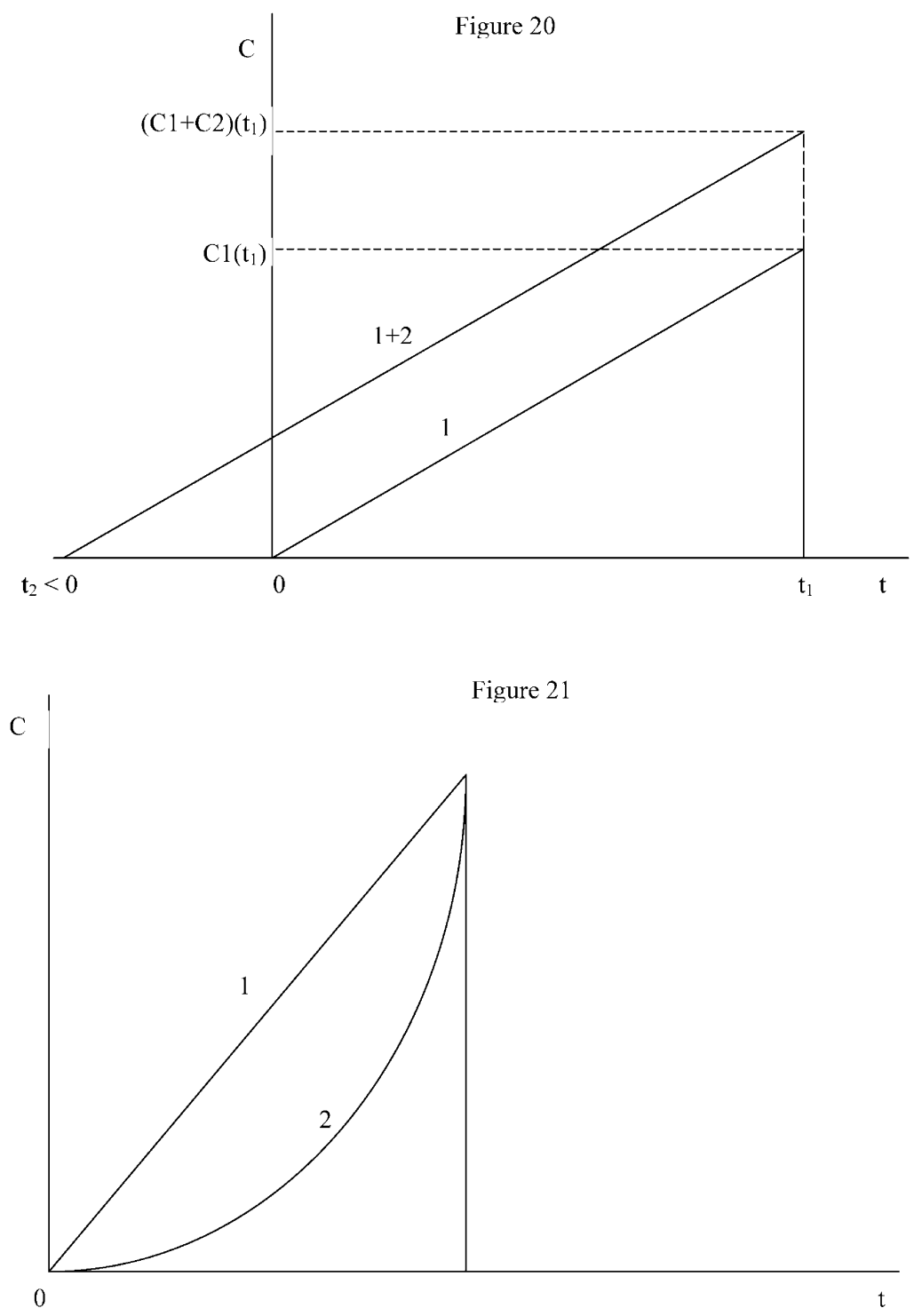

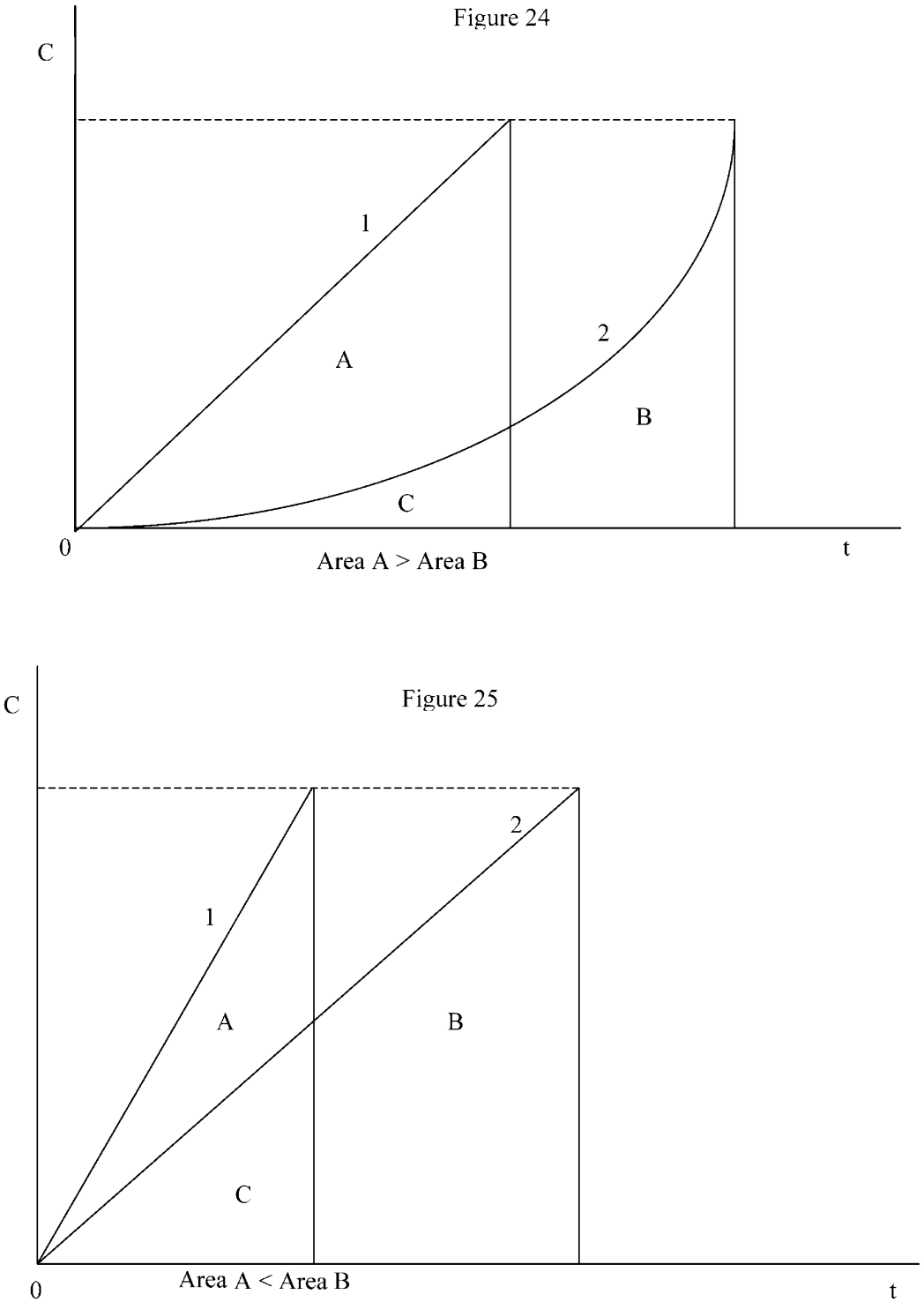


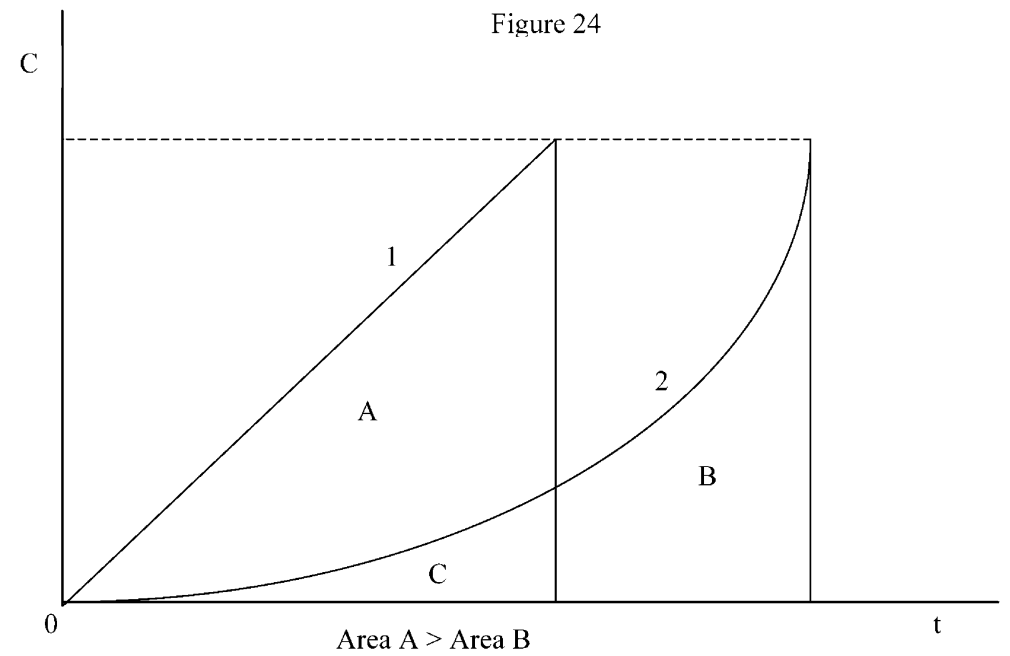

C

Figure 25

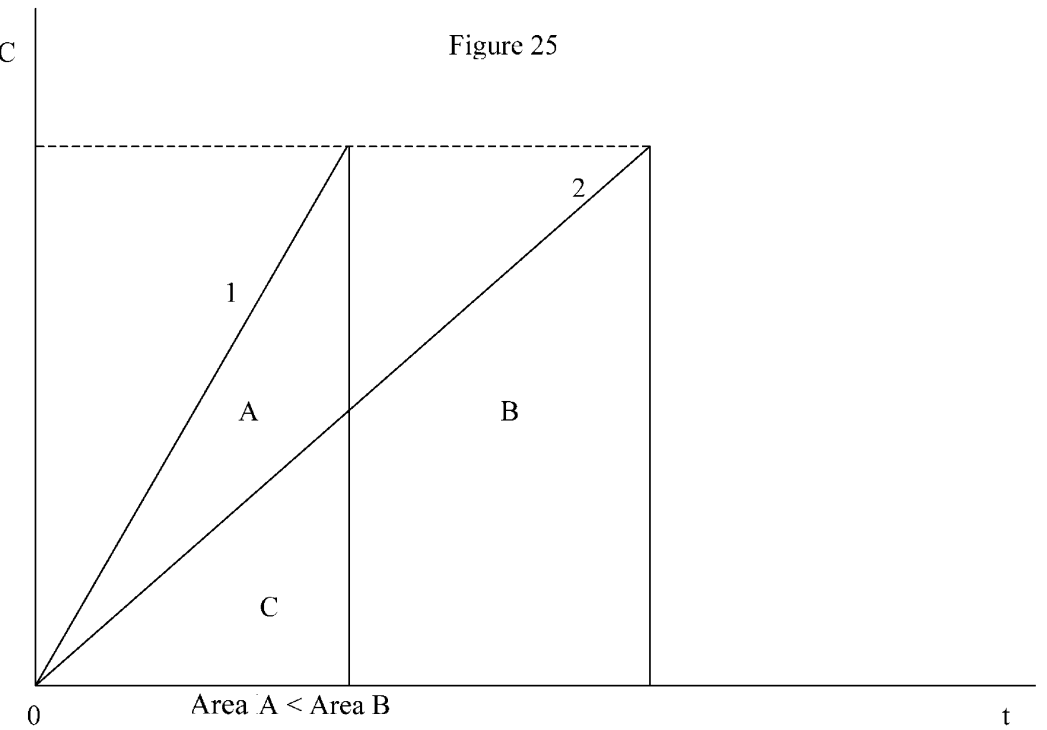


Figure 26

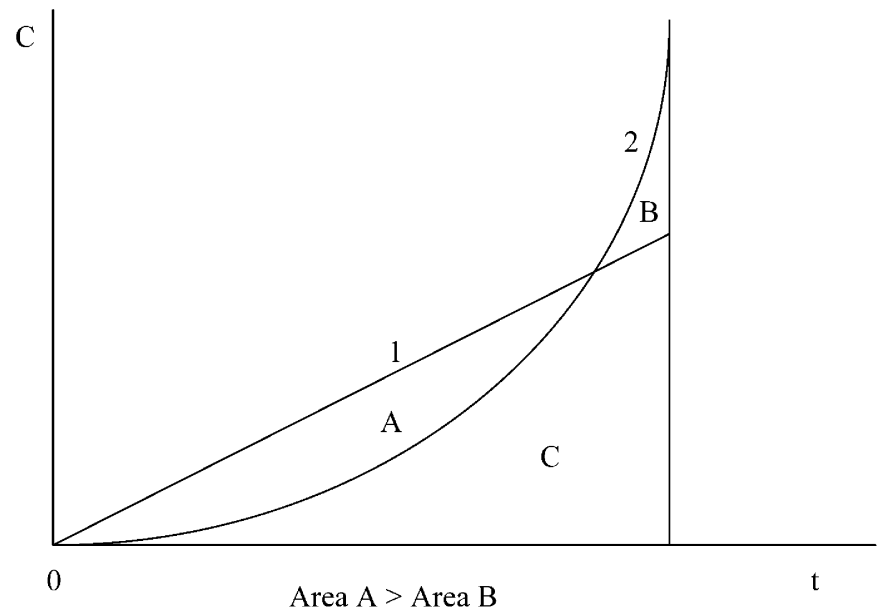

Figure 27

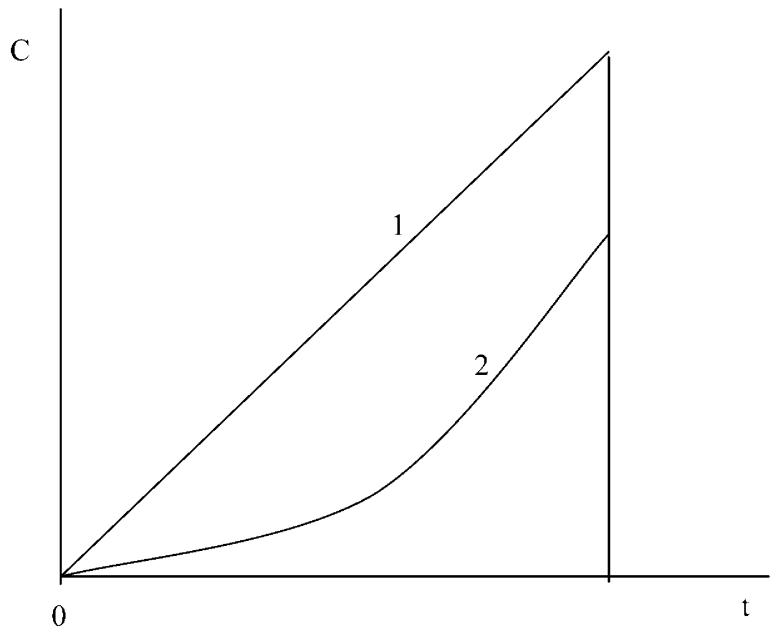


Figure 28

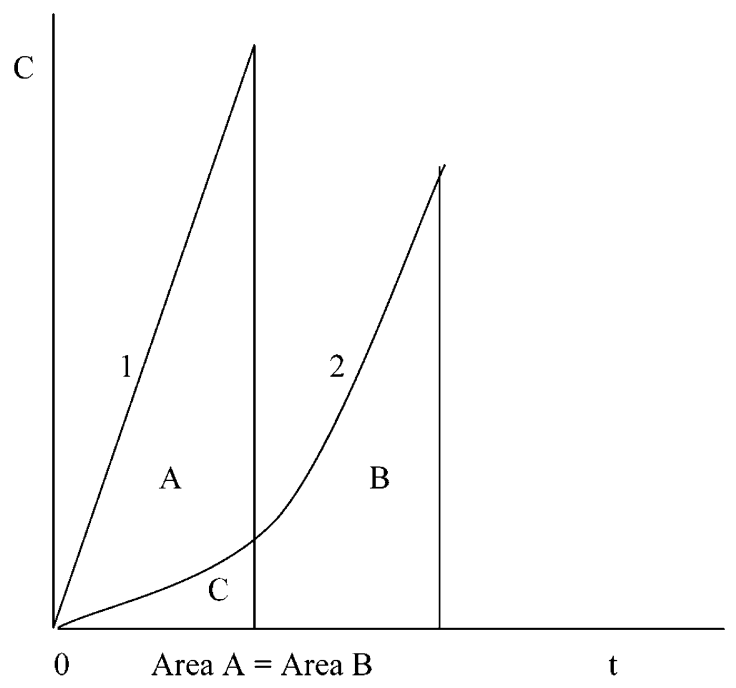

Figure 29

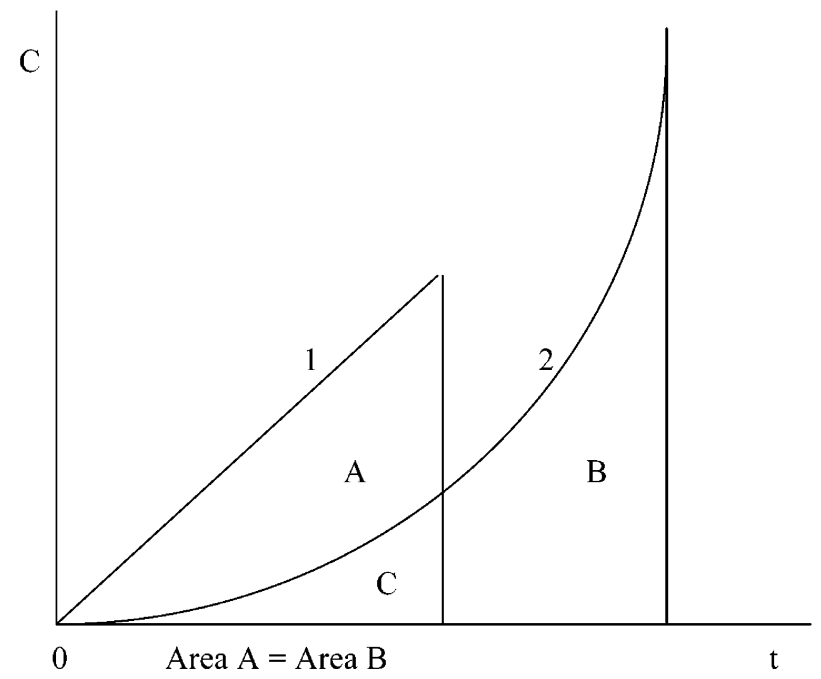



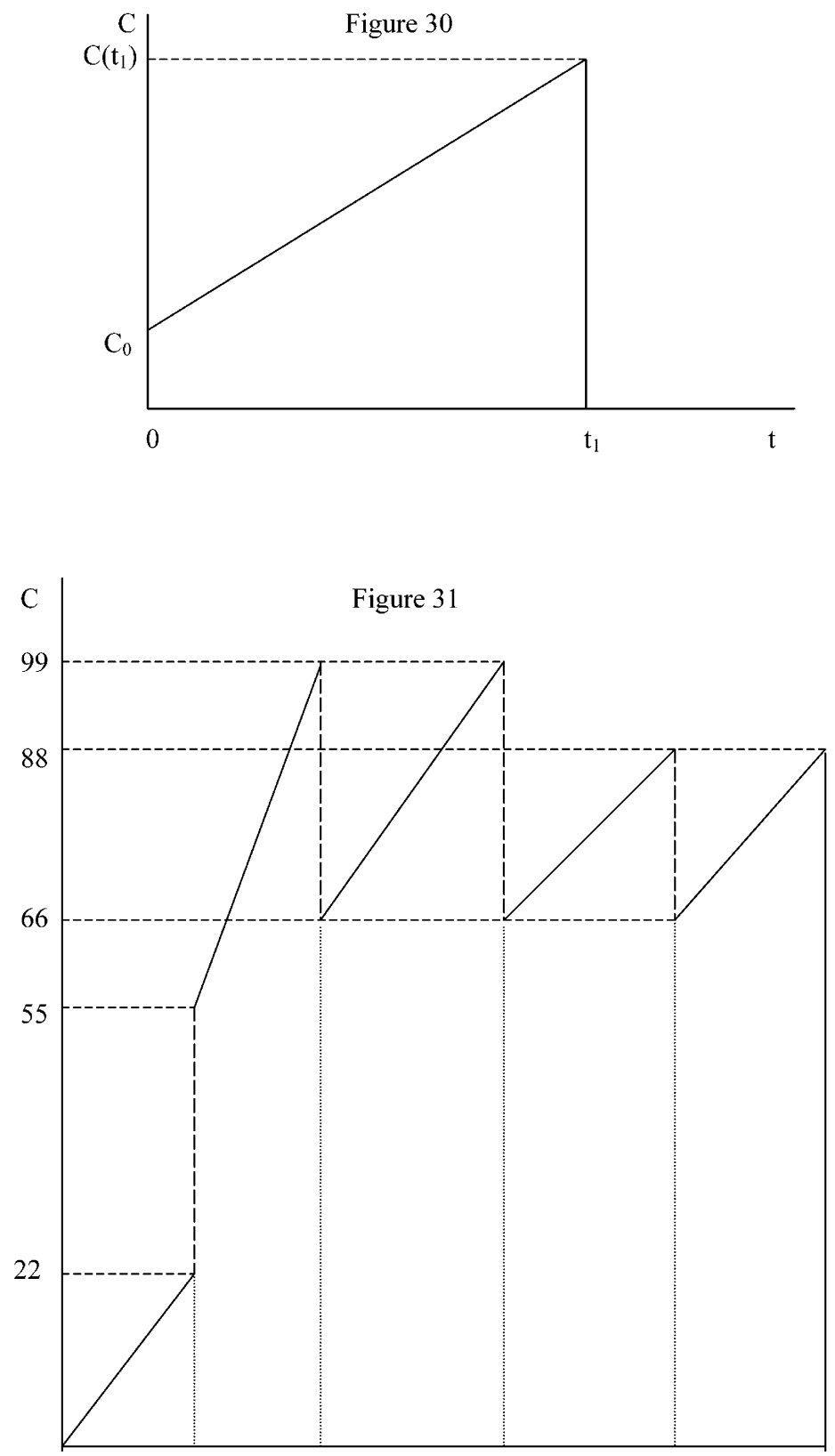


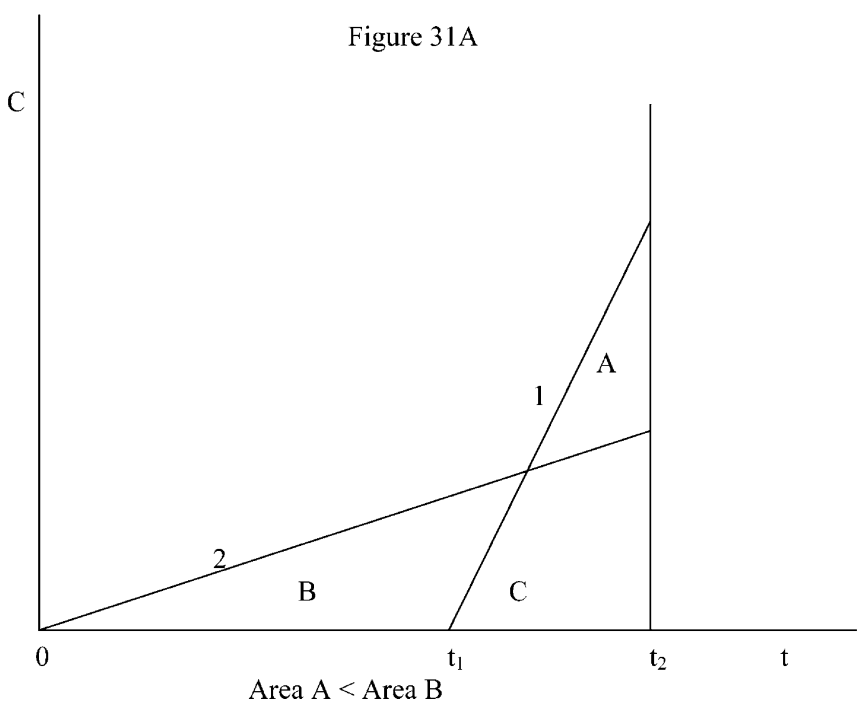

Figure 31B

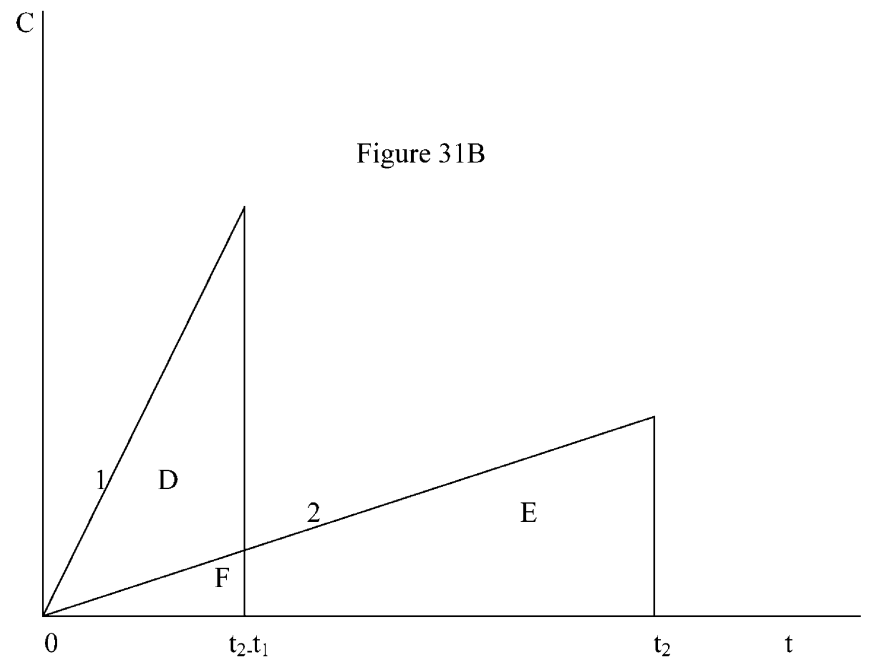


Area $\mathrm{D}<$ Area $\mathrm{E}$
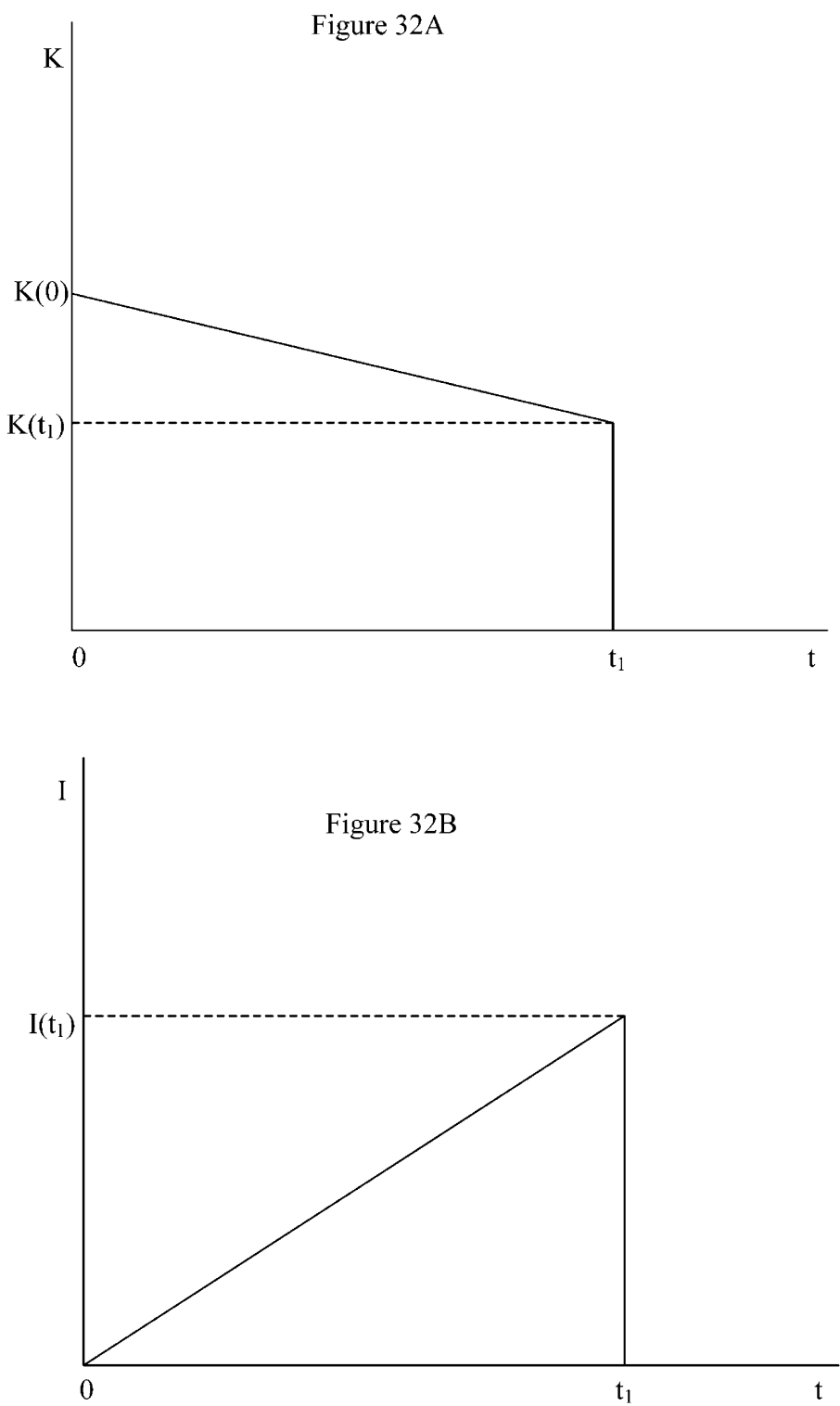
Figure 33A

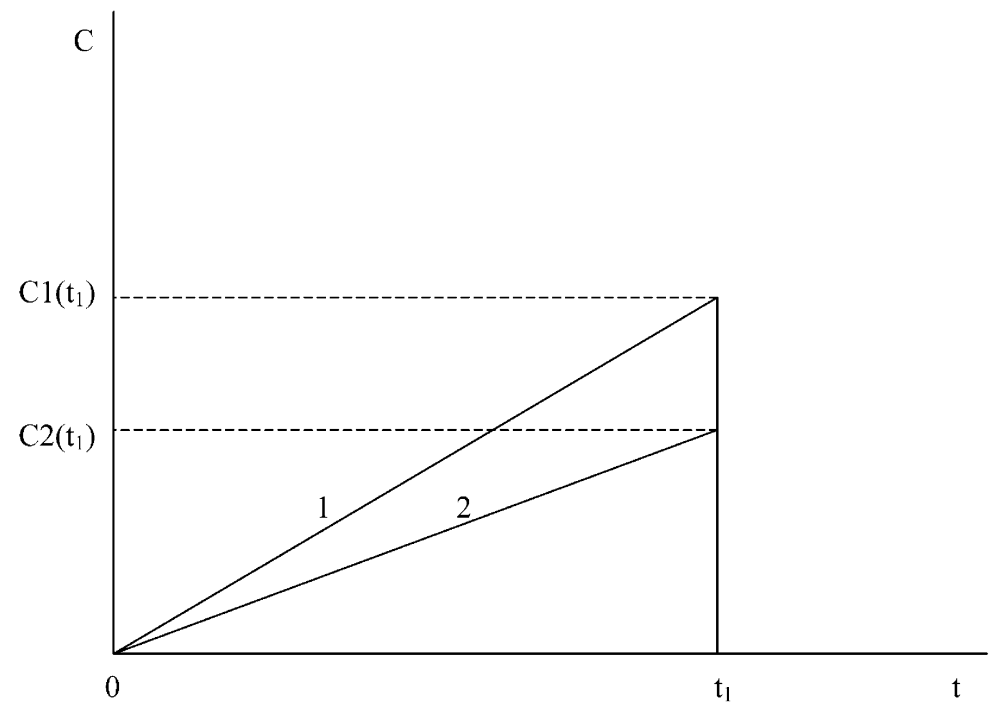

Figure 33B

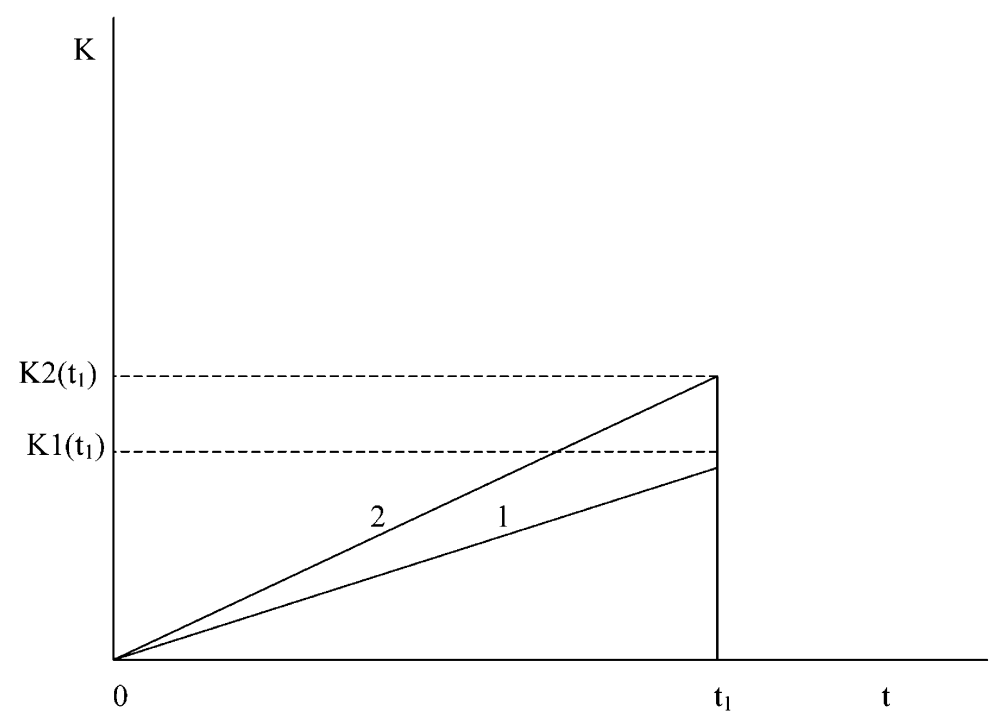



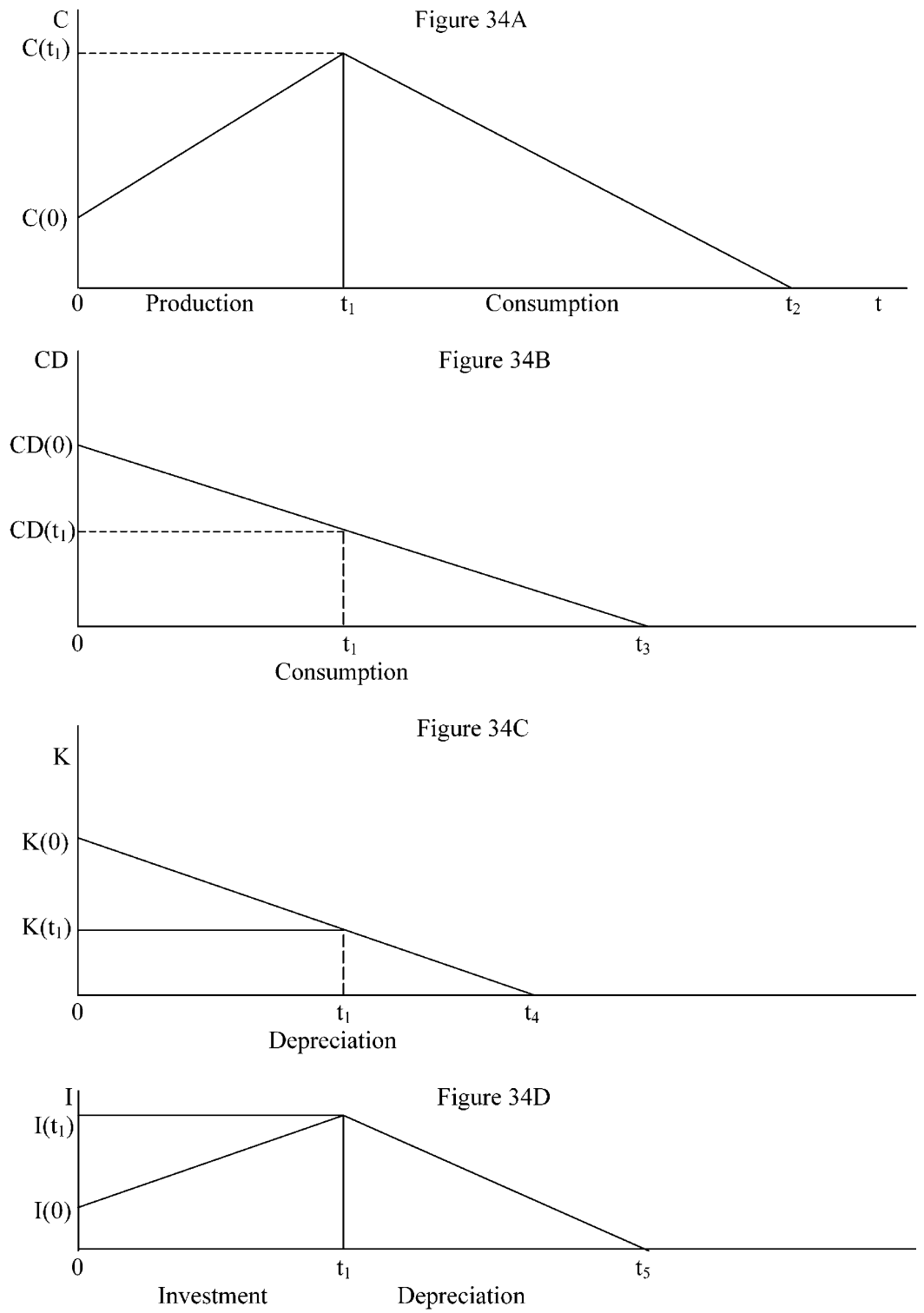


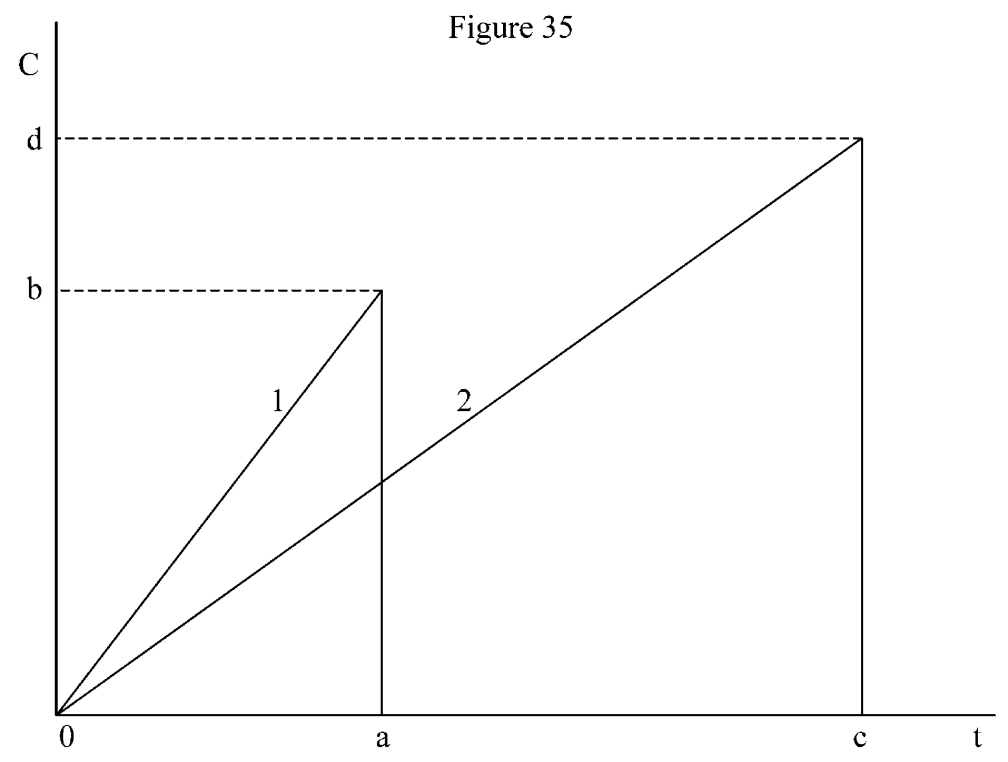


Figure H1

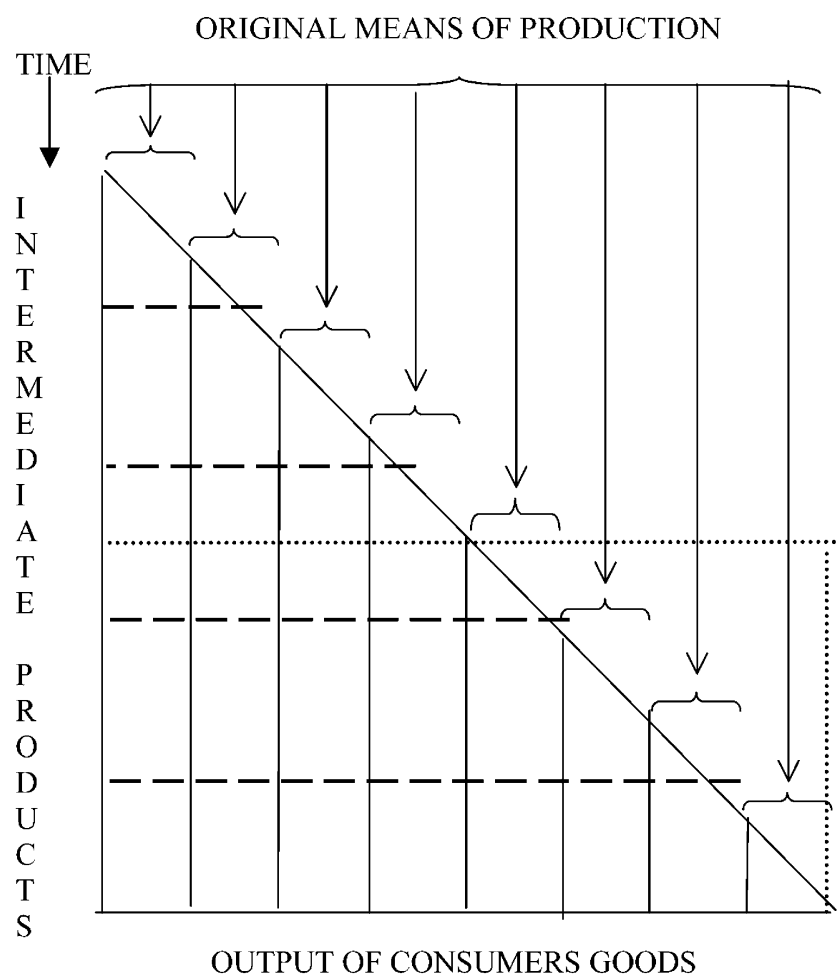

Figure H2

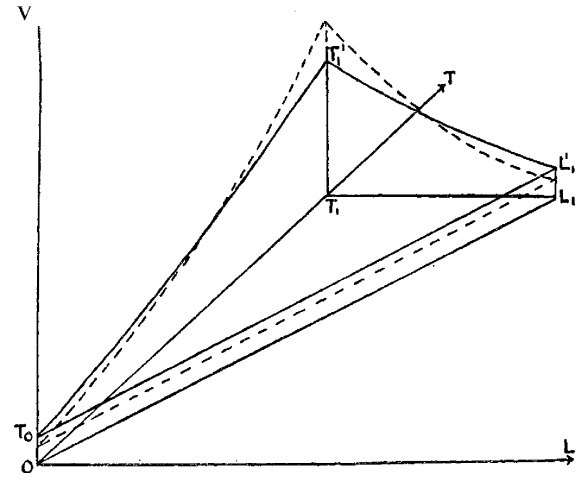


Figure H3

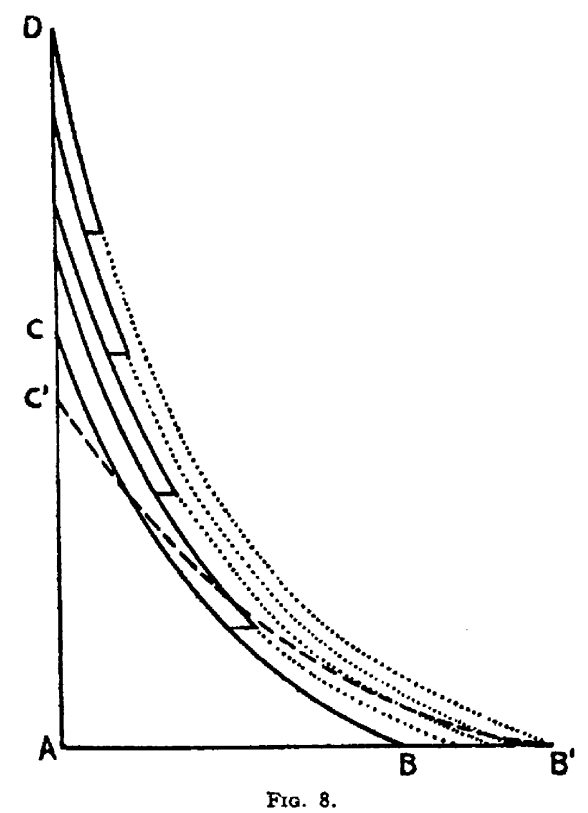




\section{REFERENCES}

Abrams, M.A. (1934), Money, and a Changing Civilization. London: The Bodley Head.

Barnett II, W. (2003), "The Modern Theory of Consumer Behavior: Ordinal or Cardinal?» Quarterly Journal of Austrian Economics. 6 (1): 41-65.

- (2004), «Dimensions and Economics: Some Problems.» Quarterly Journal of Austrian Economics. 7 (1): 95-104.

BARNETT, William II, and BlOCK, Walter. Unpublished A. «Interest Elasticity, Relative Prices, Growth, and Business Cycles.» - Unpublished B. «Singularism».

- Forthcoming. «Rothbard on V shaped average and total cost curves.» Quarterly Journal of Austrian Economics.

Barnett, William II, and Saliba, Michael. Unpublished ms. «Opportunity Cost: Conceptual Problems and Real World Implications.»

BARNETT, William II, and WoOD, Stuart (2002), «Austrian Business Cycle Theory in the Current Recession.» Proceedings of the Eighth Annual Austrian Scholars' Conference.

Barrow, Robert, and SAla-I-Martin, Xavier (1998), Economic Growth. The MIT Press.

Bellante, Don, and Garrison, Roger (1988), «Phillips Curves and Hayekian Triangles: Two Perspectives on Monetary Dynamics.» History of Political Economy, Vol. 20, No. 2, Summer, pp. 207-234.

http:/ / www.auburn.edu/ garriro/fm3bellante.htm BLock, Walter (1990), «The Discounted Marginal Value Product - Marginal Value Product Controversy: A Note», Review of Austrian Economics, Vol. IV, pp. 199-207.

- (1998), "Taxes and the Structure of Production.» Journal of Public Finance and Public Choice. Vol. XVII, Nos. 2-3: 154-157. 
- (2001), «Yes, We Have No Chaff: A Reply to Wagner's Austrian Business Cycle Theory: Saving the Wheat While Discarding the Chaff», Quarterly Journal of Austrian Economics, Vol. 4, No. 1, Spring 2001, pp. 63-73. / / www. mises.org/journals/qjae/pdf/qjae4_1_4.pdf

BLOCK, Walter, and BARNETT II, William. Unpublished ms. «Giffen Goods, Backward Bending Supply Curves, Price Controls and Praxeology; or, Who's Afraid of the Big Bad Boogie Man of Giffen Goods and Backward Bending Supply Curves? Not Us.»

Bohm-BAWErk, E. von (1959) [1884], Capital and Interest. Vol. 2, Positive Theory of Capital. Translated by G.D. Huncke. Libertarian Press.

Boulding, Kenneth [1941] (1966), Economic Analysis. Vol. II, Macroeconomics. 4th ed. New York: Harper and Row.

Cochran, John P., and Glahe, Fred (1999), The Hayek-Keynes

Debates: Lessons for Current Business Cycle Research, Lewiston, New York: Edwin Mellen Press.

Durbin, E.F.M. (1933) [1934], Purchasing Power E Trade Depression: A Critique of Under-Consumption Theories. London: Jonathan Cape.

- (1935), The Problem of Credit Policy. London: Chapman \& Hall.

Gaitskell, Hugh T.N. (1933), «Four Monetary Heretics», in

G.D.H. Cole, ed., What Everybody Wants to Know About Money. New York: Alfred A. Knopf.

Garrison, Roger W. (1978), "Austrian Macroeconomics: A Diagrammatical Exposition», New Directions in Austrian Economics, ed. Louis M. Spadaro, Kansas City: Sheed Andrews and McMeel.

- (1994), «Hayekian Triangles and Beyond», in Jack Birner and Rudy van Zijp, eds., Hayek, Coordination and Evolution: His Legacy in Philosophy, Politics, Economics, and the History of Ideas. London: Routledge. 
- (2001), Time and Money: The Macroeconomics of Capital Structure. London: Routledge.

- (2004), «Overconsumption and Forced Saving in the MisesHayek Theory of the Business Cycle, History of Political Economy, vol. 36, no. 2 (Summer), pp. 323-349.

- (2005), «The Austrian School.» Modern Macroeconomics: Its Origins, Development and Current State. Snowdon, Brian and Howard R. Vane, Cheltenham, U.K.: Edward Elgar, pp. 474-516.

Bellante, Don, and Garrison, Roger W. (1988), «Phillips Curves And Hayekian Triangles: Two Perspectives on Monetary Dynamics.» History of Political Economy. 20 (2): 207-234. http://www.auburn.edu/ garriro/fm3 bellante.htm.

HayeK, Friedrich A. (1931), Prices and Production. London: Routledge.

- (1935), Prices and Production. 2nd ed. London: Routledge.

- (1934A), «Capital and Industrial Fluctuations.» Econometrica, Vol. 2, No. 2, April, pp. 152-167.

- (1934B), «On the Relationship Between Investment and Output.» The Economic Journal, Vol. 44, No. 174, June, pp. 207-231.

- (1939) [1975], Profits, Interest and Investment, Clifton: Kelley.

- (1941) [1975], Pure Theory of Capital, Chicago: University of Chicago Press.

- (1948), «The Conditions of Equilibrium between the Production of Consumers' Goods and the Production of Producers' Goods.» In The Essence of Hayek.

HorwITZ, Steven (2005). Forthcoming. «Monetary Disequilibrium Theory and Austrian Macroeconomics: Further Thoughts on a Synthesis.» In Roger Koppl, ed., Money, Markets, and Method: Essays in Honor of Leland B. Yeager. London: Routledge. 
Huerta de Soto, Jesús (1998), "A Critical Note on Fractional Reserve Free Banking», The Quarterly Journal of Austrian Economics, Vol. 1, No. 4, Fall.

Hughes, Arthur Middleton (1997), «The Recession of 1990: An Austrian Explanation», The Review of Austrian Economics, Vol. 10, No. 1.

Jevons, William Stanley (1871) [1965], The Theory of Political Economy, 3d ed. London, New York, Macmillan and Co. Kirzner, Israel M. (1963), Market Theory and the Price System, Princeton N.J.: D. Van Nostrand.

- (1973), Competition and Entrepreneurship. Chicago: University of Chicago Press.

- (1976), «Discussion of M. Rothbard, 'Austrian Definitions of the Money Supply.'» Presented at a symposium on Austrian Economics, Windsor Castle, England. Unpubl.

Macfie, Alec L. (1934), Theories of the Trade Cycle. London: Macmillan.

Mises, Ludwig von (1971) [1912], The Theory of Money and Credit, New York: The Foundation for Economic Education.

- (1998), Human Action: The Scholar's Edition, Auburn, Ala.: The Mises Institute.

O'Driscoll, Gerald P. (1977), Economics as a Coordination Problem:

The Contributions of Friedrich A. Hayek, Kansas City: Sheed, Andrews and McMeel.

PAminI, Paolo (2002), «Behavioral Finance and Monetary Policy.» Masters' Thesis. University of Zurich.

Rothbard, Murray N. [1962] (1993), Man, Economy and State, Auburn AL: Ludwig von Mises Institute.

- (1978), "Austrian Definitions of the Supply of Money.» Louis Spadaro (ed.), New Directions in Austrian Economics. Kansas City: Sheed Andrews and McMeel, Inc., pp. 143-156. Reprinted in The Logic of Action One: Method, Money, and the Austrian School. Glos, UK: Edward Elgar Publishing Ltd., 1997, pp. 337-349. 
SALERnO, Joseph (1994), «Ludwig von Mises's Monetary Theory in Light of Modern Monetary Thought.» Review of Austrian Economics. Vol. 8, No. 1.

- (2001), «Does the Concept of Secular Growth Have a Place in Capital-Based Macroeconomics», The Quarterly Journal of Austrian Economics, Vol. 4, No. 3, Fall.

SAULNIER, Raymond J. (1938), Contemporary Monetary Theory. New York: Columbia University Press. Part III, pp. 213-300.

Simpson, Barry Dean, and Scott A. KJAR. Unpublished. «Israel Kirzner's Didactic Rediscovered.»

SKousen, Mark (1990), The Structure of Production, New York: New York University Press.

- (1991), Economics, Homewood, IL: Irwin.

Snowdon, Brian, Howard Vane, and Peter Wynarczyk (1994), A

Modern Guide to Macroeconomics: An Introduction to Competing

Schools of Thought, Cheltenham, U.K.: Edward Elgar.

Stigler, George (1962) [1942]), The Theory of Price. New York: Macmillan.

STRIGL, Richard von (1934) [2000]), Capital \& Production. Auburn, AL: The Mises Institute.

TAussig, Frank W. (1896), Wages and Capital. New York: Augustus M. Kelley.

WagneR, Richard E. (2000), «Austrian Cycle Theory: Saving the Wheat while Discarding the Chaff», Festschrift for James Buchanan; http://www.gmu.edu/jbc/fest/files / wagner.htm

Wien-Claudi, Franz (1936), Austrian Theories of Capital, Interest, and The Trade-Cycle. London: Stanley Nott Ltd.

White, Larry (1977), «T Shirt with Hayekian Structure of Production Triangle on it.»

Wicksell, Knut (1934), Lectures on Political Economy. George Routledge and Sons, Ltd.

- (1969), Selected Papers on Economic Theory. New York: Augustus M. Kelley. 